\title{
Structure prediction and synthesis of pyridine-based macrocyclic peptide natural products
}

Graham A. Hudson ${ }^{\dagger}$, Annie R. Hooper ${ }^{\dagger}$, Adam J. DiCaprio ${ }^{\dagger *}$, David Sarlah ${ }^{\dagger}$, Douglas A. Mitchell ${ }^{\dagger *}$

'Department of Chemistry, University of Illinois at Urbana-Champaign, 600 South Mathews Avenue, Urbana, Illinois 61801, USA. 'Carl R. Woese Institute for Genomic Biology, University of Illinois at Urbana-Champaign, 1206 West Gregory Drive, Urbana, Illinois 61801, USA

* Corresponding author:

Douglas A. Mitchell (douglasm@illinois.edu), phone: 1-217-333-1345, fax: 1-217-333-0508 


\section{Table of Contents:}

Experimental Methods

S3-S12

Table S1: Sequences of pyritide precursors and $m r o D$ for optimal $E$. coli expression. .............................. S13

Figure S1: Bioinformatically identified pyritide biosynthetic gene clusters

Figure S2: Synthetic scheme to produce 1

S15-S16

Figure S3: SDS-PAGE analysis of proteins used in this study

Figure S4: Tandem MS fragmentation of chemically and chemoenzymatically synthesized 1

Figure S5: Analytical HPLC retention time and purity analysis of chemically and chemoenzymatically synthesized pyritides

Figure S6: NMR spectra of chemically synthesized 1 $\mathrm{S} 20-\mathrm{S} 22$

Figure S7: TOCSY assignments of chemoenzymatically synthesized 1 S23

Figure S8: Aromatic ${ }^{1} \mathrm{H}$ assignments of chemoenzymatically synthesized 1 S24

Figure S9: NOESY contacts used in the backbone assignment of chemoenzymatically synthesized 1 S25

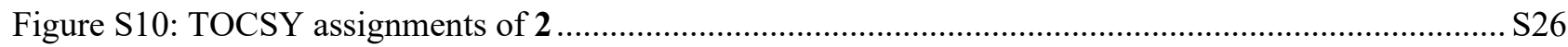

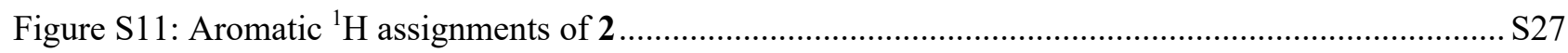

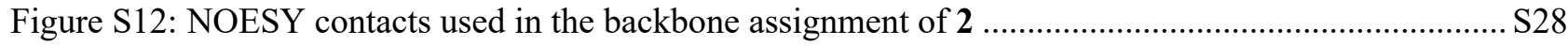

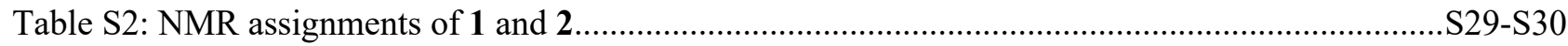

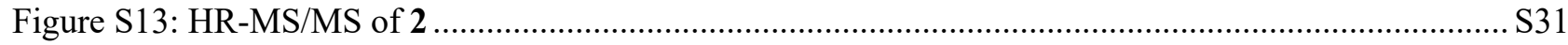

Figure S14: HR-MS/MS of MroA2 eliminated carboxamide leader peptide (6)..................................... S32

Table S3: MS fragment assignments. .S33-S34

Table S4: Minimum inhibitory concentrations (MICs) of $\mathbf{1}, \mathbf{2}$, and $\mathbf{1 + 2}$ against indicator strains S35

Figure S15: NMR spectra of synthetic intermediates/reagents used in this study S36-S56

Supporting References S57 


\section{Experimental Methods.}

General materials and methods. Reagents used for molecular biology experiments were purchased from New England BioLabs (Ipswich, MA), Thermo Fisher Scientific (Waltham, MA), or Gold Biotechnology Inc. (St. Louis, MO). Other chemicals were purchased from Sigma-Aldrich (St. Louis, MO). Escherichia coli DH5 $\alpha$ and BL21(DE3) strains were used for plasmid maintenance and protein overexpression, respectively. Plasmid inserts were sequenced at University of Illinois core sequencing facility. MALDI-TOF-MS analysis was performed using a Bruker UltrafleXtreme matrix-assisted laser desorption/ionization time-of-flight (MALDI-TOF) mass spectrometer (Bruker Daltonics) in reflector positive mode at the University of Illinois School of Chemical Sciences Mass Spectrometry Laboratory. MALDI-TOF-MS samples were desalted prior to analysis by using a $\mathrm{C}_{18}$ ZipTip (EMD Millipore) prior to co-crystallization in a matrix consisting of $20 \mathrm{mg} / \mathrm{mL} \alpha$-Cyano-4-hydroxycinnamic acid (CHCA, Sigma-Aldrich) and $10 \mathrm{mg} / \mathrm{mL}$ 2,5-Dihydroxybenzoic acid (DHB, Sigma-Aldrich) in 50\% acetonitrile. Electrospray ionization (ESI)-MS/MS analyses were performed using a ThermoFisher Scientific Orbitrap Fusion ESI-MS using an Advion TriVersa Nanomate 100. Lyophilization was performed using a Labconco (Kansas City, MO) freeze dryer.

Molecular biology techniques. Oligonucleotides were purchased from Integrated DNA Technologies Inc. (Coralville, IA). Genes optimized for recombinant expression of Micromonospora rosaria pyritide precursor peptides ( $m r o A 1$ and $m r o A 2)$, chimeras, and [4+2]-cycloaddition enzyme $(m r o D)$ in $E$. coli were synthesized by Twist Bioscience (South San Francisco, CA) in pUC57 (kanamycin, Kan) vectors with BamHI and XhoI sites flanking each gene at the 5' and 3' ends, respectively. The GenBank locus tag and E. coli optimized sequence for $m r o D$ is provided in Table S1. E. coli DH5 $\alpha$ were transformed with pUC57-Kan vectors containing each gene for replication and subsequent isolation using a QIAprep Spin Miniprep Kit (Qiagen). The isolated DNA was then treated with BamHI-HF and XhoI-HF (New England Biolabs; NEB). The digested genes were separated on a 1\% $(\mathrm{w} / \mathrm{v})$ agarose gel, purified using a QIAQuick gel extraction kit (Qiagen), and ligated into an appropriately endonuclease-digested and gel-purified pET28 vector with maltose-binding protein (MBP) 5' to the multiple cloning site using T4 DNA ligase (NEB). Ligation reactions were used to transform chemically competent DH5 $\alpha$ cells, which were plated on Luria-Bertani (LB) agar plates containing $50 \mu \mathrm{g} / \mathrm{mL}$ Kan and grown at $37^{\circ} \mathrm{C}$. Colonies were picked at random and grown in LB broth for 16-20 h prior to plasmid isolation using a QIAprep Spin Miniprep Kit. The 5' end of ligated genes was sequenced with the MBP-F primer (5'GAGGAAGAGTTGGCGAAAGATCCACGTATTGCC-3') while the 3' was sequenced with the T7 terminator primer (5'-GCTAGTTATTGCTCAGCGG-3').

Bioinformatic analysis of pyritide gene clusters. Position-iterative BLAST (PSI-BLAST) was performed using the sequences of the known thiopeptide [4+2] enzyme TbtD, from thiomuracin (WP_050760415.1) against the nonredundant NCBI protein database in February 2020. Accessions for the resultant proteins were then analyzed using Rapid ORF Description \& Evaluation Online (RODEO) in conjunction with custom profile Hidden Markov Models (pHMMs) as described previously. ${ }^{1,2}$ Pyritide biosynthetic gene clusters (BGCs) were segregated from thiopeptide BGCs based on the co-occurrence of only glutamylation, elimination, and [4+2]-cycloaddition enzymes. The resulting RODEO output is available in Supplementary Dataset 1. Precursor peptide prediction and junction between leader and core peptide were performed using the RODEO thiopeptide precursor module and verified by hand-translating intergenic regions in all six reading frames. The BGCs for all detected pyritides are featured in Figures 1 and S1.

General experimental procedures for synthesis of pyritide A1 (1). Unless otherwise noted, all reactions were carried out under an ambient atmosphere. All chemicals were purchased from commercial suppliers and used as received. Dry dichloromethane $\left(\mathrm{CH}_{2} \mathrm{Cl}_{2}\right)$ and tetrahydrofuran (THF) were obtained by passing commercially available anhydrous, oxygen-free formulations through activated alumina columns. Analytical thin-layer chromatography was performed on Merck silica gel $60 \mathrm{~F}_{254}$ glass plates. Visualization was accomplished with UV light and/or potassium permanganate $\left(\mathrm{KMnO}_{4}\right)$ solutions. Retention factor $\left(R_{\mathrm{f}}\right)$ values reported were measured using a $5 \times 2 \mathrm{~cm}$ TLC plate in a developing chamber containing the solvent system described. Flash column chromatography was performed using Silicycle SiliaFlash ${ }^{\circledR} \mathrm{P} 60\left(\mathrm{SiO}_{2}, 40-63 \mu \mathrm{m}\right.$ particle size, 230-400 mesh). ${ }^{1} \mathrm{H}$ and ${ }^{13} \mathrm{C}$ NMR spectra were recorded on Varian Unity Inova $500\left(500 \mathrm{MHz},{ }^{1} \mathrm{H} ; 125 \mathrm{MHz},{ }^{13} \mathrm{C}\right) \mathrm{MHz}$ or Bruker 500 $\left(500 \mathrm{MHz},{ }^{1} \mathrm{H} ; 125 \mathrm{MHz},{ }^{13} \mathrm{C}\right)$ spectrometers. Spectra are referenced to residual chloroform $\left(\delta=7.26 \mathrm{ppm}\right.$, ${ }^{1} \mathrm{H}$; 
$\left.77.16 \mathrm{ppm},{ }^{13} \mathrm{C}\right)$, residual methanol $\left(\delta=3.31 \mathrm{ppm},{ }^{1} \mathrm{H} ; 49.0 \mathrm{ppm},{ }^{13} \mathrm{C}\right)$, and residual dimethyl sulfoxide $(\delta=2.50$ ppm, ${ }^{1} \mathrm{H} ; 39.5 \mathrm{ppm},{ }^{13} \mathrm{C}$ ). Chemical shifts are reported in parts per million (ppm). Multiplicities are indicated by $\mathrm{s}$ (singlet), d (doublet), t (triplet), q (quartet), m (multiplet), and br (broad). Coupling constants $J$ are reported in Hertz $(\mathrm{Hz})$. NMR spectra used for the characterization of synthetic compounds may be found in Figure S15. Mass spectrometry (MS) was performed by the University of Illinois Mass Spectrometry Laboratory. Electrospray ionization $\left(\mathrm{ESI}^{+}\right)$spectra were performed using a time-of-flight (TOF) mass analyzer. Data are reported in the form of $\mathrm{m} / \mathrm{z}$. For several compounds, Waters Q-TOF Ultima ESI and Agilent 6230 ESI TOF LC/MS spectrometers were used to obtain the high-resolution mass spectra. Infrared spectra were measured neat on a Perkin-Elmer spectrum BX FT-IR spectrometer. Peaks are reported in $\mathrm{cm}^{-1}$ with indicated relative intensities: $\mathrm{s}$ (strong, $0-33 \% \mathrm{~T}$ ); $\mathrm{m}$ (medium, 34-66\% T), w (weak, 67-100\% T), and br (broad). Melting points were measured on a Buchi B-540 melting point apparatus and are uncorrected. Optical rotations were recorded on a Jasco P-2000 polarimeter at 589 $\mathrm{nm}$ and are reported in units of $10^{-1}\left(\mathrm{deg} \mathrm{cm}^{2} \mathrm{~g}^{-1}\right)$. HPLC was performed on a Shimadzu Prominence HPLC system with SPD-M20A UV/VIS Photodiode array detector.

Synthesis of S1: The following was prepared according to a slightly modified literature procedure. ${ }^{1}$ Boc-L-Trp-

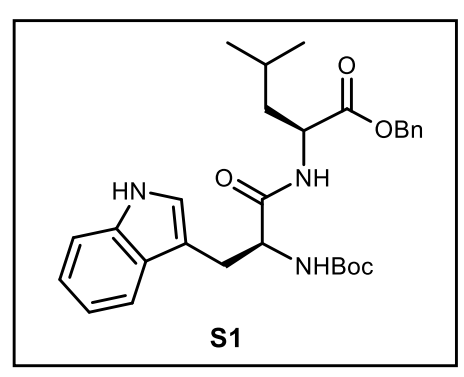
$\mathrm{OH}(2.00 \mathrm{~g}, 6.57 \mathrm{mmol}, 1.0 \mathrm{eq}$.) was dissolved in DCM $(55 \mathrm{~mL})$ and cooled to 0 ${ }^{\circ} \mathrm{C}$. Then $N$-methylmorpholine (1.6 mL, $14.5 \mathrm{mmol}, 2.2 \mathrm{eq}$.), followed by addition of HOBt (1.11 g, $7.23 \mathrm{mmol}, 1.1$ eq.) and EDC (1.39 g, $7.23 \mathrm{mmol}, 1.1$ eq.). After 15 minutes, leucine benzyl ester $p$-toluenesulfonate salt $(2.84 \mathrm{~g}, 7.23 \mathrm{mmol}, 1.1$ eq.) was added and slowly warmed to room temperature $\left(25^{\circ} \mathrm{C}\right)$ overnight. Upon completion (monitored by TLC), the reaction was quenched with water $(45 \mathrm{~mL})$, the organic phase was separated, and washed with citric acid $(10 \%$ aq. solution, $3 \times 30 \mathrm{~mL})$. The aqueous phase was extracted with DCM $(3 \times 40 \mathrm{~mL})$, the combined organic extracts were washed with $\mathrm{NaHCO}_{3}$ (aq. solution, $3 \times 90 \mathrm{~mL}$ ), dried over $\mathrm{MgSO}_{4}$, filtered, and concentrated under reduced pressure. The resulting residue was purified by flash chromatography $\left(\mathrm{SiO}_{2}\right.$, hexanes:EtOAc $\left.=4: 1 \rightarrow 2: 1\right)$ to give the desired compound $\mathbf{S 1}$ as a light yellow oil $(2.98 \mathrm{~g}$, $5.88 \mathrm{mmol}, 89 \%$ ).

$\boldsymbol{R}_{\mathbf{f}}=0.3$ (hexanes:EtOAc $=2: 1, \mathrm{UV}$ ).

${ }^{1}$ H NMR: $\left(500 \mathrm{MHz}, \mathrm{CD}_{3} \mathrm{OD}\right) \delta 7.57(\mathrm{~d}, J=7.9 \mathrm{~Hz}, 1 \mathrm{H}), 7.36-7.26(\mathrm{~m}, 6 \mathrm{H}), 7.11-7.05(\mathrm{~m}, 2 \mathrm{H}), 7.00(\mathrm{t}, J=7.4$ $\mathrm{Hz}, 1 \mathrm{H}), 5.12(\mathrm{~d}, J=12.5 \mathrm{~Hz}, 1 \mathrm{H}), 5.09(\mathrm{~d}, J=12.3 \mathrm{~Hz}, 1 \mathrm{H}), 4.51(\mathrm{t}, J=7.3 \mathrm{~Hz}, 1 \mathrm{H}), 4.39(\mathrm{dd}, J=8.0,5.7 \mathrm{~Hz}$, $1 \mathrm{H}), 3.20(\mathrm{dd}, J=14.7,5.8 \mathrm{~Hz}, 1 \mathrm{H}), 3.01(\mathrm{dd}, J=14.7,8.0 \mathrm{~Hz}, 1 \mathrm{H}), 1.65-1.54(\mathrm{~m}, 2 \mathrm{H}), 1.36(\mathrm{~s}, 9 \mathrm{H}), 1.24-1.16$ $(\mathrm{m}, 1 \mathrm{H}), 0.88(\mathrm{dd}, J=15.6,6.0 \mathrm{~Hz}, 6 \mathrm{H})$.

${ }^{13}$ C NMR: $\left(125 \mathrm{MHz}, \mathrm{CD}_{3} \mathrm{OD}\right) \delta 174.8,173.6,157.6,138.0,137.2,129.6,129.3,128.9,128.6,124.6,122.3,119.7$, $119.4,112.2,110.9,80.6,67.9,56.6,52.3,41.5,29.1,28.6,25.7,23.2,21.9$.

HRMS: (ESI) m/z: [M+H] $]^{+}$Calcd. for $\mathrm{C}_{29} \mathrm{H}_{38} \mathrm{~N}_{3} \mathrm{O}_{5}$ 508.2811; Found 508.2798.

IR: (ATR, neat, $\left.\mathrm{cm}^{-1}\right): 3313$ (w), 2958 (w), 1660 (s), 1497 (m), $1456(\mathrm{~m}), 1390$ (m), 1366 (m), 1246 (m), 1158 (s), $1097(\mathrm{~m}), 856(\mathrm{~m}), 739(\mathrm{~s}), 697(\mathrm{~s})$.

$[\boldsymbol{\alpha}]_{\mathbf{D}}{ }^{23}:-28.6(c=0.01$ in $\mathrm{MeOH})$

Synthesis of S2: The following was prepared according to a slightly modified literature procedure. ${ }^{3}$ Compound S1

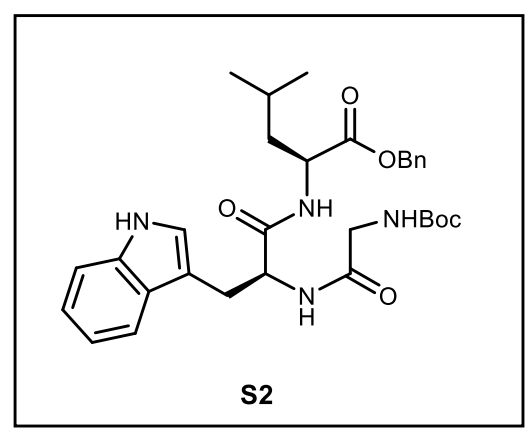
(6.67 g, $13.1 \mathrm{mmol}, 1.0$ eq.) was dissolved in DCM $(88 \mathrm{~mL})$ and thioanisole ( $4.0 \mathrm{~mL}, 34.2 \mathrm{mmol}, 2.6$ eq.) was added. The reaction was cooled to $0{ }^{\circ} \mathrm{C}$ in an ice bath, treated with TFA $(44 \mathrm{~mL}, 0.3 \mathrm{M})$, and stirred at room temperature $(25$ ${ }^{\circ} \mathrm{C}$ ). Upon completion (monitored by TLC), the mixture was concentrated under reduced pressure and TFA was azeotropically removed by co-distillation with toluene $(3 \times 1 \mathrm{~mL})$. Boc-L-Gly-OH $(2.76 \mathrm{~g}, 15.8 \mathrm{mmol}, 1.1 \mathrm{eq}$.) was dissolved in DCM $(80 \mathrm{~mL})$ and cooled to $0{ }^{\circ} \mathrm{C}$ in an ice bath. Then $\mathrm{N}$ methylmorpholine (3.2 mL, $28.9 \mathrm{mmol}, 2.2 \mathrm{eq}$.$) , HOBt (2.21 g, 14.4 \mathrm{mmol}$, 1.1 eq.), and $\operatorname{EDC}(2.77 \mathrm{~g}, 14.4 \mathrm{mmol}, 1.1 \mathrm{eq}$.$) were added to the reaction.$ After 15 minutes, the above deprotected $\mathbf{S 1}$ (5.35 g, $13.1 \mathrm{mmol}, 1.0$ eq.) was dissolved in DCM $(29 \mathrm{~mL})$ and added dropwise. After addition, the reaction was slowly warmed to room 
temperature $\left(25^{\circ} \mathrm{C}\right)$ overnight. Upon completion (monitored by TLC), the reaction was quenched with water (60 $\mathrm{mL})$, the organic phase was separated and washed with citric acid $(10 \%$ aq. solution, $3 \times 50 \mathrm{~mL})$. The aqueous phase was extracted with $\mathrm{DCM}(60 \mathrm{~mL} \times 3)$, the combined organic extracts were washed with $\mathrm{NaHCO}_{3}$ (aq. solution, $3 \times 120 \mathrm{~mL}$ ), dried over $\mathrm{MgSO}_{4}$, filtered, and concentrated under reduced pressure. The resulting residue was purified by flash chromatography $\left(\mathrm{SiO}_{2}\right.$, hexanes:EtOAc $\left.=2: 1 \rightarrow 1: 1\right)$ to give the desired compound $\mathbf{S} 2$ as a colorless oil (3.29 g, $5.83 \mathrm{mmol}, 44 \%)$.

$\boldsymbol{R}_{\mathbf{f}}=0.2$ (hexanes:EtOAc $\left.=1: 1, \mathrm{UV}\right)$.

${ }^{1}$ H NMR: $\left(500 \mathrm{MHz}, \mathrm{CD}_{3} \mathrm{OD}\right) \delta 7.56(\mathrm{~d}, J=7.9 \mathrm{~Hz}, 1 \mathrm{H}), 7.36-7.27(\mathrm{~m}, 6 \mathrm{H}), 7.11-7.06(\mathrm{~m}, 2 \mathrm{H}), 7.01(\mathrm{t}, J=7.5$ $\mathrm{Hz}, 1 \mathrm{H}), 5.12(\mathrm{~d}, J=12.4 \mathrm{~Hz}, 1 \mathrm{H}), 5.10(\mathrm{~d}, J=12.4 \mathrm{~Hz}, 1 \mathrm{H}), 4.72(\mathrm{t}, J=6.5 \mathrm{~Hz}, 1 \mathrm{H}), 4.48(\mathrm{t}, J=7.1 \mathrm{~Hz}, 1 \mathrm{H})$, $3.69-3.57(\mathrm{~m}, 2 \mathrm{H}), 3.24$ (dd, $J=14.8,5.8 \mathrm{~Hz}, 1 \mathrm{H}), 3.14(\mathrm{dd}, J=14.8,7.3 \mathrm{~Hz}, 1 \mathrm{H}), 1.58-1.53(\mathrm{~m}, 2 \mathrm{H}), 1.38(\mathrm{~s}, 9 \mathrm{H})$, $1.31-1.27$ (m, 1H), 0.86 (dd, $J=15.6,4.4 \mathrm{~Hz}, 6 \mathrm{H})$.

${ }^{13}$ C NMR: (125 MHz, $\left.\mathrm{CD}_{3} \mathrm{OD}\right) \delta 173.9,173.5,172.2,158.4,138.0,137.2,129.6,129.33,129.31,128.9,124.7$, $122.4,119.9,119.3,112.3,110.5,80.8,67.8,55.1,52.4,44.8,41.4,28.7,28.6,25.7,23.2,22.0$.

HRMS: (ESI) m/z: [M+H] $]^{+}$Calcd for $\mathrm{C}_{31} \mathrm{H}_{41} \mathrm{~N}_{4} \mathrm{O}_{6} 563.3026$; Found: 563.3026 .

IR: (ATR, neat, $\left.\mathrm{cm}^{-1}\right): 3277$ (w), 1742 (m), 1697 (m), 1653 (m), $1514(\mathrm{~m}), 1366(\mathrm{w}), 1271$ (m), 1197 (m), 1152 (s), $944(\mathrm{~m}), 744(\mathrm{~s}), 551(\mathrm{~m})$.

$[\boldsymbol{\alpha}]_{\mathbf{D}}{ }^{23}:-112.2(c=0.004$ in $\mathrm{MeOH})$

Synthesis of S3: Compound S2 (610 mg, $1.08 \mathrm{mmol}, 1.0$ eq.) and Pd/C (192 mg, 3 wt \%, 0.05 mmol, $5.0 \mathrm{~mol} \%)$

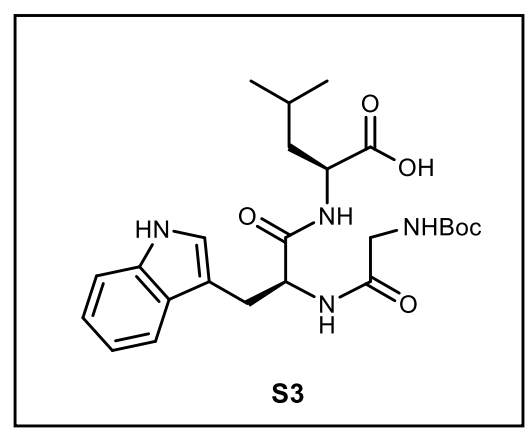
in $\mathrm{MeOH}(5.4 \mathrm{~mL}, 0.2 \mathrm{M})$ were stirred at room temperature $\left(25^{\circ} \mathrm{C}\right)$ under hydrogen atmosphere for $12 \mathrm{~h}$. Upon completion, the mixture was passed through a plug of Celite, which was rinsed with additional $\mathrm{MeOH}(10 \mathrm{~mL})$, and then concentrated under reduced pressure. Compound $\mathbf{S 3}$ was used without characterization or further purification.

Synthesis of S4: The following was prepared according to a slightly modified literature procedure. ${ }^{1} \mathrm{Cbz}-\mathrm{L}-\mathrm{Val}-\mathrm{OH}$

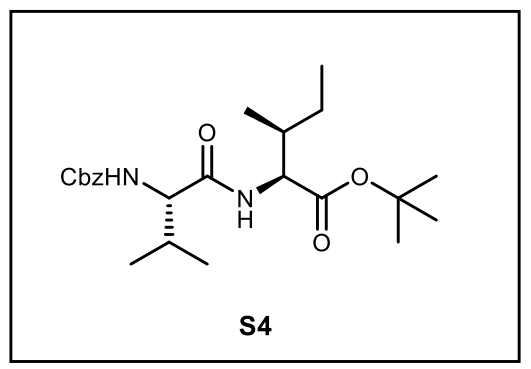
(587 mg, $2.34 \mathrm{mmol}, 1.0$ eq.) was dissolved in DCM $(20 \mathrm{~mL})$ and cooled to 0 ${ }^{\circ} \mathrm{C}$. Then $N$-methylmorpholine (0.6 mL, $5.14 \mathrm{mmol}, 2.2$ eq.), HOBt (394 mg, $2.57 \mathrm{mmol}, 1.1$ eq.), and EDC (493 mg, $2.57 \mathrm{mmol}, 1.1$ eq.) were added to the reaction. After 15 minutes, L-isoleucine $t$-butyl ester hydrochloride $(575 \mathrm{mg}$, $2.57 \mathrm{mmol}, 1.1$ eq.) was added and mixture was slowly warmed to room temperature $\left(25^{\circ} \mathrm{C}\right)$ overnight. Upon completion (monitored by TLC), the reaction was quenched with water $(20 \mathrm{~mL})$. The organic phase was separated, washed with citric acid $(10 \%$ aq. solution, $3 \times 20 \mathrm{~mL})$, and the aqueous phase was extracted with DCM $(3 \times 20 \mathrm{~mL})$. The combined organic extracts were washed with $\mathrm{NaHCO}_{3}$ (aq. solution, $3 \times 60 \mathrm{~mL}$ ), dried over $\mathrm{MgSO}_{4}$, filtered, and concentrated under reduced pressure. The resulting residue was purified by flash chromatography $\left(\mathrm{SiO}_{2}\right.$, hexanes:EtOAc $\left.=4: 1\right)$ to give the desired compound $\mathbf{S} 4$ as a colorless oil (954 mg, $2.27 \mathrm{mmol}, 97 \%)$.

$\boldsymbol{R}_{\mathbf{f}}=0.3$ (hexanes:EtOAc $=4: 1, \mathrm{UV}$ ).

${ }^{1}$ H NMR: (500 MHz, $\left.\mathrm{CD}_{3} \mathrm{OD}\right) \delta$ 7.37-7.26 (m, 5H), $5.11(\mathrm{~d}, J=12.4 \mathrm{~Hz}, 1 \mathrm{H}), 5.07(\mathrm{~d}, J=12.5 \mathrm{~Hz}, 1 \mathrm{H}), 4.25(\mathrm{~d}$, $J=6.2 \mathrm{~Hz}, 1 \mathrm{H}), 4.00(\mathrm{~d}, J=7.3 \mathrm{~Hz}, 1 \mathrm{H}), 2.04(\mathrm{~h}, J=6.9 \mathrm{~Hz}, 1 \mathrm{H}), 1.88-1.81(\mathrm{~m}, 1 \mathrm{H}), 1.54-1.48(\mathrm{~m}, 1 \mathrm{H}), 1.46(\mathrm{~s}$, 9H), 1.28-1.19 (m, 1H), 1.00-0.87 (m, 12H). 
${ }^{13}$ C NMR: (125 MHz, $\left.\mathrm{CD}_{3} \mathrm{OD}\right) \delta 174.2,172.0,158.6,138.3,129.5,129.0,128.8,82.8,67.6,61.9,58.8,38.4,32.0$, 28.3, 26.4, 19.8, 18.7, 15.9, 11.7 .

HRMS: (ESI) m/z: [M+H] $]^{+}$Calcd. for $\mathrm{C}_{23} \mathrm{H}_{37} \mathrm{~N}_{2} \mathrm{O}_{5} 421.2702$; Found: 421.2714 .

IR: (ATR, neat, $\mathrm{cm}^{-1}$ ): 3300 (w), 3070 (w), 2963 (w), 1739 (s), 1687 (s), 1645 (s), 1547 (s), 1500 (w), 1455 (m), $1144(\mathrm{~s}), 1028(\mathrm{~m}), 905(\mathrm{w}), 695(\mathrm{~s})$.

$[\boldsymbol{\alpha}]_{\mathbf{D}}{ }^{\mathbf{2 3}} \mathbf{:}-31.4(c=0.01$ in $\mathrm{MeOH})$

Synthesis of S5: The following was prepared according to a slightly modified literature procedure. ${ }^{1}$ Compound S4

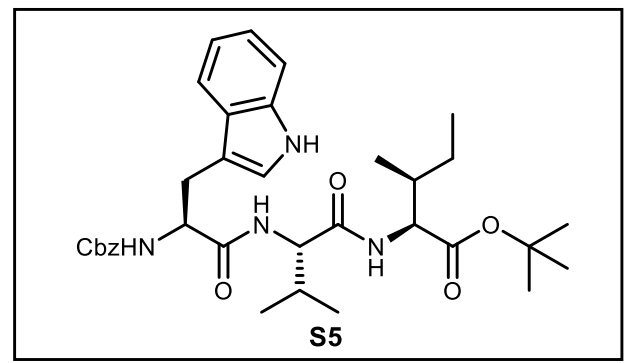
(1.06 g, $2.52 \mathrm{mmol}, 1.0$ eq.) and $\mathrm{Pd} / \mathrm{C}$ (447 mg, $3 \mathrm{wt} \%, 0.13 \mathrm{mmol}, 5.0$ mol \%) in $\mathrm{MeOH}(12.6 \mathrm{~mL})$ were stirred at room temperature $\left(25^{\circ} \mathrm{C}\right)$ under hydrogen atmosphere for $12 \mathrm{~h}$. Upon completion (monitored by TLC), the mixture was passed through a plug of Celite, which was rinsed with additional $\mathrm{MeOH}(50 \mathrm{~mL})$, and then concentrated under reduced pressure. BocHN-L-Trp-OH (899 mg, $2.77 \mathrm{mmol}, 1.1$ eq.) was dissolved in DCM $(16 \mathrm{~mL})$ and cooled to $0{ }^{\circ} \mathrm{C}$. Then $N$ methylmorpholine (0.6 mL, $5.55 \mathrm{mmol}, 2.2$ eq.), HOBt (425 mg, 2.77 mmol, 1.1 eq.), and EDC (532 $\mathrm{mg}, 2.77 \mathrm{mmol}, 1.1$ eq.) were added to the reaction. After 15 minutes, the above deprotected $\mathbf{S 4}$ (766 mg, $2.52 \mathrm{mmol}, 1.0$ eq.) was dissolved in DCM (5 $\mathrm{mL})$ and added dropwise. The reaction slowly warmed to room temperature $\left(25^{\circ} \mathrm{C}\right)$ overnight. Upon completion (monitored by TLC), the reaction was quenched with water $(20 \mathrm{~mL})$, the organic phase was separated, and washed with citric acid $(10 \%$ aq. solution, $3 \times 15 \mathrm{~mL})$. The aqueous phase was extracted with DCM $(3 \times 15 \mathrm{~mL})$, the combined organic extracts were washed with $\mathrm{NaHCO}_{3}$ (aq. solution, $3 \times 60 \mathrm{~mL}$ ), dried over $\mathrm{MgSO}_{4}$, filtered, and concentrated under reduced pressure. The resulting residue was purified by flash chromatography $\left(\mathrm{SiO}_{2}\right.$, hexanes:EtOAc $\left.=2: 1\right)$ to give the desired compound $\mathbf{S 5}$ as a white solid (933 $\mathrm{mg}, 1.64 \mathrm{mmol}, 65 \%)$.

$\boldsymbol{R}_{\mathbf{f}}=0.1$ (hexanes:EtOAc $=2: 1, \mathrm{UV}$ ).

${ }^{1}$ H NMR: $\left(500 \mathrm{MHz}, \mathrm{CD}_{3} \mathrm{OD}\right) \delta 7.60(\mathrm{~d}, J=7.7 \mathrm{~Hz}, 1 \mathrm{H}), 7.35-7.23(\mathrm{~m}, 6 \mathrm{H}), 7.10-7.05(\mathrm{~m}, 2 \mathrm{H}), 7.01-6.96(\mathrm{~m}$, $1 \mathrm{H}), 5.01(\mathrm{~s}, 2 \mathrm{H}), 4.51(\mathrm{dd}, J=8.6,5.2 \mathrm{~Hz}, 1 \mathrm{H}), 4.24(\mathrm{dd}, J=17.4,6.9 \mathrm{~Hz}, 1 \mathrm{H}), 3.27(\mathrm{dd}, J=14.8,5.3 \mathrm{~Hz}, 1 \mathrm{H})$, $3.06(\mathrm{dd}, J=14.8,8.6 \mathrm{~Hz}, 1 \mathrm{H}), 2.03(\mathrm{~h}, J=6.9 \mathrm{~Hz}, 1 \mathrm{H}), 1.87-1.79(\mathrm{~m}, 1 \mathrm{H}), 1.55-1.48(\mathrm{~m}, 1 \mathrm{H}), 1.46(\mathrm{~s}, 9 \mathrm{H}), 1.28-$ $1.18(\mathrm{~m}, 1 \mathrm{H}), 0.95-0.87(\mathrm{~m}, 12 \mathrm{H})$.

${ }^{13}$ C NMR: (125 MHz, CD 3 OD) $\delta 174.5,173.4,172.0,158.3,138.2,138.1,129.4,128.9,128.8,128.7,124.6,122.4$, $119.8,119.4,112.2,111.0,82.8,67.6,59.9,59.0,57.2,38.3,32.2,29.0,28.3,26.5,19.8,18.8,15.9,11.8$.

HRMS: (ESI) m/z: [M+H] $]^{+}$Calcd. for $\mathrm{C}_{34} \mathrm{H}_{47} \mathrm{~N}_{4} \mathrm{O}_{6} 607.3496$; Found: 607.3501.

IR: (ATR, neat, $\mathrm{cm}^{-1}$ ): 3406 (w), 3286 (w), 2964 (w), 1727 (w), 1691 (m), 1640 (s), 1535 (m), 1456 (w), 1265 (m), $1087(\mathrm{w}), 738(\mathrm{~s}), 534(\mathrm{w})$.

m.p.: $177-178^{\circ} \mathrm{C}$.

$[\alpha]_{\mathbf{D}}^{23}:-42.9(c=0.01$ in $\mathrm{MeOH})$

Synthesis of S6: Compound S5 (186 mg, $314 \mu \mathrm{mol}, 1.0$ eq.) and Pd/C (56 mg, $3 \mathrm{wt} \%, 15.7 \mu \mathrm{mol}, 5.0 \mathrm{~mol} \%)$ in

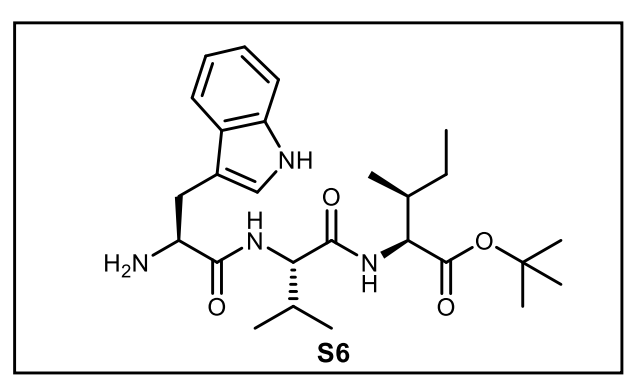
$\mathrm{MeOH}(2 \mathrm{~mL}, 0.2 \mathrm{M})$ were stirred at room temperature $\left(25^{\circ} \mathrm{C}\right)$ under hydrogen atmosphere for $12 \mathrm{~h}$. Upon completion, the mixture was passed through a plug of Celite, which was rinsed with additional $\mathrm{MeOH}$ $(10 \mathrm{~mL})$, and then concentrated under reduced pressure. Compound $\mathbf{S 6}$ was used without further purification. 
Synthesis of S7: The pyridine ester was synthesized following a known procedure with slight modifications. ${ }^{2}$

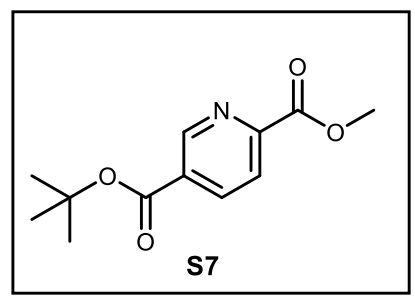
Concentrated sulfuric acid $(0.6 \mathrm{~mL}, 31.6 \mathrm{M})$ was added to a solution of 2,5pyridinedicarboyxlic acid $(3.00 \mathrm{~g}, 18.0 \mathrm{mmol}, 1.0 \mathrm{eq}$.) in methanol $(37 \mathrm{~mL})$ and the reaction was stirred and heated in an oil bath at reflux for two hours. After cooling to room temperature $\left(25^{\circ} \mathrm{C}\right)$, the reaction was poured into ice-cold water $(150 \mathrm{~mL})$. The precipitate was filtered, washed with water $(2 \times 8 \mathrm{~mL})$, and dried to obtain a light yellow solid. This solid was suspended in THF $(12 \mathrm{~mL})$ and $\mathrm{Boc}_{2} \mathrm{O}(4.94 \mathrm{~g}, 22.6$ mmol, 2.5 eq.) and DMAP (553 mg, $4.53 \mathrm{mmol}, 0.5$ eq.) were added and the resulting mixture was stirred for six hours (conversion monitored by TLC). To the mixture was added $\mathrm{NH}_{4} \mathrm{Cl}$ (sat. aq. solution, $10 \mathrm{~mL}$ ), EtOAc $(10 \mathrm{~mL})$, and the organic phase was separated. The aqueous phase was extracted with EtOAc $(3 \times 10 \mathrm{~mL})$, the combined organic extracts were washed with brine $(20 \mathrm{~mL})$, dried over $\mathrm{MgSO}_{4}$, filtered, and concentrated under reduced pressure. The resulting residue was purified by flash chromatography $\left(\mathrm{SiO}_{2}\right.$, hexanes:EtOAc $\left.=4: 1\right)$ to give the desired compound $\mathbf{S} 7$ as a white solid $(1.74 \mathrm{~g}, 7.33 \mathrm{mmol}$, $41 \%)$.

$\boldsymbol{R}_{\mathbf{f}}=0.3$ (hexanes:EtOAc $=4: 1, \mathrm{UV}$ ).

${ }^{1}$ H NMR: $\left(500 \mathrm{MHz}, \mathrm{CDCl}_{3}\right) \delta 9.23(\mathrm{~d}, J=2.1 \mathrm{~Hz}, 1 \mathrm{H}), 8.36(\mathrm{dd}, J=8.1,2.1 \mathrm{~Hz}, 1 \mathrm{H}), 8.17(\mathrm{~d}, J=8.1 \mathrm{~Hz}, 1 \mathrm{H})$, $4.02(\mathrm{~s}, 3 \mathrm{H}), 1.61(\mathrm{~s}, 9 \mathrm{H})$.

${ }^{13}$ C NMR: $\left(125 \mathrm{MHz}, \mathrm{CDCl}_{3}\right) \delta 165.2,163.6,150.9,150.5,138.2,130.4,124.7,83.0,53.3,28.2$.

The analytical data was in accordance with previously reported values. ${ }^{4}$

Synthesis of S8: Compound S7 (1.67 g, $7.04 \mathrm{mmol}, 1.0$ eq.) was dissolved in DCM (14 mL) at $0{ }^{\circ} \mathrm{C}$ and $m \mathrm{CPBA}$

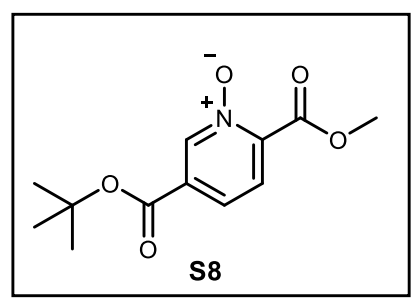
( $3.47 \mathrm{~g}, 14.1 \mathrm{mmol}, 2.0$ eq.) was added in small portions. The reaction was stirred and let to warm to room temperature $\left(25^{\circ} \mathrm{C}\right)$ overnight. Then, $\mathrm{K}_{2} \mathrm{CO}_{3}(2.92 \mathrm{~g}, 21.1 \mathrm{mmol}$, 3.0 eq.) was added and the resulting mixture was passed through a plug of Celite, which was rinsed with additional DCM $(10 \mathrm{~mL})$, and concentrated under reduced pressure. The resulting residue was purified by flash chromatography $\left(\mathrm{SiO}_{2}\right.$, hexanes:EtOAc $=1: 4)$ to afford compound $\mathbf{S 8}$ as a colorless oil $(1.48 \mathrm{~g}, 5.84 \mathrm{mmol}$, $83 \%)$.

$\boldsymbol{R}_{\mathbf{f}}=0.3$ (hexanes:EtOAc $=1: 4, \mathrm{UV}$ ).

${ }^{1}$ H NMR: $\left(500 \mathrm{MHz}, \mathrm{CDCl}_{3}\right) \delta 8.72(\mathrm{~d}, J=1.4 \mathrm{~Hz}, 1 \mathrm{H}), 7.77(\mathrm{~d}, J=8.2 \mathrm{~Hz}, 1 \mathrm{H}), 7.62(\mathrm{~d}, J=8.2 \mathrm{~Hz}, 1 \mathrm{H}), 4.00(\mathrm{~s}$, $3 \mathrm{H}), 1.58(\mathrm{~s}, 9 \mathrm{H})$.

${ }^{13}$ C NMR: $\left(125 \mathrm{MHz}, \mathrm{CDCl}_{3}\right) \delta 161.7,161.3,143.9,141.9,132.6,126.5,125.2,84.1,53.6,28.1$.

HRMS: (ESI) m/z: [M+H] Calcd. for $\mathrm{C}_{12} \mathrm{H}_{16} \mathrm{NO}_{5}$ 254.1028; Found: 254.1024.

IR: (ATR, neat, $\left.\mathrm{cm}^{-1}\right)$ : 2976 (w), 2949 (w), 1750 (m), 1722 (s), 1607 (w), 1459 (w), 1311 (s), 1236 (s), 1163 (m), $1130(\mathrm{~m}), 1115(\mathrm{~s}), 889(\mathrm{~m}), 754(\mathrm{~s})$.

Synthesis of S9: To a stirred solution of KCN (1.65 g, $25.4 \mathrm{mmol}, 3.0$ eq.) in MeOH (29 mL, 0.3 M), compound

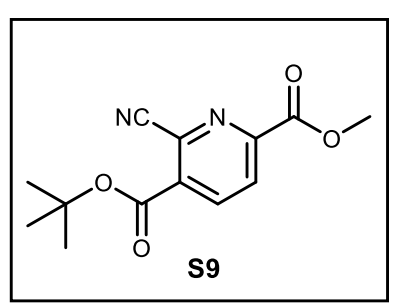
S8 (2.14 g, $8.46 \mathrm{mmol}, 1.0$ eq.) in MeCN (36 mL, $0.2 \mathrm{M})$ was added, followed by dropwise addition of benzoyl chloride $(3.57 \mathrm{~g}, 25.4 \mathrm{mmol}, 3.0$ eq.). The reaction stirred for three hours. Upon completion by TLC, the reaction was quenched with $\mathrm{K}_{2} \mathrm{CO}_{3}(10 \%$ aq. solution, $47 \mathrm{~mL})$ and the aqueous layer was extracted with $\mathrm{DCM}(3 \times 45 \mathrm{~mL})$. The combined organic extracts were dried over $\mathrm{MgSO}_{4}$, filtered, and concentrated under reduced pressure. The resulting residue was purified by flash chromatography $\left(\mathrm{SiO}_{2}\right.$, hexanes:EtOAc $=4: 1)$ to give the desired compound $\mathbf{S 9}$ as a white solid $(1.79 \mathrm{~g}, 6.83$ mmol, 81\%).

$\boldsymbol{R}_{\mathbf{f}}=0.2$ (hexanes:EtOAc $\left.=4: 1, \mathrm{UV}\right)$.

${ }^{1}$ H NMR: $\left(500 \mathrm{MHz}, \mathrm{CDCl}_{3}\right) \delta 8.52(\mathrm{~d}, J=8.2 \mathrm{~Hz}, 1 \mathrm{H}), 8.35(\mathrm{~d}, J=8.2 \mathrm{~Hz}, 1 \mathrm{H}), 4.05(\mathrm{~s}, 3 \mathrm{H}), 1.68(\mathrm{~s}, 9 \mathrm{H})$. 
${ }^{13}$ C NMR: $\left(125 \mathrm{MHz}, \mathrm{CDCl}_{3}\right) \delta 163.7,161.4,150.9,140.4,133.8,133.5,127.4,115.5,85.9,53.8,28.1$.

HRMS: (ESI) m/z: [M+H] $]^{+}$Calcd. For $\mathrm{C}_{13} \mathrm{H}_{15} \mathrm{~N}_{2} \mathrm{O}_{4}$ 263.1032; Found: 263.1031.

IR: (ATR, neat, $\left.\mathrm{cm}^{-1}\right)$ : 3095 (w), 2986 (w), 2932 (w), 1718 (s), 1582 (w), 1457 (m), 1434 (m), 1317 (m), 1292 (s), $1259(\mathrm{~m}), 1138(\mathrm{~s}), 767(\mathrm{~s})$.

m.p.: $69-70{ }^{\circ} \mathrm{C}$.

Synthesis of S10: Compound S9 (340 mg, $1.30 \mathrm{mmol}, 1.0$ eq.) and Pd/C (230 mg, $3 \mathrm{wt} \%, 0.07 \mathrm{mmol}, 5.0 \mathrm{~mol} \%)$

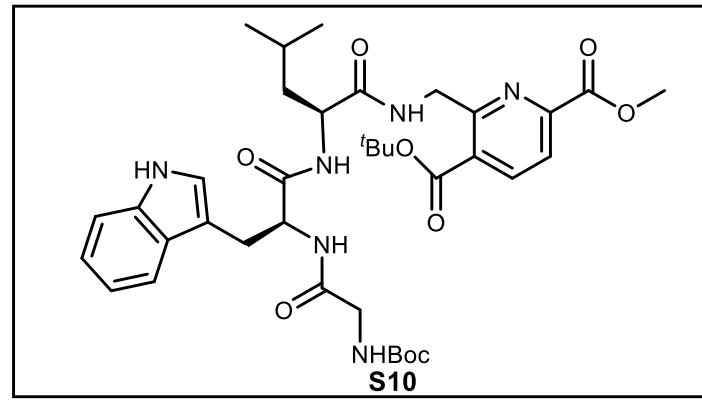
in acetic acid $(6.5 \mathrm{~mL})$ were stirred at room temperature $\left(25^{\circ} \mathrm{C}\right)$ under hydrogen atmosphere for $12 \mathrm{~h}$. Upon completion (monitored by TLC), the mixture was passed through a plug of Celite, which was rinsed with $\mathrm{MeOH}(15 \mathrm{~mL})$, concentrated under reduced pressure, and acetic acid was azeotropically removed by codistillation with toluene $(3 \times 1 \mathrm{~mL})$. Compound $\mathbf{S 3}(512 \mathrm{mg}$, $1.08 \mathrm{mmol}, 1.0$ eq.) was then dissolved in THF $(7.8 \mathrm{~mL})$ and $N$ methylmorpholine $(0.59 \mathrm{~mL}, 5.39 \mathrm{mmol}, 5.0$ eq. $)$ was added under nitrogen atmosphere. The resulting solution was cooled to $-40{ }^{\circ} \mathrm{C}$ and isobutyl chloroformate $(0.2 \mathrm{~mL}, 1.29 \mathrm{mmol}, 1.2$ eq.) was added dropwise. After 15 minutes, the deprotected $\mathbf{S 9}$ prepared above (500 $\mathrm{mg}, 1.30 \mathrm{mmol}, 1.2 \mathrm{eq}$.) was taken up in THF ( $3 \mathrm{~mL})$ and added dropwise to the reaction. The mixture was allowed to slowly warmed to room temperature $\left(25^{\circ} \mathrm{C}\right)$ while stirred overnight. The reaction was quenched with $\mathrm{NaHCO}_{3}$ (aq. solution, $10 \mathrm{~mL}$ ), diluted with EtOAc $(10 \mathrm{~mL})$, the organic phase was separated, and the aqueous phase was extracted with EtOAc $(3 \times 10 \mathrm{~mL})$. The combined organic extracts were washed with brine $(20 \mathrm{~mL})$, dried over $\mathrm{MgSO}_{4}$, filtered, and concentrated under reduced pressure. The resulting residue was purified by flash chromatography $\left(\mathrm{SiO}_{2}\right.$, hexanes:EtOAc $\left.=1: 4\right)$ to give the desired compound $\mathbf{S 1 0}$ as a yellow oil (604 $\mathrm{mg}, 0.84 \mathrm{mmol}, 78 \%$ ).

$\boldsymbol{R}_{\mathbf{f}}=0.3$ (hexanes:EtOAc $=1: 4, \mathrm{UV}$ ).

${ }^{1}$ H NMR: $\left(500 \mathrm{MHz}, \mathrm{CD}_{3} \mathrm{OD}\right) \delta 8.34(\mathrm{~d}, J=8.0 \mathrm{~Hz}, 1 \mathrm{H}), 8.01(\mathrm{~d}, J=8.0 \mathrm{~Hz}, 1 \mathrm{H}), 7.60-7.49(\mathrm{~m}, 1 \mathrm{H}), 7.15-7.06$ $(\mathrm{m}, 2 \mathrm{H}), 6.87-6.96(\mathrm{~m}, 2 \mathrm{H}), 4.81-4.72(\mathrm{~m}, 2 \mathrm{H}), 4.59(\mathrm{~d}, J=18.0 \mathrm{~Hz}, 1 \mathrm{H}), 4.54-4.48(\mathrm{~m}, 1 \mathrm{H}), 3.92(\mathrm{~s}, 3 \mathrm{H}), 3.69$ $(\mathrm{s}, 2 \mathrm{H}), 3.29-3.22(\mathrm{~m}, 1 \mathrm{H}), 3.21-3.13(\mathrm{~m}, 1 \mathrm{H}), 1.64(\mathrm{~s}, 9 \mathrm{H}), 1.58-1.49(\mathrm{~m}, 2 \mathrm{H}), 1.39(\mathrm{~s}, 9 \mathrm{H}), 1.31-1.20(\mathrm{~m}, 1 \mathrm{H})$, $0.89(\mathrm{dd}, J=12.2,5.8 \mathrm{~Hz}, 6 \mathrm{H})$.

${ }^{13}$ C NMR: (125 MHz, CD $\left.{ }_{3} \mathrm{OD}\right) \delta 174.8,173.8,172.4,166.4,165.6,158.4,158.0,149.6,141.1,137.8,130.5,128.7$, $124.7,124.4,122.4,119.9,119.3,112.2,110.6,84.4,80.8,55.7,53.5,53.2,44.9,44.7,41.8,28.7,28.6,28.4,25.7$, $23.6,22.0$

HRMS: (ESI) m/z: Calcd. for $\mathrm{C}_{37} \mathrm{H}_{51} \mathrm{~N}_{6} \mathrm{O}_{9}$ 723.3718; Found: 723.3714 .

IR: (ATR, neat, $\left.\mathrm{cm}^{-1}\right)$ : 3279 (w), 2955 (w), 1718 (m), 1636 (s), 1513 (m), 1457 (m), 1391 (m), 1287 (s), 1246 (m), $1140(\mathrm{~s}), 845(\mathrm{~m}), 740(\mathrm{~m}), 560(\mathrm{~m})$.

$[\boldsymbol{\alpha}]_{\mathbf{D}}{ }^{23}:-25.2(c=0.03$ in DCM $)$

Synthesis of S11: Compound S10 (604 mg, $0.84 \mathrm{mmol}, 1.0$ eq.) was dissolved in DCM (8.4 mL) and thioanisole

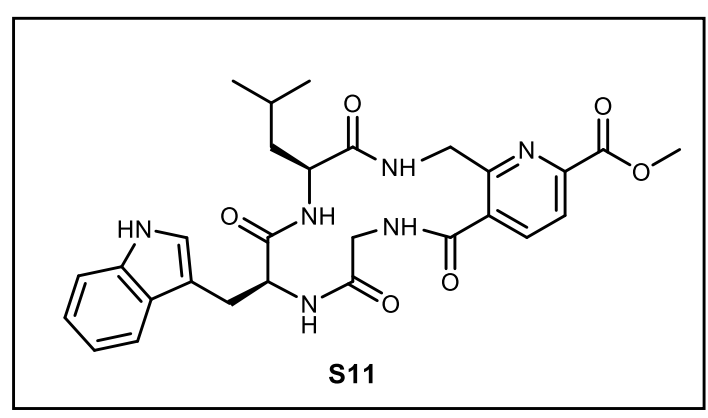
$(0.3 \mathrm{~mL}, 2.2 \mathrm{mmol}, 2.6 \mathrm{eq}$.) was added. The reaction was then treated with a solution of $\mathrm{HCl}$ in dioxane $(2.1 \mathrm{~mL}, 4.0 \mathrm{M})$ and stirred at room temperature $\left(25^{\circ} \mathrm{C}\right)$. Upon completion (monitored by LCMS), the reaction was concentrated under reduced pressure and $\mathrm{HCl}$ was azeotropically removed by co-distillation with toluene $(3 \times 1 \mathrm{~mL})$. The residue was dissolved in NMP $(3.5 \mathrm{~mL})$ and added dropwise to a stirring solution of DIPEA $(0.7 \mathrm{~mL}, 8.3 \mathrm{mmol}$, 6.0 eq.) T3P ( $0.8 \mathrm{~mL}, 1.4 \mathrm{mmol}, 50 \mathrm{wt} \%$ in EtOAc, 2.0 eq.) in NMP $(3.5 \mathrm{~mL})$ under nitrogen atmosphere at room temperature (25 ${ }^{\circ} \mathrm{C}$ ), stirring until starting material was fully consumed (monitored 
by LCMS). Then the reaction was quenched with $\mathrm{NaHCO}_{3}$ (aq. solution, $7 \mathrm{~mL}$ ), diluted with EtOAc $(10 \mathrm{~mL})$, the organic phase was separated, and the aqueous phase was extracted with EtOAc $(5 \times 5 \mathrm{~mL})$. The combined organic phase was washed with brine $(20 \mathrm{~mL})$, dried over $\mathrm{MgSO}_{4}$, filtered, and concentrated under reduced pressure. The resulting residue was purified by flash chromatography $\left(\mathrm{SiO}_{2}\right.$, EtOAc: $\left.\mathrm{MeOH}=49: 1 \rightarrow 10: 1\right)$, and then $\mathrm{C}_{18}$ functionalized $\mathrm{SiO}_{2}, \mathrm{H}_{2} \mathrm{O}: \mathrm{MeCN}=2: 3$ ) to give the desired compound $\mathbf{S 1 1}$ as a white solid (193 $\mathrm{mg}, 0.35 \mathrm{mmol}$, $51 \%)$.

$\boldsymbol{R}_{\mathbf{f}}=0.3($ EtOAc: $\mathrm{MeOH}=10: 1, \mathrm{UV})$.

${ }^{1}$ H NMR: $\left(500 \mathrm{MHz}\right.$, DMSO- $\left.d_{6}\right) \delta 10.90(\mathrm{~d}, J=2.5 \mathrm{~Hz}, 1 \mathrm{H}), 9.58(\mathrm{~d}, J=6.1 \mathrm{~Hz}, 1 \mathrm{H}), 9.47(\mathrm{~d}, J=5.8 \mathrm{~Hz}, 1 \mathrm{H})$, $7.98(\mathrm{~d}, J=7.8 \mathrm{~Hz}, 1 \mathrm{H}), 7.88(\mathrm{~d}, J=7.8 \mathrm{~Hz}, 1 \mathrm{H}), 7.56-7.51(\mathrm{~m}, 2 \mathrm{H}), 7.36(\mathrm{~d}, J=8.1 \mathrm{~Hz}, 1 \mathrm{H}), 7.32(\mathrm{~d}, J=2.4 \mathrm{~Hz}$, 1H), 7.11-7.06 (m, $2 \mathrm{H}), 7.02$ (t, $J=7.4 \mathrm{~Hz}, 1 \mathrm{H}), 4.55$ (dd, $J=15.4,5.9 \mathrm{~Hz}, 1 \mathrm{H}), 4.43$ (dd, $J=15.4,6.3 \mathrm{~Hz}, 1 \mathrm{H})$, $4.38-4.30(\mathrm{~m}, 2 \mathrm{H}), 4.19(\mathrm{dd}, J=14.3,5.9 \mathrm{~Hz}, 1 \mathrm{H}), 3.91(\mathrm{~s}, 3 \mathrm{H}), 3.61(\mathrm{dd}, J=14.3,6.3 \mathrm{~Hz}, 1 \mathrm{H}), 3.20(\mathrm{dd}, J=14.8$, $3.9 \mathrm{~Hz}, 1 \mathrm{H}), 3.10$ (dd, $J=14.8,10.5 \mathrm{~Hz}, 1 \mathrm{H}), 1.63$ (ddd, $J=13.9,10.4,3.5 \mathrm{~Hz}, 1 \mathrm{H}), 1.39$ (ddtd, $J=13.3,10.5,6.6$, $4.4 \mathrm{~Hz}, 1 \mathrm{H}), 1.17$ (ddd, $J=13.9,11.5,3.9 \mathrm{~Hz}, 1 \mathrm{H}), 0.79$ (dd, $J=14.7,6.6 \mathrm{~Hz}, 6 \mathrm{H})$.

${ }^{13}$ C NMR: (125 MHz, DMSO-d $d_{6} \delta 173.3,171.3,171.0,169.3,164.7,156.2,146.4,136.8,136.2,133.7,126.8$, 124.1, 123.0, 121.1, 119.0, 117.9, 111.5, 109.5, 57.2, 52.6, 49.3, 45.7, 43.3, (39.9 observed by HSQC), 26.2, 24.0, 23.3, 20.9.

HRMS: (ESI) m/z: [M+H] $]^{+}$Calcd. for $\mathrm{C}_{28} \mathrm{H}_{33} \mathrm{~N}_{6} \mathrm{O}_{6}$ 549.2462; Found: 549.2467.

IR: (ATR, neat, $\left.\mathrm{cm}^{-1}\right)$ : $3316(\mathrm{w}), 2955$ (w), 1729 (w), 1648 (s), 1533 (s), 1459 (w), 1435 (m), 1291 (m), 1163 (m), $742(\mathrm{~m}), 533(\mathrm{~m}), 464(\mathrm{~m})$.

m.p.: $308^{\circ} \mathrm{C}$ (decomp.).

$[\boldsymbol{\alpha}]_{\mathbf{D}}{ }^{23}:-63.6(c=0.004$ in 4:1 $=$ DCM:MeOH $)$

Synthesis of S12: Compound S11 (53.0 mg, $96.6 \mu \mathrm{mol}, 1.0$ eq.) was dissolved in THF/MeOH (1.0:0.5 mL) and

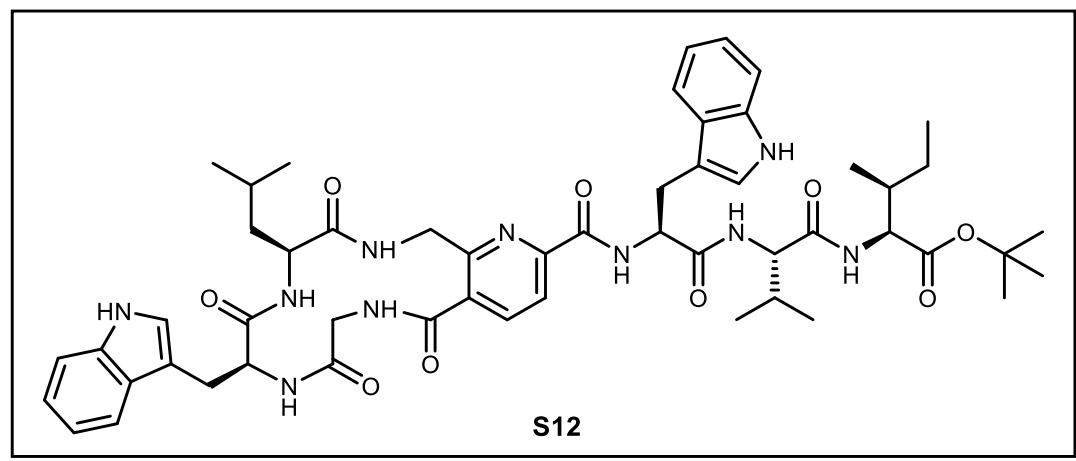

$\mathrm{NaOH}$ (1 M aq. sol., $0.6 \mathrm{~mL}, 0.58 \mathrm{mmol}$, 6.0 eq.). was added. Upon completion (monitored by TLC), the reaction was concentrated under reduced pressure, and the mixture was dry-loaded on Celite and purified on with was purified by flash chromatography using reverse phase (Biotage Isolera, $\mathrm{C}_{18}$ modified silica, $\mathrm{H}_{2} \mathrm{O}: \mathrm{MeCN}=0 \rightarrow 100 \%$ ). The resulting residue was dissolved in NMP $(0.3 \mathrm{~mL})$ and $N$-methylmorpholine $(35 \mu \mathrm{L}, 314$ $\mu$ mol, 5.0 eq.) was added. After 5 minutes, the solution was cooled to $-20{ }^{\circ} \mathrm{C}$ in a dry ice and acetone bath and isobutyl chloroformate ( $33 \mu \mathrm{L}, 252 \mu \mathrm{mol}, 4.0$ eq.) was added dropwise. After 15 minutes, compound $\mathbf{S 6}$ (149 mg, $314 \mu \mathrm{mol}, 5.0$ eq.) was taken up in NMP $(0.3 \mathrm{~mL})$ and added dropwise to the reaction. The reaction slowly warmed to room temperature and stirred overnight. The reaction was quenched with $\mathrm{NaHCO}_{3}$ (aq. solution, $5 \mathrm{~mL}$ ) and diluted with EtOAc $(7 \mathrm{~mL})$. The organic phase was separated, and the aqueous phase was extracted with EtOAc $(5 \times 5 \mathrm{~mL})$. The combined organic extracts were washed with brine $(20 \mathrm{~mL})$, dried over $\mathrm{MgSO}_{4}$, filtered and concentrated under reduced pressure. The resulting residue was purified by flash chromatography $\left(\mathrm{SiO}_{2}\right.$, DCM:MeOH $=49: 1 \rightarrow 10: 1$, and then $\mathrm{C}_{18}$ functionalized $\left.\mathrm{SiO}_{2}, \mathrm{H}_{2} \mathrm{O}: \mathrm{MeCN}=1: 1 \rightarrow 1: 9\right)$ to give the desired compound $\mathbf{S 1 2}$ as a white solid (15 mg, $15.4 \mu \mathrm{mol}, 16 \%)$.

$\boldsymbol{R}_{\mathbf{f}}=0.4(\mathrm{DCM}: \mathrm{MeOH}=9: 1, \mathrm{UV})$.

${ }^{1}$ H NMR: (500 MHz, DMSO-d $\left.d_{6}\right) \delta 10.90(\mathrm{~d}, J=2.4 \mathrm{~Hz}, 1 \mathrm{H}), 10.79(\mathrm{~d}, J=2.5 \mathrm{~Hz}, 1 \mathrm{H}), 9.50(\mathrm{t}, J=6.1 \mathrm{~Hz}, 1 \mathrm{H})$, $9.46(\mathrm{~d}, J=5.9 \mathrm{~Hz}, 1 \mathrm{H}), 8.58(\mathrm{~d}, J=7.8 \mathrm{~Hz}, 1 \mathrm{H}), 8.29(\mathrm{~d}, J=9.0 \mathrm{~Hz}, 1 \mathrm{H}), 8.16(\mathrm{~d}, J=7.7 \mathrm{~Hz}, 1 \mathrm{H}), 7.91(\mathrm{~d}, J=$ $7.9 \mathrm{~Hz}, 1 \mathrm{H}), 7.84(\mathrm{~d}, J=7.9 \mathrm{~Hz}, 1 \mathrm{H}), 7.58(\mathrm{~d}, J=7.9 \mathrm{~Hz}, 1 \mathrm{H}), 7.55-7.49(\mathrm{~m}, 2 \mathrm{H}), 7.36(\mathrm{~d}, J=8.1 \mathrm{~Hz}, 1 \mathrm{H}), 7.32$ $(\mathrm{d}, J=2.4 \mathrm{~Hz}, 1 \mathrm{H}), 7.28(\mathrm{~d}, J=8.1 \mathrm{~Hz}, 1 \mathrm{H}), 7.11-7.06(\mathrm{~m}, 3 \mathrm{H}), 7.04-6.99(\mathrm{~m}, 2 \mathrm{H}), 6.90(\mathrm{t}, J=7.4 \mathrm{~Hz}, 1 \mathrm{H}), 4.90$ (td, $J=7.4,5.4 \mathrm{~Hz}, 1 \mathrm{H}), 4.51(\mathrm{dd}, J=16.5,6.0 \mathrm{~Hz}, 1 \mathrm{H}), 4.43-4.37(\mathrm{~m}, 2 \mathrm{H}), 4.37-4.28(\mathrm{~m}, 2 \mathrm{H}), 4.17(\mathrm{td}, J=14.3$, 
$5.8 \mathrm{~Hz}, 1 \mathrm{H}), 4.90(\mathrm{t}, J=7.1 \mathrm{~Hz}, 1 \mathrm{H}), 3.57(\mathrm{dd}, J=14.4,6.4 \mathrm{~Hz}, 1 \mathrm{H}), 3.27-3.22(\mathrm{~m}, 2 \mathrm{H}), 3.19(\mathrm{dd}, J=14.8,3.9 \mathrm{~Hz}$, $1 \mathrm{H}), 3.09$ (dd, $J=14.9,10.5 \mathrm{~Hz}, 1 \mathrm{H}), 2.09-1.98(\mathrm{~m}, 1 \mathrm{H}), 1.77$ (dtd, $J=8.9,6.7,4.4 \mathrm{~Hz}, 1 \mathrm{H}), 1.62$ (ddd, $J=13.9$, $10.3,3.5 \mathrm{~Hz}, 1 \mathrm{H}), 1.49-1.43(\mathrm{~m}, 1 \mathrm{H}), 1.40(\mathrm{~s}, 9 \mathrm{H}), 1.39-1.34(\mathrm{~m}, 1 \mathrm{H}), 1.28-1.20(\mathrm{~m}, 1 \mathrm{H}), 1.17$ (ddd, $J=14.8,11.4$, $3.8 \mathrm{~Hz}, 1 \mathrm{H}), 0.93-0.86(\mathrm{~m}, 12 \mathrm{H}), 0.78$ (dd, $J=14.7,6.6 \mathrm{~Hz}, 6 \mathrm{H})$.

${ }^{13}$ C NMR: $\left(125 \mathrm{MHz}, \mathrm{DMSO}-d_{6}\right) \delta 173.1,171.3,171.1,171.0,170.7,170.3,169.4,162.3,155.0,148.3,137.1$, $136.2,136.0,133.0,127.5,126.8,124.1,123.8,121.0,120.8,119.9,118.6,118.5,118.2,117.9,111.5,111.2$, $109.53,109.48,80.4,57.20,57.17,53.2,49.3,45.6,43.3,40.4$, (39.9 observed by HSQC), 36.2, 31.0, 27.9, 27.6, $26.2,25.0,24.0,23.3,20.9,19.2,18.2,15.4,11.3$.

HRMS: (ESI) m/z: [M+H] $]^{+}$Calcd. for $\mathrm{C}_{53} \mathrm{H}_{69} \mathrm{~N}_{10} \mathrm{O}_{9}$ 989.5249; Found: 989.5266.

IR: (ATR, neat, $\left.\mathrm{cm}^{-1}\right)$ : 3314 (w), 2963 (w), 1650 (s), 1513 (s), 1458 (m), 1368 (w), 1233 (w), 1152 (m), 1100 (w), $844(\mathrm{w}), 741(\mathrm{~s}), 534(\mathrm{~m})$.

m.p.: $282{ }^{\circ} \mathrm{C}$ (decomp.).

$[\alpha]_{\mathbf{D}}{ }^{23}:-96.1(c=0.003$ in DCM $)$

Synthesis of 1: Compound S12 (6.4 mg, $6.5 \mu \mathrm{mol}, 1.0$ eq.) was dissolved in DCM (0.2 mL) and thioanisole $(4 \mu \mathrm{L}$, $32 \mu \mathrm{mol}, 5.0$ eq.) was added. The resulting mixture was treated with a solution of $\mathrm{HCl}$ in dioxane $(0.1 \mathrm{~mL}, 4.0 \mathrm{M})$

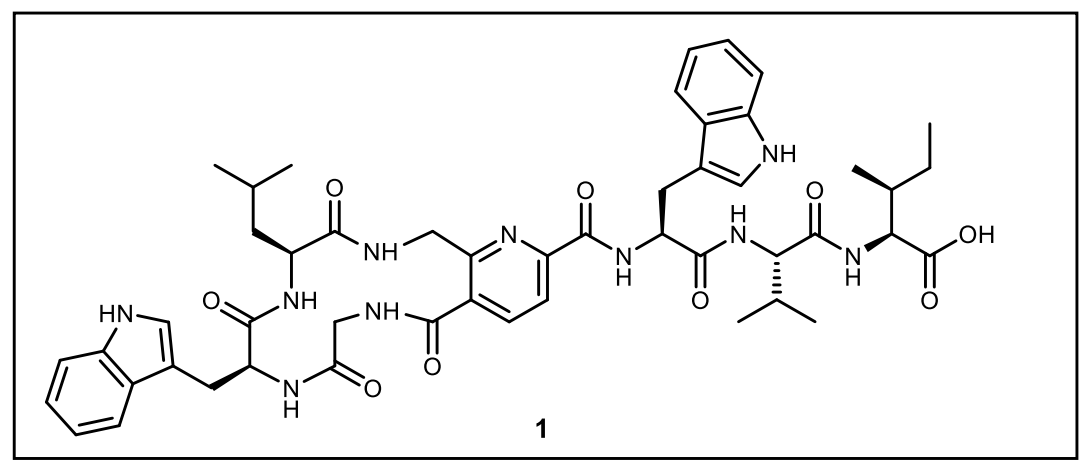
and stirred at room temperature $\left(25^{\circ} \mathrm{C}\right)$. Upon completion (monitored by TLC), the reaction was concentrated under reduced pressure and $\mathrm{HCl}$ was azeotropically removed by co-distillation with toluene $(3 \times 1 \mathrm{~mL})$. The resulting residue was purified by flash chromatography $\left(\mathrm{C}_{18}\right.$ functionalized $\mathrm{SiO}_{2}$, $\left.\mathrm{H}_{2} \mathrm{O}: \mathrm{MeCN}=1: 1 \rightarrow 1: 9\right)$ to give the desired compound $\mathbf{1}$ as a white solid (2.8 $\mathrm{mg}, 6.5 \mu \mathrm{mol}, 46 \%)$.

$\boldsymbol{R}_{\mathbf{f}}=0.1(\mathrm{DCM}: \mathrm{MeOH}=9: 1, \mathrm{UV})$.

${ }^{1}$ H NMR: (500 MHz, DMSO- $\left.d_{6}\right) \delta 10.90(\mathrm{~d}, J=2.4 \mathrm{~Hz}, 1 \mathrm{H}), 10.78(\mathrm{~d}, J=2.4 \mathrm{~Hz}, 1 \mathrm{H}), 9.50(\mathrm{t}, J=6.1 \mathrm{~Hz}, 1 \mathrm{H})$, $9.46(\mathrm{~d}, J=5.9 \mathrm{~Hz}, 1 \mathrm{H}), 8.58(\mathrm{~d}, J=7.2 \mathrm{~Hz}, 1 \mathrm{H}), 8.29(\mathrm{~d}, J=8.9 \mathrm{~Hz}, 1 \mathrm{H}), 8.09(\mathrm{~d}, J=7.8 \mathrm{~Hz}, 1 \mathrm{H}), 7.91(\mathrm{~d}, J=$ $7.8 \mathrm{~Hz}, 1 \mathrm{H}), 7.84(\mathrm{~d}, J=7.8 \mathrm{~Hz}, 1 \mathrm{H}), 7.59(\mathrm{~d}, J=7.9 \mathrm{~Hz}, 1 \mathrm{H}), 7.54(\mathrm{~d}, J=7.9 \mathrm{~Hz}, 1 \mathrm{H}), 7.51(\mathrm{t}, J=6.1 \mathrm{~Hz}, 1 \mathrm{H})$, $7.36(\mathrm{~d}, J=8.1 \mathrm{~Hz}, 1 \mathrm{H}), 7.32(\mathrm{~d}, J=2.4 \mathrm{~Hz}, 1 \mathrm{H}), 7.28(\mathrm{~d}, J=8.0 \mathrm{~Hz}, 1 \mathrm{H}), 7.12-7.05(\mathrm{~m}, 3 \mathrm{H}), 7.02(\mathrm{dt}, J=8.6,4.3$ $\mathrm{Hz}, 2 \mathrm{H}), 6.91(\mathrm{t}, J=7.5 \mathrm{~Hz}, 1 \mathrm{H}), 4.90(\mathrm{q}, J=7.2 \mathrm{~Hz}, 1 \mathrm{H}), 4.51(\mathrm{dd}, J=15.6,5.9 \mathrm{~Hz}, 1 \mathrm{H}), 4.41-4.28(\mathrm{~m}, 4 \mathrm{H}), 4.24-$ $4.13(\mathrm{~m}, 2 \mathrm{H}), 3.57(\mathrm{dd}, J=14.3,6.3 \mathrm{~Hz}, 1 \mathrm{H}), 3.29-3.22(\mathrm{~m}, 2 \mathrm{H}), 3.19(\mathrm{dd}, J=15.1,3.7 \mathrm{~Hz}, 1 \mathrm{H}), 3.09(\mathrm{dd}, J=14.9$, $10.5 \mathrm{~Hz}, 1 \mathrm{H}), 2.07-1.97(\mathrm{~m}, 1 \mathrm{H}), 1.80(\mathrm{dp}, J=17.1,6.3 \mathrm{~Hz}, 1 \mathrm{H}), 1.62$ (ddd, $J=14.0,10.1,3.5 \mathrm{~Hz}, 1 \mathrm{H}), 1.46$ (ddd, $J=12.7,7.3,4.6 \mathrm{~Hz}, 1 \mathrm{H}), 1.39(\mathrm{dtt}, J=10.6,6.6,4.2 \mathrm{~Hz}, 1 \mathrm{H}), 1.30-1.22(\mathrm{~m}, 1 \mathrm{H}), 1.21-1.13(\mathrm{~m}, 1 \mathrm{H}), 0.89(\mathrm{dd}, J$ $=11.4,5.1 \mathrm{~Hz}, 12 \mathrm{H}), 0.78(\mathrm{dd}, J=14.8,6.5 \mathrm{~Hz}, 6 \mathrm{H})$.

${ }^{13}$ C NMR: $\left(126 \mathrm{MHz}, \mathrm{DMSO}-d_{6}\right) \delta 173.1,172.8,171.3,171.1,171.0,170.7,169.4,162.4,155.0,148.3,137.1$, $136.2,136.0,133.0,127.5,126.8,124.1,123.8,121.1,120.8,119.9,118.6,118.5,118.2,117.9,111.5,111.2$, 109.53, 109.50, 57.4, 57.2, 56.4, 53.2, 49.3, 45.6, 43.3, (39.4 observed by HSQC), 36.1, 30.9, 27.9, 26.2, 24.8, 24.0, 23.3, 20.9, 19.2, 18.2, 15.6, 11.4 .

HRMS: (ESI) m/z: [M+H] $]^{+}$Calcd. for $\mathrm{C}_{49} \mathrm{H}_{61} \mathrm{~N}_{10} \mathrm{O}_{9}$ 933.4623; Found: 933.4667.

IR: (ATR, neat, cm-1): 3320 (w), 3003 (w), 2960 (w), 1987 (w), 1657 (s), 1569 (m), 1520 (s), 903 (w), 743 (w).

m.p.: $297^{\circ} \mathrm{C}$ (decomp.).

$[\boldsymbol{\alpha}]_{\mathbf{D}}{ }^{23}:-59.6(c=0.004$ in $1: 1=\mathrm{DCM}: \mathrm{MeOH})$ 
MBP-tagged precursor peptide expression. E. coli BL21(DE3) cells were transformed with a pET28 plasmid encoding N-terminally MBP-tagged pyritide precursor peptide. Cells were grown for $24 \mathrm{~h}$ on LB agar plates containing $50 \mu \mathrm{g} / \mathrm{mL}$ kanamycin at $37^{\circ} \mathrm{C}$. Single colonies were used to inoculate $10 \mathrm{~mL}$ of LB containing the same concentration of antibiotics and grown at $37{ }^{\circ} \mathrm{C}$ for $16-18 \mathrm{~h}$. This culture was used to inoculate $1 \mathrm{~L}$ of TB $(24 \mathrm{~g} / \mathrm{L}$ yeast extract, $12 \mathrm{~g} / \mathrm{L}$ tryptone, $4 \mathrm{~mL} / \mathrm{L}$ glycerol, $17 \mathrm{mM} \mathrm{KH}_{2} \mathrm{PO}_{4}$, and $72 \mathrm{mM} \mathrm{K}_{2} \mathrm{HPO}_{4}$ ) supplemented with the same concentration of kanamycin and grown to an optical density at $600 \mathrm{~nm}\left(\mathrm{OD}_{600}\right)$ of 1.0 before being placed on ice for $15 \mathrm{~min}$. Protein expression was then induced with the addition of $1.0 \mathrm{mM}$ isopropyl $\beta$-D-1-thiogalactopyranoside (IPTG). Expression was allowed to proceed for $1 \mathrm{~h}$ at $37^{\circ} \mathrm{C}$. Cells were harvested by centrifugation at $3,000 \times g$ for $20 \mathrm{~min}$, washed with phosphate-buffered saline (PBS; $137 \mathrm{mM} \mathrm{NaCl}, 2.7 \mathrm{mM} \mathrm{KCl}, 10 \mathrm{mM} \mathrm{Na}_{2} \mathrm{HPO}_{4}$, and 1.8 $\mathrm{mM} \mathrm{KH} \mathrm{PO}_{4}$ ), and harvested by centrifugation. The harvested cells were flash-frozen and stored at $-80{ }^{\circ} \mathrm{C}$ for a maximum of one week before use.

MBP-tagged MroD expression. MroD was expressed similarly to MroA1 and MroA2 with these notable differences: BL21(DE3) cells were co-transformed with pET28-MBP-MroD and a pACYC-Duet plasmid encoding the cold chaperonins from Oleispira antarctica bearing a chloramphenicol marker. Both plasmids were selected for during transformation, seed culture growth, and expression. Cells were induced with $0.4 \mathrm{mM} \mathrm{IPTG}$ at $12{ }^{\circ} \mathrm{C}$ for 24 $\mathrm{h}$ prior to harvesting.

MBP-tagged peptide and protein purification. Cells were resuspended in lysis buffer [50 mM Tris- $\mathrm{HCl} \mathrm{pH} 7.5$, $150 \mathrm{mM} \mathrm{NaCl}, 2.5 \%$ glycerol $(v / v)$, and $0.1 \%$ Triton X-100 $(v / v)]$ containing $4 \mathrm{mg} / \mathrm{mL}$ lysozyme, $2 \mu \mathrm{M}$ leupeptin, $2 \mu \mathrm{M}$ benzamidine, and $2 \mu \mathrm{M}$ E64. Cells were further lysed by sonication $(3 \times 45 \mathrm{~s}$ with $10 \mathrm{~min}$ agitation periods at $4{ }^{\circ} \mathrm{C}$ ). Insoluble debris was removed by centrifugation at $20,000 \times \mathrm{g}$ for $90 \mathrm{~min}$ at $4{ }^{\circ} \mathrm{C}$. The supernatant was then applied to a pre-equilibrated amylose resin (NEB; $15 \mathrm{~mL}$ of resin per L of initial cell culture). The column was washed with 10 column volumes (CV) of lysis buffer followed by $10 \mathrm{CV}$ of wash buffer (lysis buffer with $400 \mathrm{mM}$ $\mathrm{NaCl}$ and lacking Triton X-100). The MBP-tagged proteins were eluted using elution buffer (lysis buffer with 300 $\mathrm{mM} \mathrm{NaCl}, 10 \mathrm{mM}$ maltose, but omitting Triton X-100) until the eluent no longer contained protein detectable with the Bradford reagent. Eluent was concentrated using a $30 \mathrm{kDa}$ molecular weight cut-off (MWCO) Amicon Ultra centrifugal filter (EMD Millipore). A buffer exchange with $10 \times$ volume of reaction buffer $\left(50 \mathrm{mM} \mathrm{K}_{2} \mathrm{HPO}_{4}, 100\right.$ $\mathrm{mM} \mathrm{NaCl}$ ) for precursor peptides or protein storage buffer [50 mM 4-(2-hydroxyethyl)-1-piperazineethanesulfonic acid (HEPES) pH 7.5, $300 \mathrm{mM} \mathrm{NaCl}, 2.5 \%$ glycerol $(v / v)]$ for MroD was performed prior to final concentration and storage under liquid nitrogen. Protein concentrations were determined using both absorbance at $280 \mathrm{~nm}$ (theoretical extinction coefficients were calculated using the ExPASy ProtParam tool; http://web.expasy.org/protparam/protpar-ref.html) and a Bradford colorimetric assay. Purity was assessed visually by analysis of Coomassie-stained SDS-PAGE gels (Figure S3). All wash, elution, storage, and reaction buffers were supplemented with $0.5 \mathrm{mM}$ tris-(2-carboxyethyl)-phosphine (TCEP).

Preparation of dibromohexanediamide (DBHDA, 3). DBHDA was chemically synthesized and purified as previously described, with the notable exception that water trituration was performed three times to remove residue $N$-bromosuccinimide. The synthesis was verified by ${ }^{1} \mathrm{H}$ NMR and found to be in agreement with published spectra (Figure S15). ${ }^{5,6}$

Chemical dehydrothiolation and enzymatic cycloaddition of pyritide precursors. Purified MBP-tagged precursor peptides were treated with DBHDA in reaction buffer (defined above). DBHDA was dissolved in dimethylformamide (DMF) to a concentration of $0.5 \mathrm{M}$ and infused into the MBP-tagged peptide solution to a molar excess of 500-fold relative to precursor peptide. The reaction was allowed to proceed for $2 \mathrm{~h}$ at $25{ }^{\circ} \mathrm{C}$ with gentle agitation that did not cause foaming or precipitation of protein. Afterwards, the reaction mixture was placed in a water bath set to $37^{\circ} \mathrm{C}$ for $12 \mathrm{~h}$ without mixing. This two-step procedure was adapted from a literature protocol owing to the slower step, which displaces a second equivalent of bromine to produce the sulfonium intermediate. Once the dehydrothiolation reaction was complete, the sample was subjected to centrifugation for 10 min at 20,000 $\times g$ to remove insoluble debris. The supernatant was then buffer exchanged utilizing a $30 \mathrm{kDa}$ MWCO Amicon Ultra centrifugal filter (EMD Millipore) into fresh reaction buffer to remove residual DMF and DBHDA. MBPtagged MroD was added to the reaction mixture at $1 / 10^{\text {th }}$ the concentration of precursor peptide. The reaction was then analyzed by MALDI-TOF-MS. For detection of unmodified precursor peptide, DBHDA-treated intermediate, 
or ejected leader peptide, TEV protease was added at $1 / 10^{\text {th }}$ the concentration of the precursor peptide and allowed to react for $10 \mathrm{~min}$ at $25^{\circ} \mathrm{C}$ to cleave the MBP affinity tag and enable analysis.

Purification of chemoenzymatically synthesized pyritide A1 (1) and pyritide A2 (2). Bulk reaction mixtures of chemically desulfurized and enzymatically macrocyclized pyritide were added dropwise to acetonitrile to a final concentration of $20 \%$ water, $80 \%$ acetonitrile $(v / v)$. The precipitated proteinaceous debris was removed by centrifugation for $30 \mathrm{~min}$ at $20,000 \times \mathrm{g}$. The supernatant was then flash-frozen in liquid nitrogen and lyophilized to dryness. The resulting white powder was then dissolved in dimethylsulfoxide (DMSO) and diluted with $0.1 \%$ formic acid to a final concentration of $20 \%$ DMSO $(v / v)$ prior to HPLC purification. Purification was carried out using a Machery-Nagel (Düren, Germany) EC 250/4.6 Nucleodur $\mathrm{C}_{18}$ gravity $5 \mu \mathrm{m}$ column (part number 760101.46). The mobile phases used were the following: A: $0.1 \%$ formic acid, B: acetonitrile with $0.1 \%$ formic acid. The following HPLC method was used: 0-10 min 20\% B isocratic, 10-40 min gradient transitioning from $20 \% \mathrm{~B}$ to $80 \% \mathrm{~B}, 40-45$ min gradient transitioning from $80 \%$ B to $95 \% \mathrm{~B}$, and $45-50 \mathrm{~min}$ return to initial conditions. 1 presented a retention time of $34.0 \mathrm{~min}$ while 2 presented a retention time of $25.8 \mathrm{~min}$. From approximately $30 \mathrm{~L}$ of culture for each precursor peptide (MBP-MroA1 and MBP-MroA2) and $8 \mathrm{~L}$ of culture for MBP-MroD, $\sim 2.5 \mathrm{mg}$ and $\sim 2.3 \mathrm{mg}$ of chemoenzymatically produced $\mathbf{1}$ and $\mathbf{2}$ were isolated, respectively.

NMR Spectroscopy. Samples were prepared by dissolving HPLC-purified and lyophilized pyritide in $290 \mu \mathrm{L}$ DMSO- $_{6}$ (99.9 atom \% D, Cambridge Isotope Laboratories). After dissolution, precipitate was removed by centrifugation $(17,000 \times \mathrm{g}, 10 \mathrm{~min}$.). Samples were analyzed in a $5 \mathrm{~mm}$ DMSO-matched Shigemi tube (Shigemi Co., Ltd.) on a $750 \mathrm{MHz}$ Agilent VNMRS narrow-bore NMR operating at $749.375 \mathrm{MHz}$ equipped with a triple resonance ${ }^{1} \mathrm{H}-{ }^{13} \mathrm{C} /{ }^{15} \mathrm{~N}$ Varian probe with gradient and pulse-shaping capabilities. Data was collected on a console operating VnmrJ 3.2A. Temperature was held at $25.0{ }^{\circ} \mathrm{C}$ for all acquisitions. Standard Varian Biopack pulse sequences were used for all acquisitions. Mixing times for ${ }^{1} \mathrm{H}-{ }^{1} \mathrm{H}$ TOCSY and ${ }^{1} \mathrm{H}-{ }^{1} \mathrm{H}$ NOESY experiments were set to $70 \mathrm{~ms}$ and $400 \mathrm{~ms}$, respectively. All spectra were collected with 128 increments in the indirect dimension under WET solvent suppression. Raw FIDs were imported into NMRPipe ${ }^{7}$ and subjected to appropriate phase and baseline processing, followed by linear prediction. Processed files were analyzed and assigned with NMRFAM Sparky. ${ }^{8}$

Microbroth dilution antimicrobial assays. A microbroth dilution assay was used to screen for antimicrobial activity of $\mathbf{1}$ and $\mathbf{2}$ individually and in combination against the following strains: Staphylococcus aureus USA300 (MRSA), Enterococcus faecium U503 (VRE), Escherichia coli MC4100, Pseudomonas aeruginosa PAO1, and Saccharomyces cerevisiae (yeast). Bacteria were grown in brain heart infusion (BHI) broth (BD Biosciences) while yeast was grown in yeast extract-peptone-dextrose (YPD) broth $(10 \mathrm{~g} / \mathrm{L}$ yeast extract, $20 \mathrm{~g} / \mathrm{L}$ peptone, $20 \mathrm{~g} / \mathrm{L}$ dextrose). Bacteria were grown overnight in $5 \mathrm{~mL}$ of appropriate media at $37^{\circ} \mathrm{C}$ for bacteria or $30{ }^{\circ} \mathrm{C}$ for yeast to stationary phase. Cultures were diluted to an $\mathrm{OD}_{600}$ of 0.015 in the appropriate media and added to a 96-well plate. 1 and 2 were tested individually, starting at $64 \mu \mathrm{g} / \mathrm{mL}$, or in combination starting at $32 \mu \mathrm{g} / \mathrm{mL}$ each. Positive controls of gentimicin (starting at $64 \mu \mathrm{g} / \mathrm{mL}$ ) for bacteria or amphotericin (starting at $8 \mu \mathrm{g} / \mathrm{mL}$ ) for yeast were used. Negative controls of DMSO starting at $1 \%(v / v)$ were also used. Cultures were allowed to grow at $37{ }^{\circ} \mathrm{C}$ for bacteria or 30 ${ }^{\circ} \mathrm{C}$ for yeast with gentle shaking. No antimicrobial activity was observed for $\mathbf{1}$ or $\mathbf{2}$ while gentimicin and amphotericin B inhibited growth in line with their reported minimum inhibitory concentrations (MICs) for bacteria and yeast, respectively. These results are reflected in Table $\mathbf{S 4}$.

Mass spectrometric characterization of pyritide macrocycles. HPLC-purified pyritide macrocycle was dissolved in $80 \% \mathrm{MeCN}$ with $1 \%$ acetic acid or, for crude reaction mixtures, desalted using a $\mathrm{C}_{18}$ ZipTip (EMD Millipore) and eluted using $80 \% \mathrm{MeCN}$ with $1 \%$ acetic acid. Samples were directly infused into a ThermoFisher Scientific Orbitrap Fusion ESI-MS using an Advion TriVersa Nanomate 100. The MS was calibrated and tuned with Pierce LTQ Velos ESI Positive Ion Calibration Solution (ThermoFisher). The MS was operated using the following parameters: resolution, 100,000; isolation width (MS/MS), $2 \mathrm{~m} / \mathrm{z}$; normalized collision energy (MS/MS), 70; activation q value (MS/MS), 0.4; activation time (MS/MS), $30 \mathrm{~ms}$. Fragmentation was performing using collisioninduced dissociation (CID) at $70 \%$. Data analysis was conducted using the Qualbrowser application of Xcalibur software (Thermo-Fisher Scientific). 
Table S1: Sequences of pyritide precursor peptides and $m r o D$ for optimal $E$. coli expression. The sequence is provided 5' to 3'. Restriction sites for cloning are underlined (5' BamHI, 3' XhoI). These genes were synthesized by Twist Bioscience (South San Francisco, CA).

mroA1 (M. rosaria precursor peptide) S1C, S6C

GGATCCATGGACAACGTCGTGACTGAAGCCGCCGAGTTCGCGGATTTGGACATTGTTGATCTGGACCTTGCAGTAG ATGAAGAACTTGCCGCTTTGAGCGTCGGGGGTTTGGGTAATACAGAGGTCGGTGCGTGCGGTTGGCTGGGCTGCTG GGTGATTTGACTCGAG

mroA2 (M. rosaria precursor peptide) S1C, S7C

GGATCCATGGACAATGCGGCTACGGAAGCTACGGAGTTTGCAGACCTTGATATTGTGAACCTGGACCTCCCTATCG ACGAAGAACTTGCCGCTGTCAGCGTCGGGGGTTTGGGTAATACAGAGGTCGGTGCGTGCGGTTTCTTTGGTCGTTG TTGGTTAATCTGACTCGAG

mroD (M. rosaria [4+2]-cycloaddition enzyme. NCBI accession identifier: WP_067368384.1)

GGATCCATGACACGTACCCCGCCGCATCGCGAAGAACCGGGTTGGCATAGTATCCAAATTCGGTATCATGCTGAGA ACAAAGACGATTTGATTCTGGATGCGGTTCACCCATTACTTACGGCCCTGGCCGACGCGGTTGACCAACCTCACCT GTTACGCCACTGGCGCCGGGGCCCGCACCTCCGCATCAACCTGCGTACCACCCCGCAGCTCTGGGCAGAAGTTGTT CGCCCGACCGCCCAGCGCGATCTTACCGCGTACCTGCATGATAACCCATCAACCGCCAGCTTACGCGAAGCCGAAC ATCTGGCGGCCCACCGCCGCCTGGCAGTGCGTGAGGCGGATCATGGACCTCTGACTCCCTGGTACCCTGATAATAC AGTTCAATTTGAACCGCATGAAGATCGGCAGCATGTTCTGGGTAGCCCGGCGCTTGCAGGTTTGCTGGCGGATGGC TATGCACGCTCGACTGCCTTAACCGTGGATACGCTGGCTGGCGTTCGTTCTGGAGCGGTGGATCGCGTAGGGCATG CTCTTGATTTAATGTTTGCATTTGGTCATCTGTCTGTGCCGCCGATTTCTCGCGGCTACATGTCCTTCCGCTCACA TGTGGAAAGTTTTTTGGGTTATACCGCTGATCCGGATGCCGTCCGCTCGACCTTCGATGAGCGTTACCATCGGCAC CGGCCCGCGCTGCGCGACCGTTTACATACTACGCGCGCCATTGTTGCGGGAAGTCGCCGTGATCCGCTGGTGGAGG CATGGCTGGAAATCGTGCGTCGCCAGAAAGCTCTGGCGGAACCGCTGTTTACGTCTGGCGCCATTGATCTGGACCA TCTTGATCAGCGCGGGATGGAATTACGCCACCGCATCGAGTTTCACGATATTCTGCGCGAGACCACTGCACATCGT CGTGAGGTACTTTCACAGGTGTGGTTTCGCTGTCATCGCTTAGCCATTAACCAACTGTACAGCCATTTGTCTCGCA TCGGTATCGTGCCCACTCAGCGCTACTTACTCTGCCATCTGGTAGCTCGCACCGTGGAGGAAGAATATGATATCAG TCCGGTGGCGCTCGCCCGTCAGTTTGTCAACGACCGTCGCTGACTCGAG 
Figure S1: Bioinformatically identified pyritide biosynthetic gene clusters. (A) Additional pyritide biosynthetic gene clusters (BGCs) identified through PSI-BLAST and analyzed using RODEO ${ }^{1,2}$ (output is available in Supplementary Dataset 1). Each BGC has the associated NCBI accession identifier for the [4+2]-cycloaddition enzyme shown as well as the translated sequence of precursor peptide(s). (B) Multiple sequence alignment of all detected pyritide precursors. The amide bond delineating leader from core peptide is marked with an asterisk $(*)$ and Ser residues unambiguously incorporated into pyritide are marked with orange. The alignment was generated using MAFFT v7.450 using the G-INS-i algorithm. ${ }^{9}$

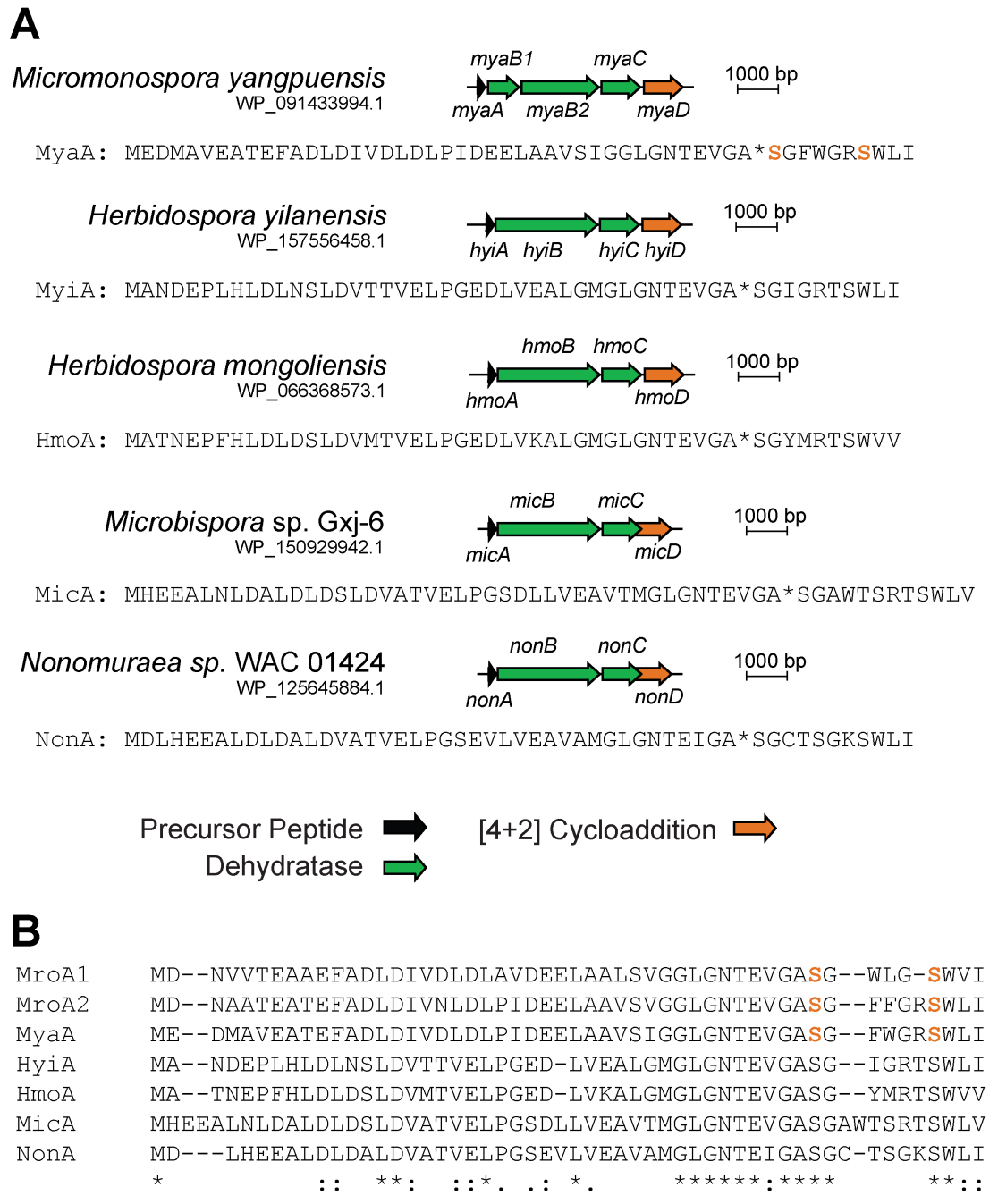


Figure S2: Synthetic scheme to produce 1. Synthetic scheme to produce 1. (A) Synthesis of tripeptides used to form the macrocyclic scaffold and extramacrocylic chain of 1. (B) Synthesis of the pyridine core. (C) Synthesis of the macrocycle. (D) Synthesis of 1 from core macrocycle and extramacrocyclic chain.

A

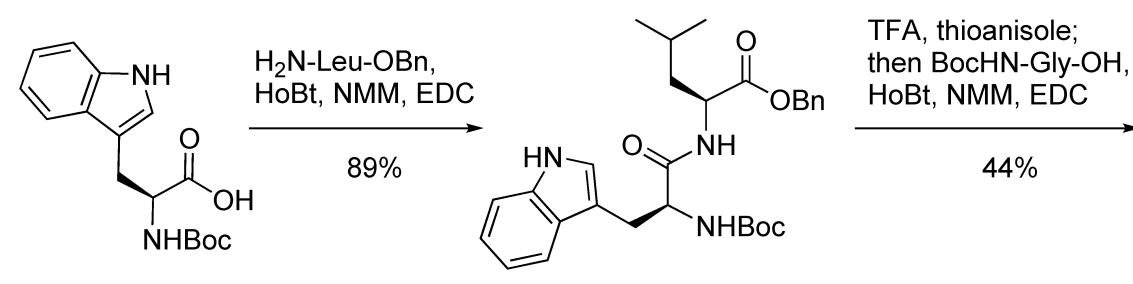

S1

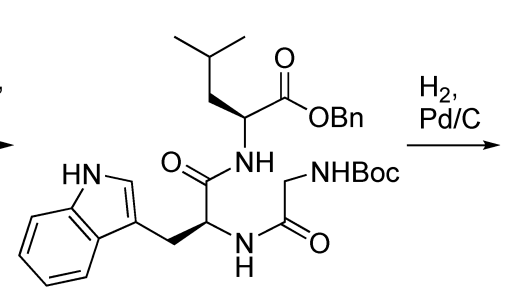

S2

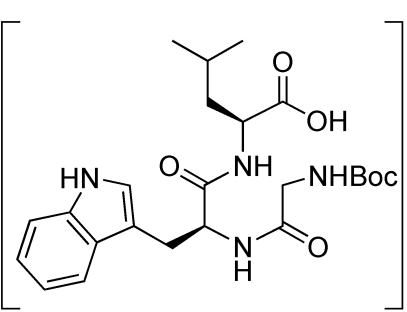

S3

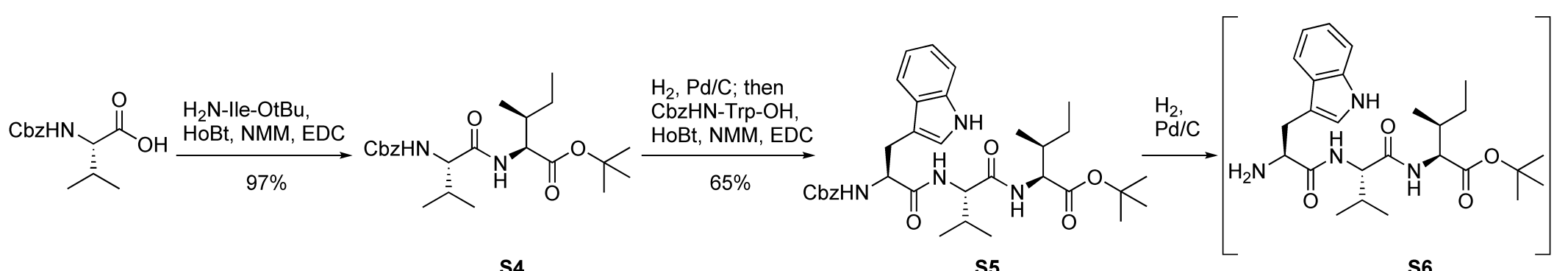

S4

S5

S6

B

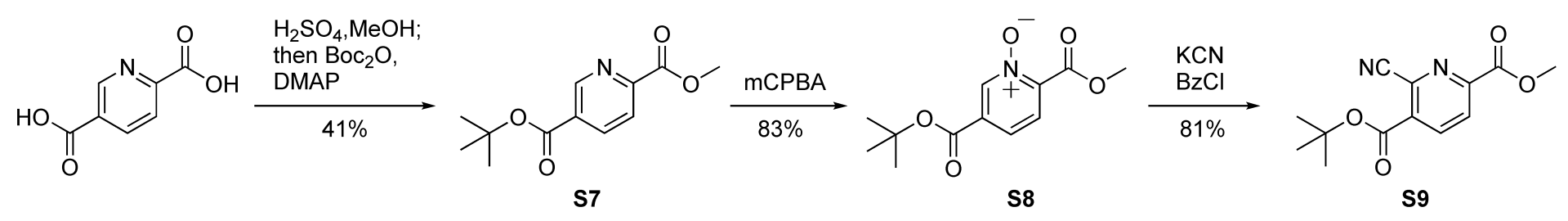

Continued on next page. 
C

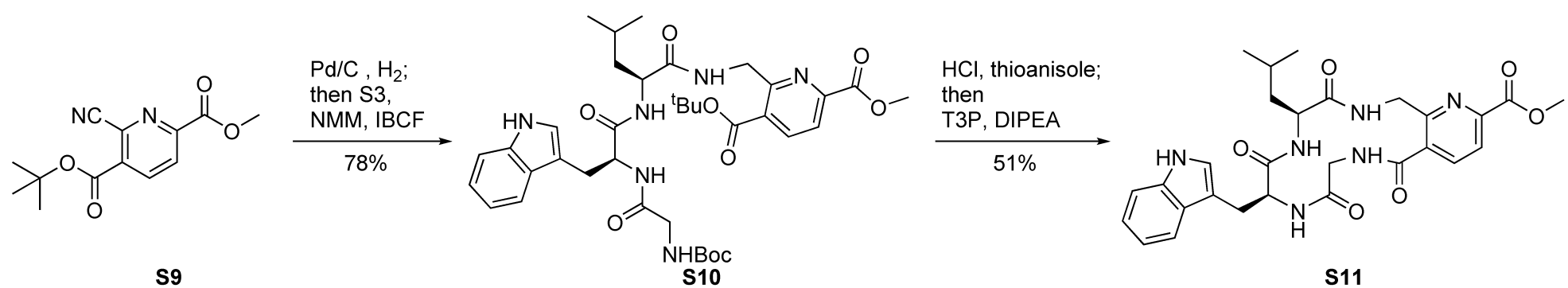

D

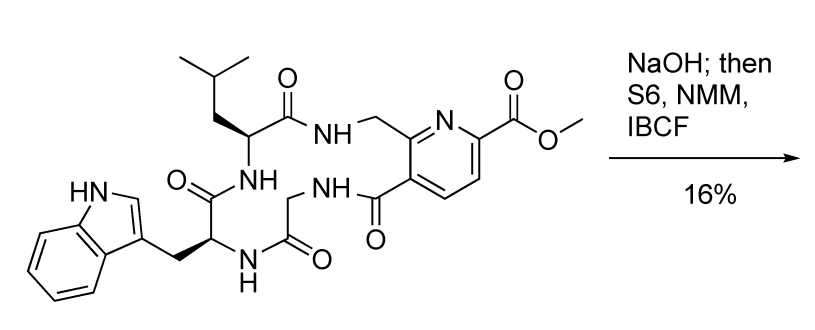

s11
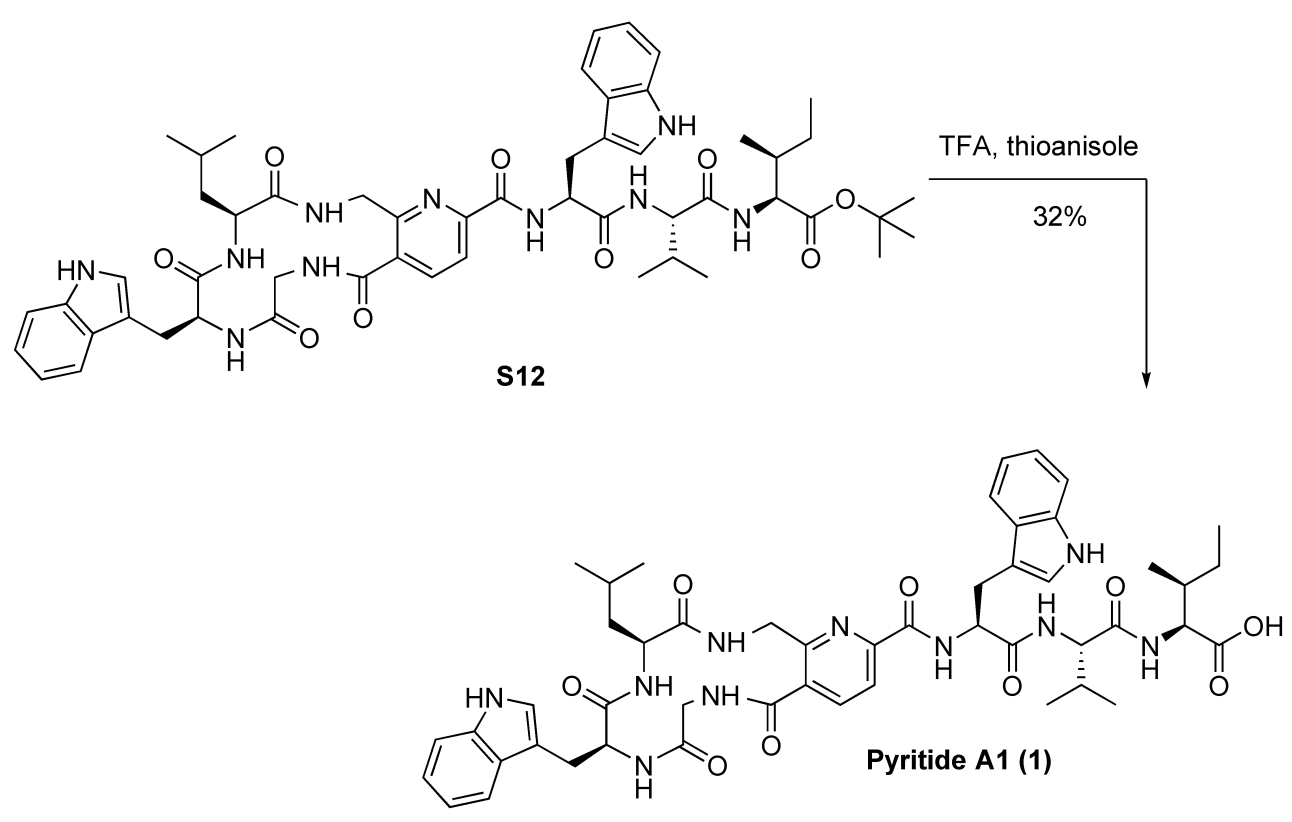
Figure S3: SDS-PAGE analysis of proteins used in this study. The expected molecular weights for maltosebinding protein (MBP)-tagged precursor peptides and MBP-tagged MroD are $\sim 52$ and $88 \mathrm{kDa}$, respectively.

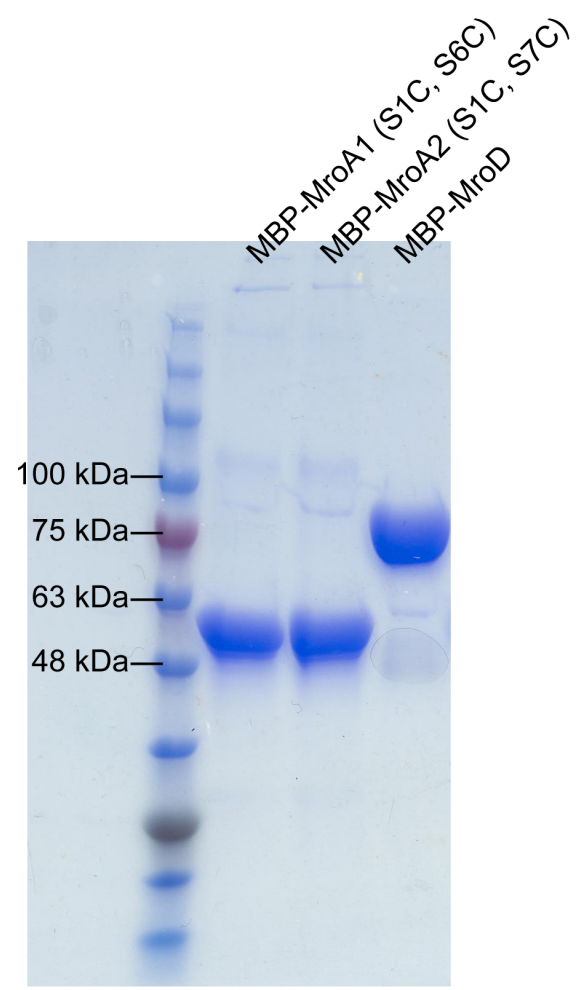


Figure S4: Tandem MS fragmentation of chemically and chemoenzymatically synthesized 1. (A) Separate samples of 1 synthesized chemically or chemoenzymatically were analyzed by collision-induced dissociation (CID) and the resultant series of ions assigned. (B) Comparison of the CID fragmentation patterns for chemically synthesized 1 (orange) or chemoenzymatically synthesized 1 (blue). A table comparing observed and theoretical $\mathrm{m} / \mathrm{z}$ values is provided in Table $\mathbf{S 3}$.

A

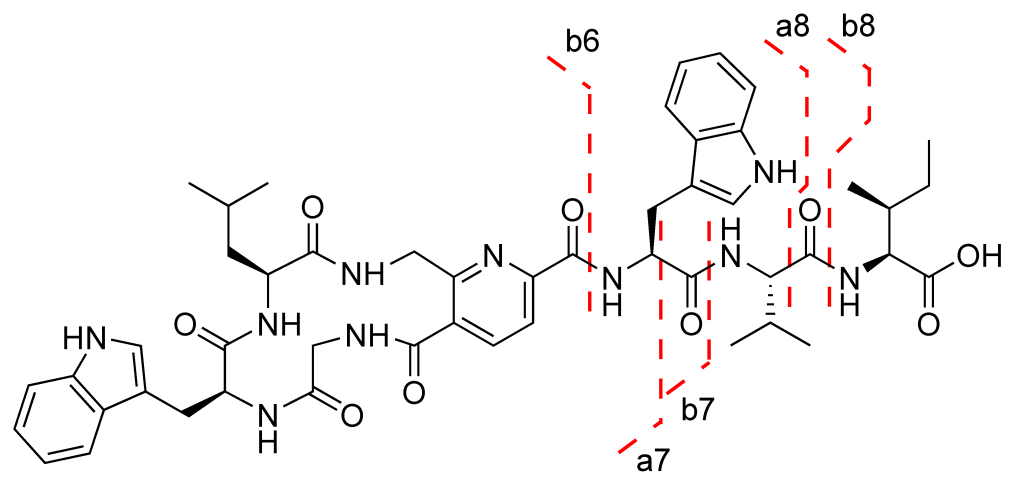

B

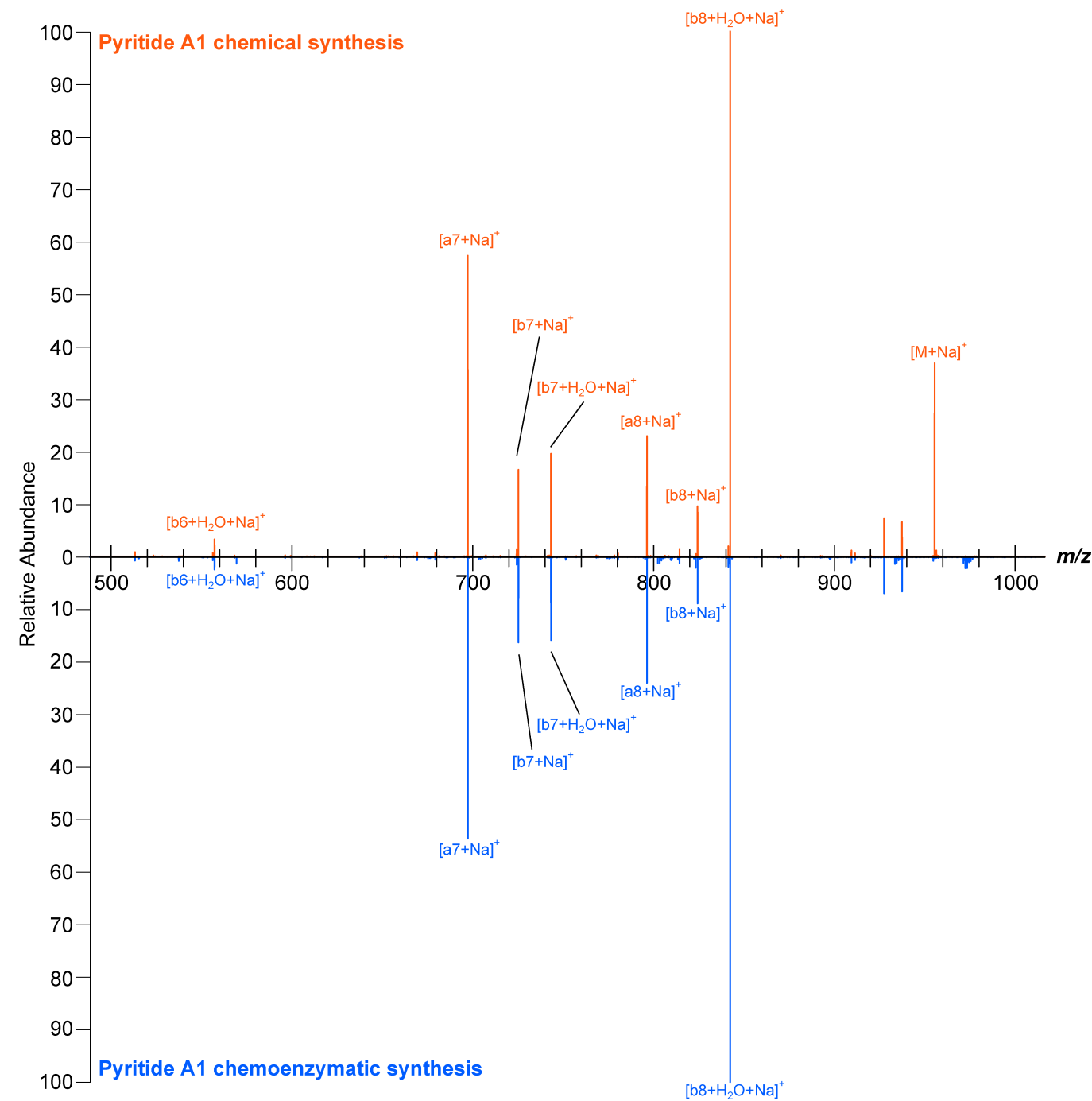


Figure S5: Analytical HPLC retention time and purity analysis of chemically and chemoenzymatically synthesized pyritides. (A) Separate samples of chemically (orange) or chemoenzymatically synthesized (blue) 1 were analyzed using reverse phase $\left(\mathrm{C}_{18}\right)$ analytical HPLC column. Both samples exhibited the same retention time, as illustrated by co-injection yielding a single, symmetric peak (black). (B) Purity analysis of pyritide A2 (compound 2) made through chemoenzymatic synthesis. Chromatograms shown were generated by monitoring absorbance at $220 \mathrm{~nm}$.

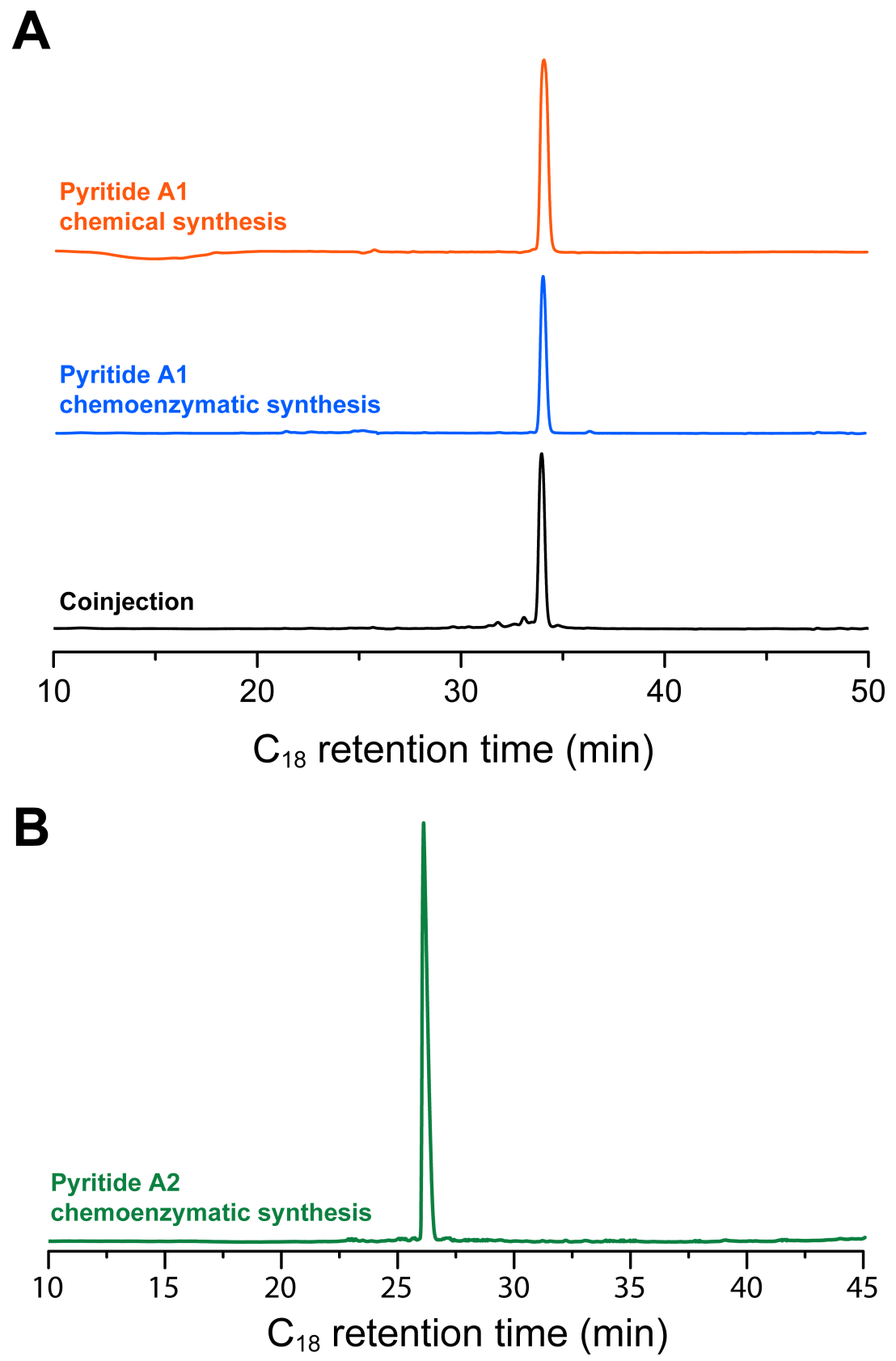


Figure S6: NMR spectra of chemically synthesized 1.

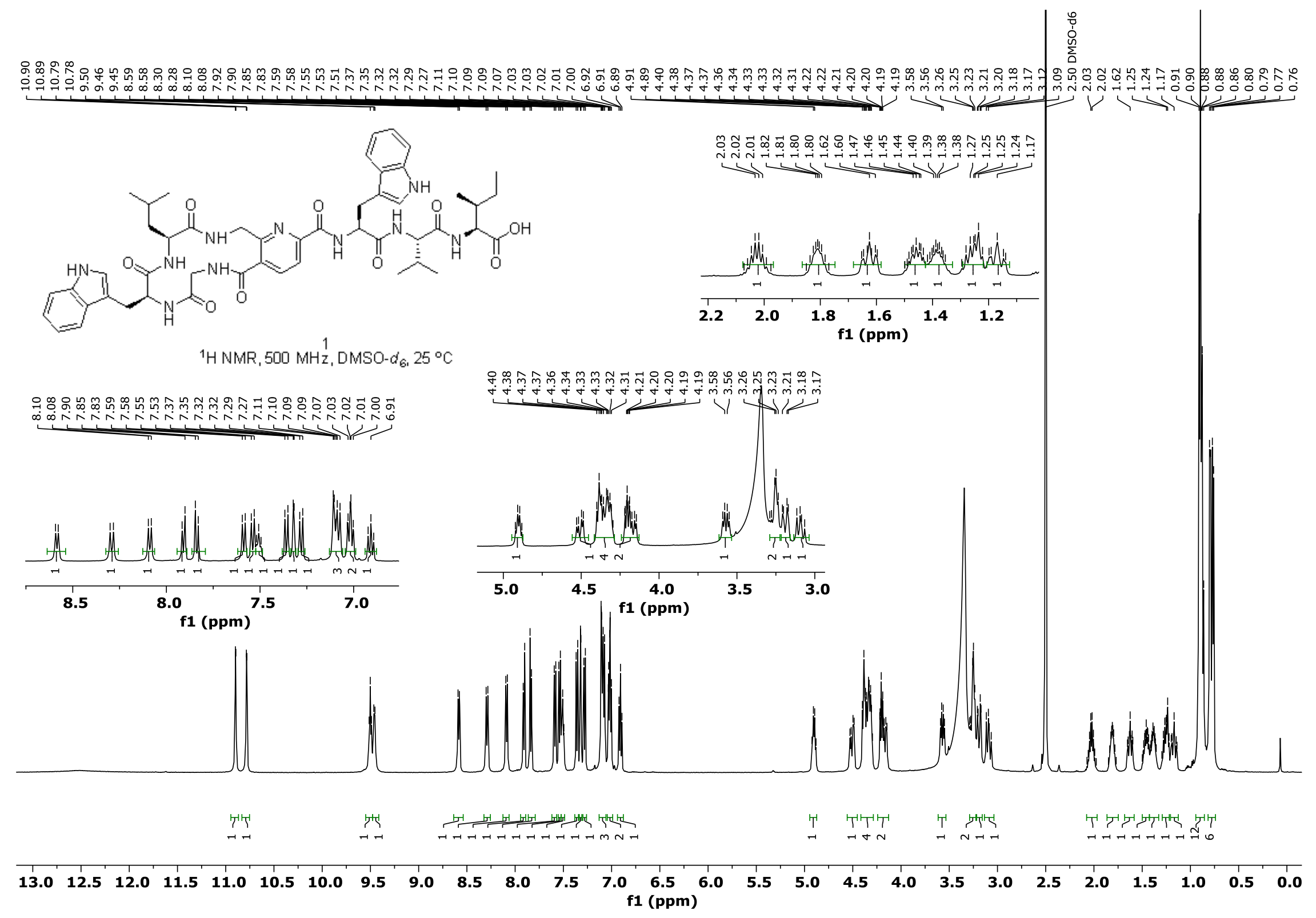




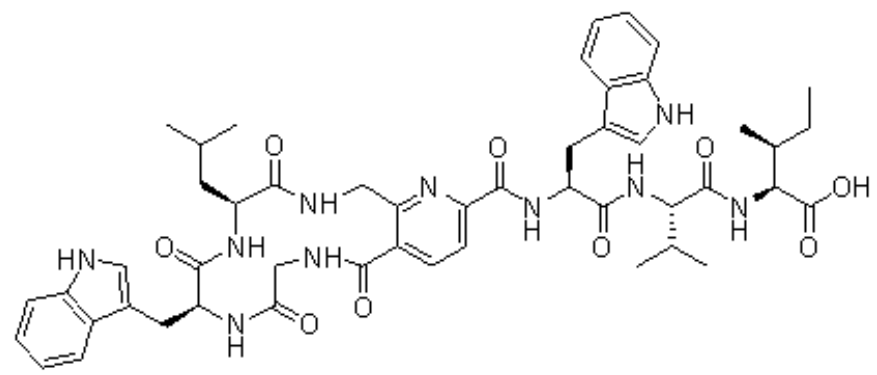

${ }^{13} \mathrm{C} N M R, 126 \mathrm{MHz}, \mathrm{DMSO}-d_{6,} 25^{\circ} \mathrm{C}$

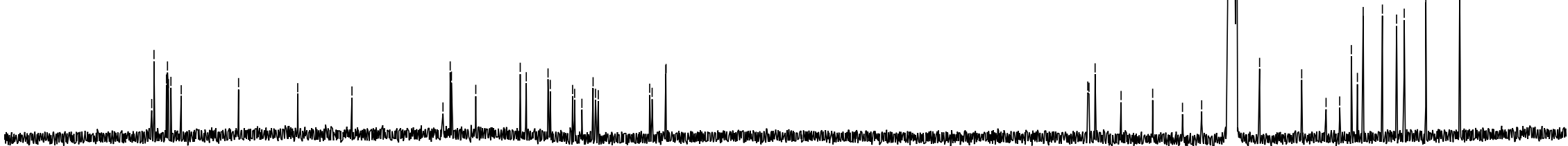

190

180

170

160

150

140

130

120

110 


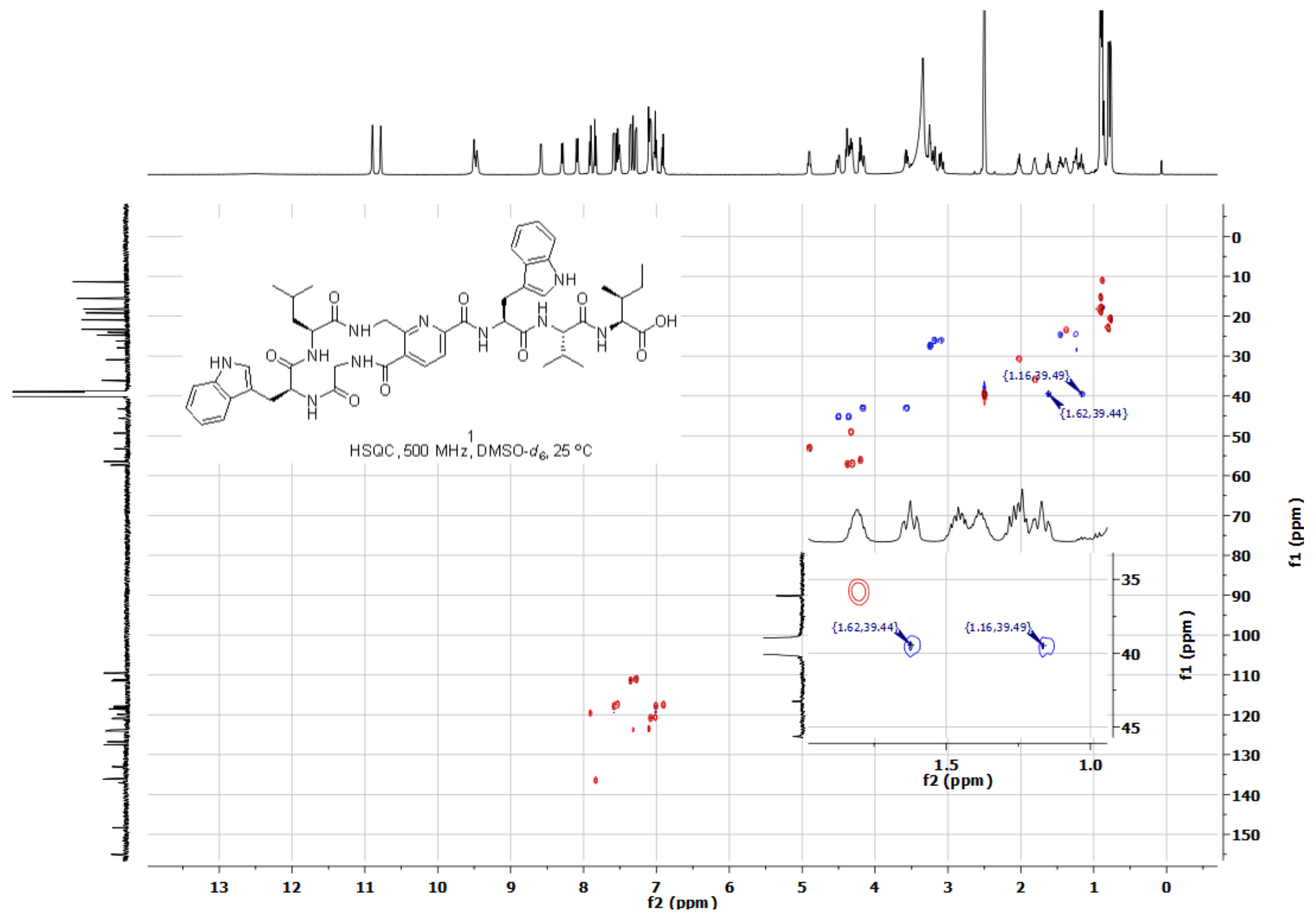


Figure S7: TOCSY assignments of chemoenzymatically synthesized 1. Resonances used in the assignment of indicated residues are colored blue. All protons were successfully assigned.
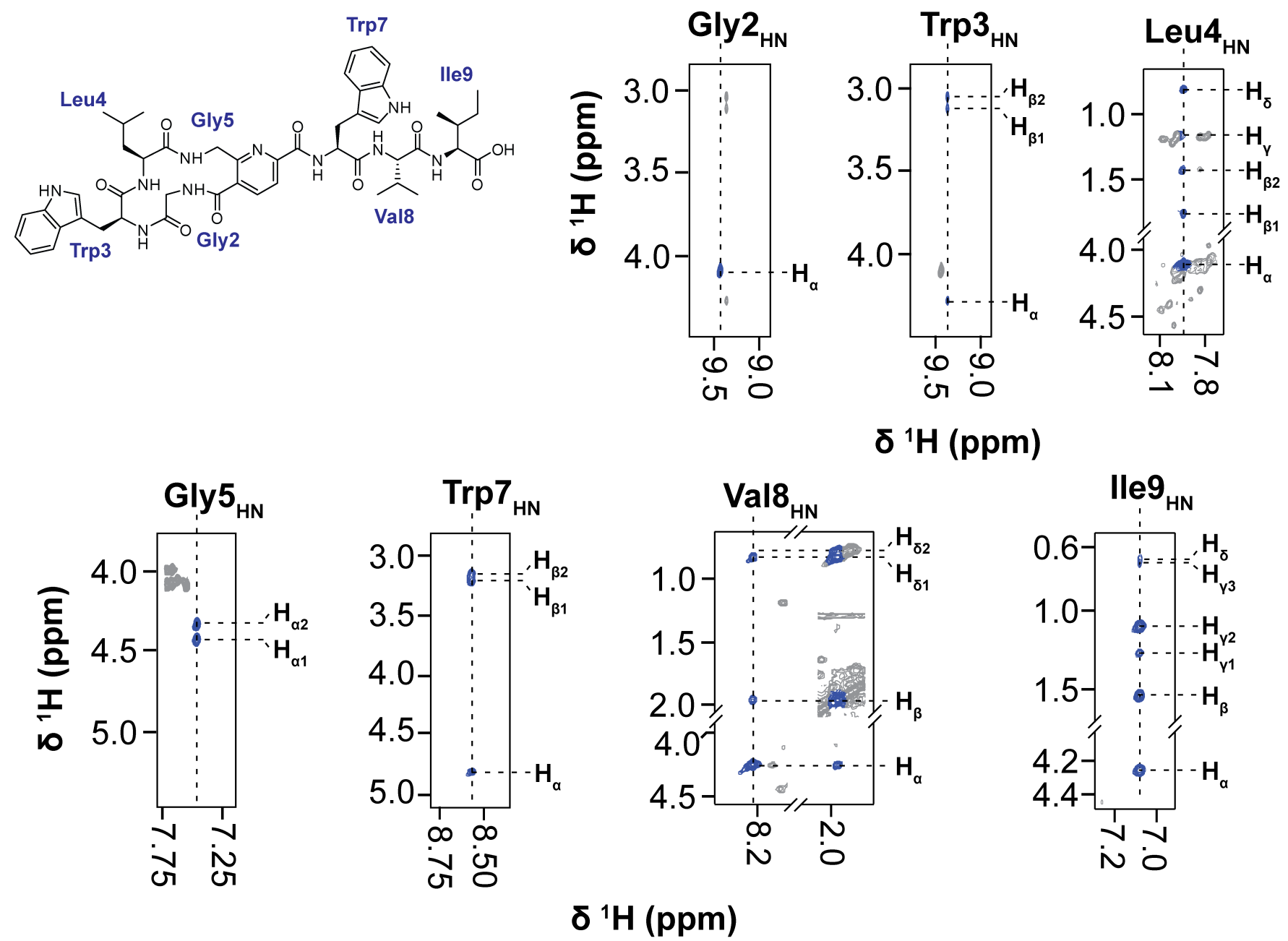

$\delta^{1} \mathrm{H}(\mathrm{ppm})$ 
Figure S8: Aromatic ${ }^{1} \mathrm{H}$ assignments of chemoenzymatically synthesized 1. TOCSY correlations are colored blue while NOESY correlations are colored red. Trp sidechain TOCSY chains were assigned using NOE between $\mathrm{H}_{\varepsilon 1}$ and $\mathrm{H}_{\zeta 2}$. Pyridine protons were assigned using the NOEs to the neighboring Gly residue, and the deshielding effect arising from proximity to the pyridine nitrogen.
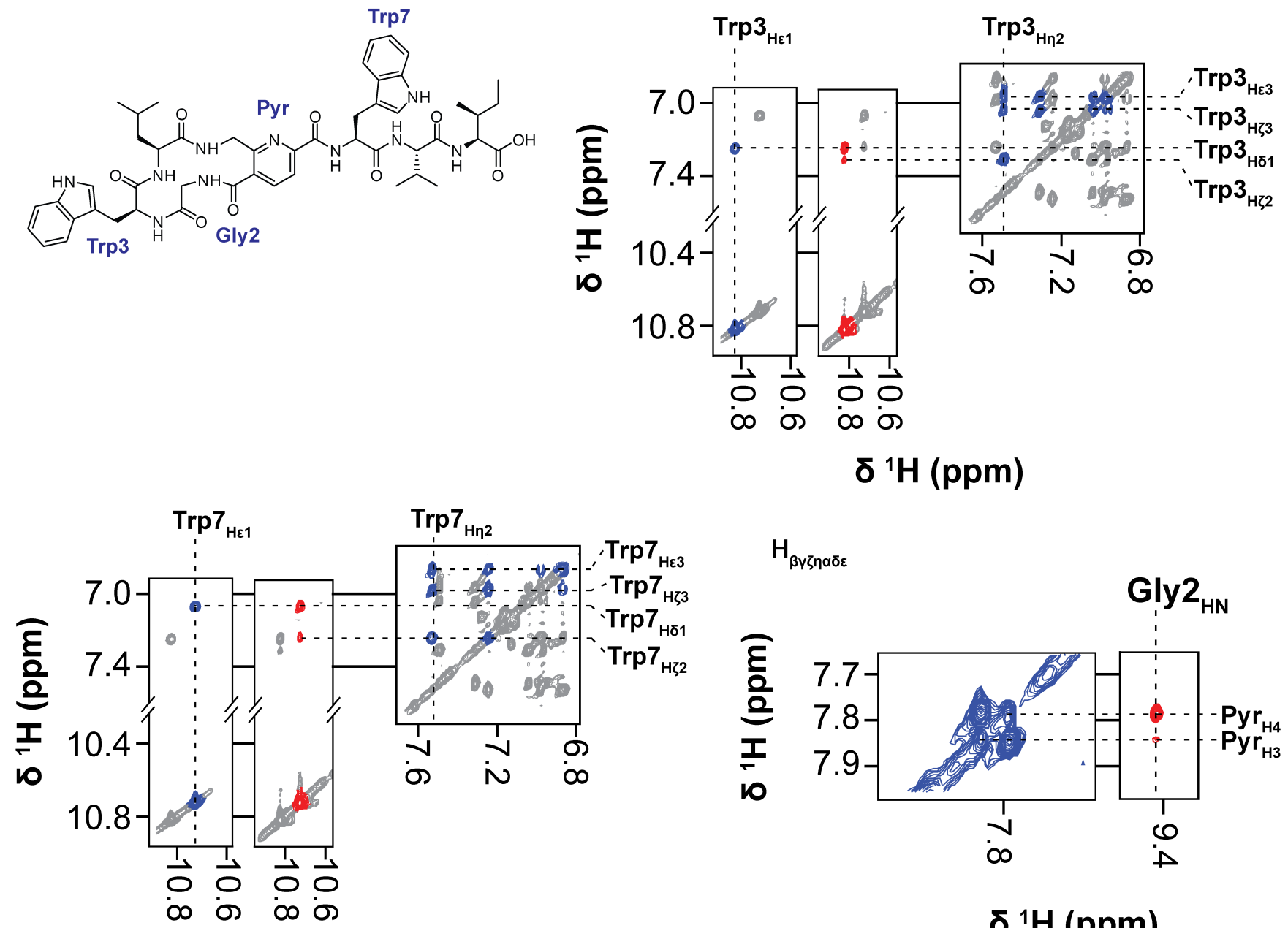

\section{$\delta^{1} \mathrm{H}(\mathrm{ppm})$}

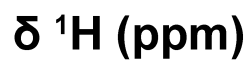


Figure S9: NOESY contacts used in the backbone assignment of chemoenzymatically synthesized 1. Relevant amide-amide NOEs (red) were used in conjunction with the TOCSY patterns on nonredundant residues to fully assign the molecule.
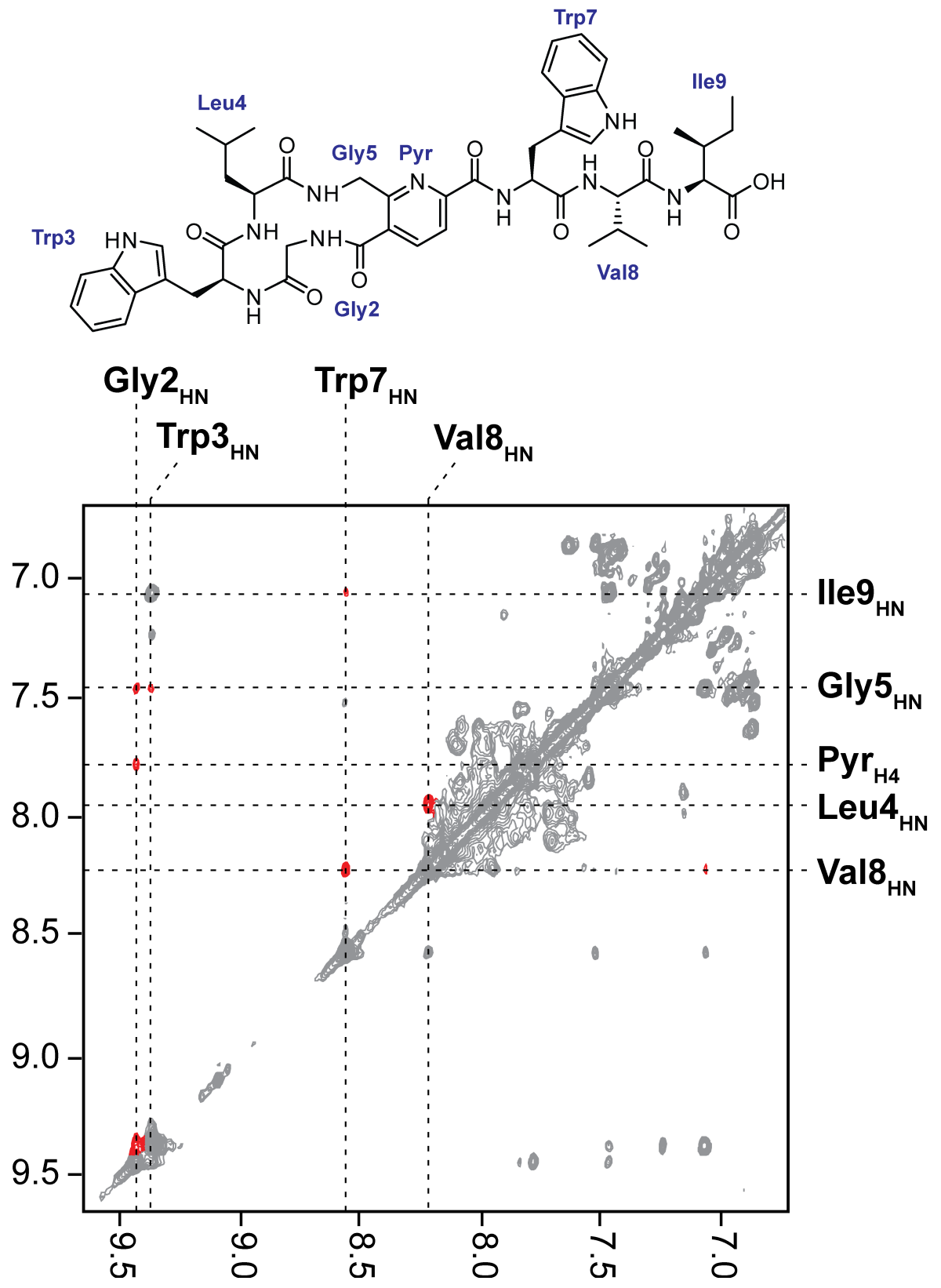
Figure S10: TOCSY assignments of 2. Resonances used in the assignment of indicated residues are colored blue. All protons were successfully assigned.

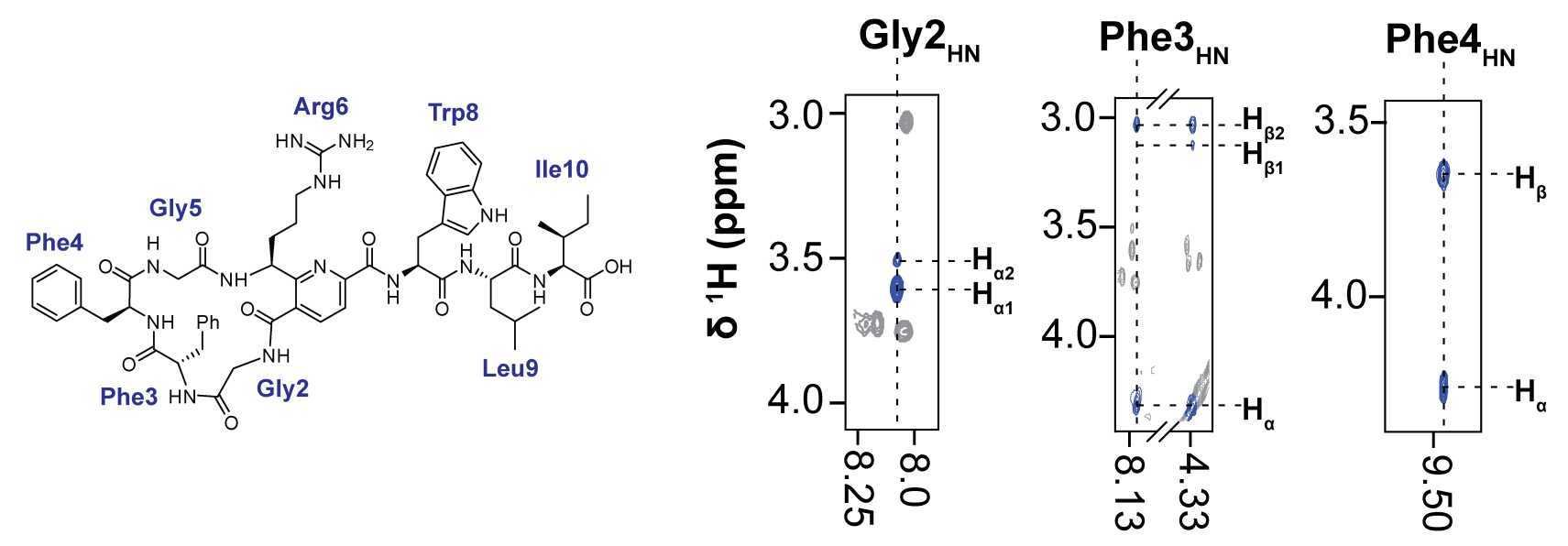

\section{$\delta^{1} \mathrm{H}(\mathrm{ppm})$}

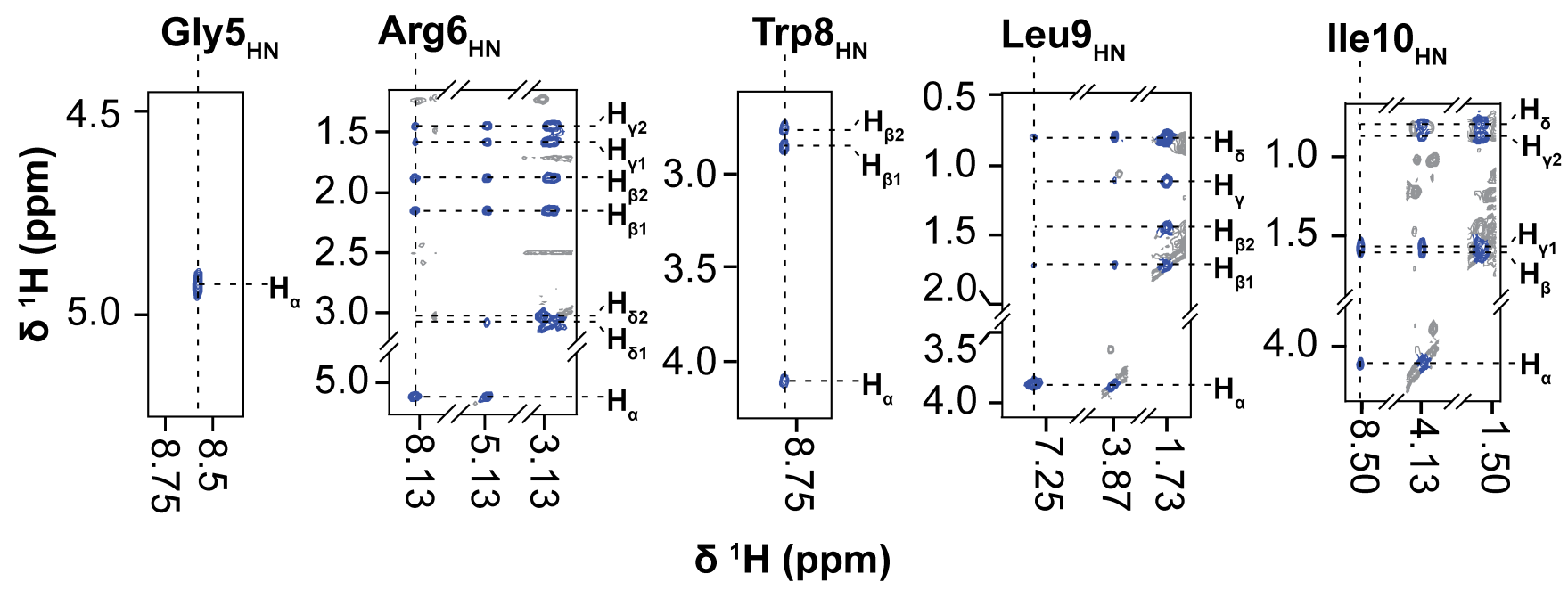


Figure S11: Aromatic ${ }^{1} \mathbf{H}$ assignments of 2. TOCSY correlations are colored blue, and NOESY correlations are colored red. Trp sidechain TOCSY chains were assigned using NOE between $\mathrm{H}_{\varepsilon 1}$ and $\mathrm{H}_{\zeta 2}$. Pyridine protons were assigned using the NOEs to the neighboring Gly residues, and the deshielding effect arising from proximity to the pyridine nitrogen. Phe3 was assigned using amide-sidechain NOEs, which were then used to fully assign the aromatic TOCSY chain. Remaining aromatic signals were assigned to Phe4, which was only partially resolved from Phe3.
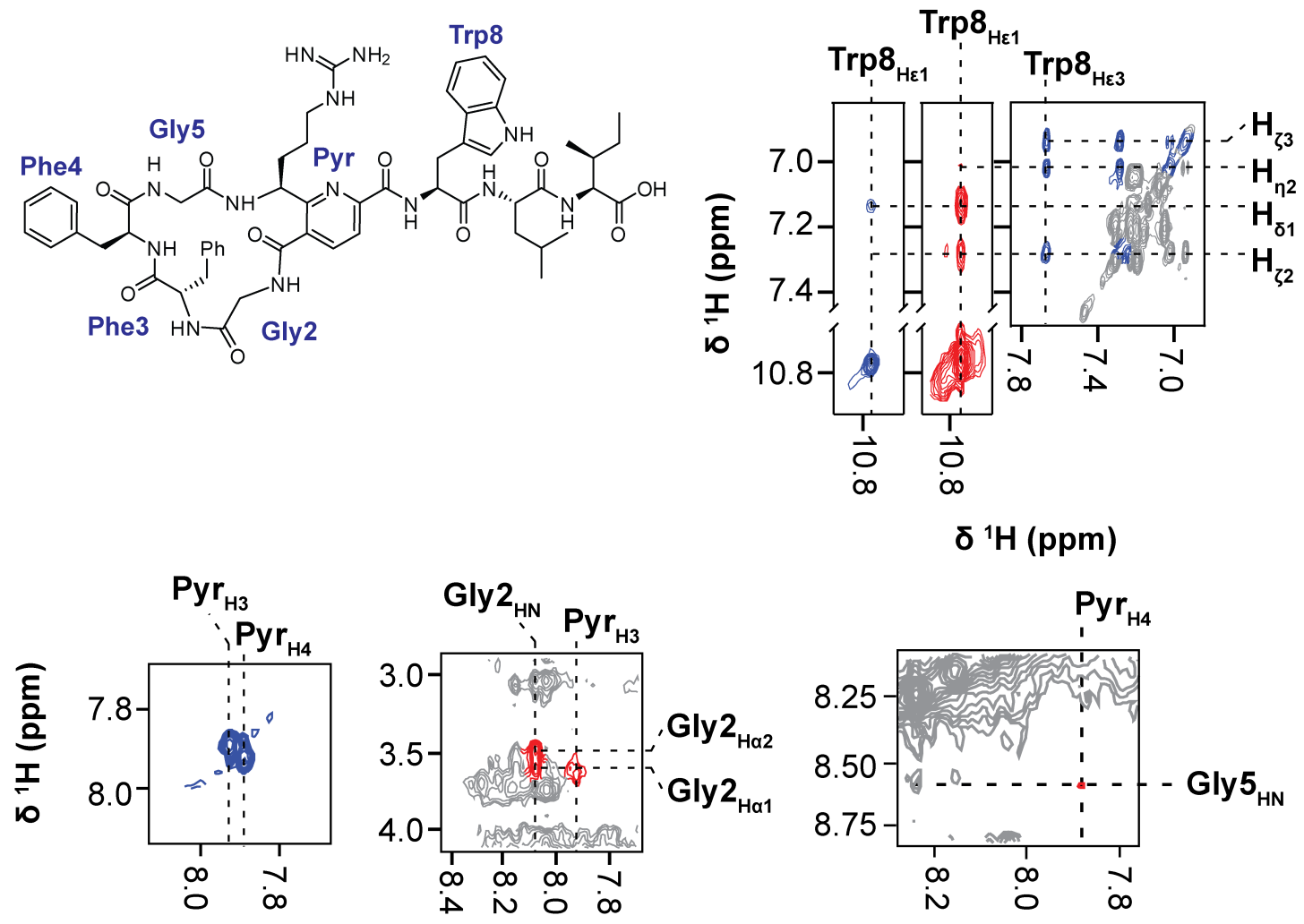

\section{$\delta^{1} \mathrm{H}(\mathrm{ppm})$}
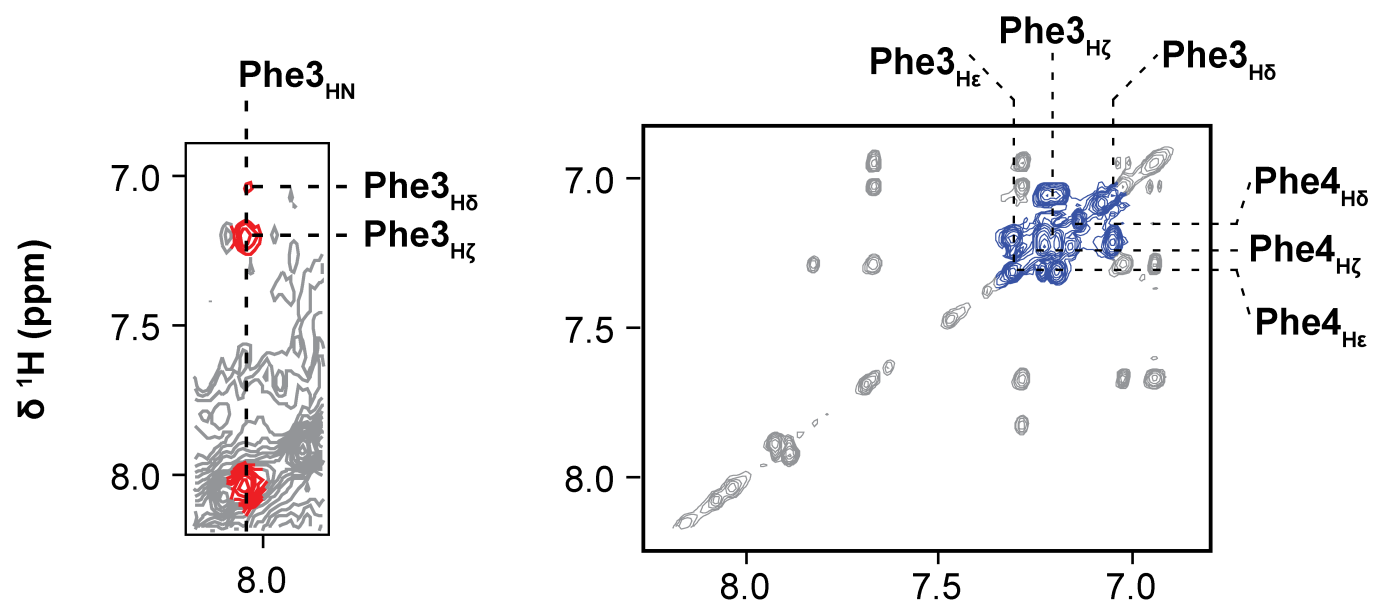

$\delta^{1} \mathrm{H}(\mathrm{ppm})$ 
Figure S12: NOESY contacts used in the backbone assignment of 2. Relevant amide-amide and amide-sidechain NOEs (red) were used in conjunction with the TOCSY patterns on nonredundant residues to fully assign the molecule.

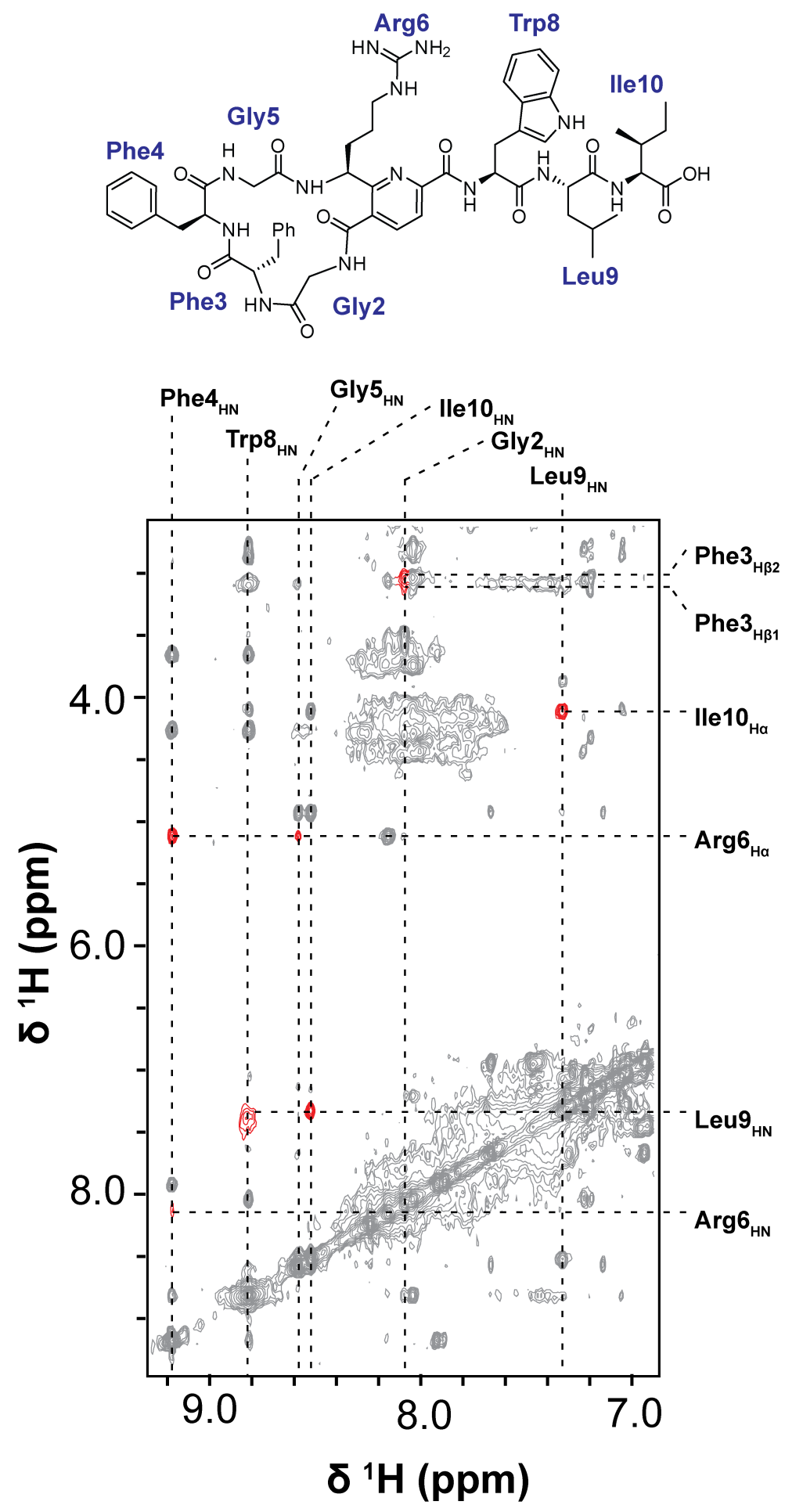


Table S2: NMR assignments of 1 and 2.

Pyritide A1 (1)

\begin{tabular}{|c|c|c|c|c|c|c|c|}
\hline $\begin{array}{l}\text { Residue } \\
\text { Number }\end{array}$ & $\begin{array}{c}\text { Residue } \\
\text { Name }\end{array}$ & Proton & $\begin{array}{c}\text { Chemical } \\
\text { Shift (ppm) }\end{array}$ & $\begin{array}{l}\text { Residue } \\
\text { Number }\end{array}$ & $\begin{array}{c}\text { Residue } \\
\text { Name }\end{array}$ & Proton & $\begin{array}{c}\text { Chemical } \\
\text { Shift (ppm) }\end{array}$ \\
\hline \multirow[t]{2}{*}{2} & Gly & $\mathrm{H}_{\mathrm{N}}$ & 9.443 & 7 & Trp & $\mathrm{H}_{\varepsilon 1}$ & 10.723 \\
\hline & & $\mathrm{H}_{\alpha}$ & 4.099 & & & $\mathrm{H}_{\mathrm{N}}$ & 8.433 \\
\hline \multirow[t]{10}{*}{3} & Trp & $\mathrm{H}_{\varepsilon 1}$ & 10.822 & & & $\mathrm{H}_{\eta 2}$ & 7.529 \\
\hline & & $\mathrm{H}_{\mathrm{N}}$ & 9.374 & & & $\mathrm{H}_{\zeta 2}$ & 7.243 \\
\hline & & $\mathrm{H}_{\mathrm{n} 2}$ & 7.494 & & & $\mathrm{H}_{\delta 1}$ & 7.069 \\
\hline & & $\mathrm{H}_{\zeta 2}$ & 7.31 & & & $\mathrm{H}_{\zeta 3}$ & 6.976 \\
\hline & & $\mathrm{H}_{\delta 1}$ & 7.247 & & & $\mathrm{H}_{\varepsilon 3}$ & 6.865 \\
\hline & & $\mathrm{H}_{\zeta 3}$ & 7.036 & & & $\mathrm{H}_{\alpha}$ & 4.812 \\
\hline & & $\mathrm{H}_{\varepsilon 3}$ & 6.968 & & & $\mathrm{H}_{\beta 2}$ & 3.354 \\
\hline & & $\mathrm{H}_{\alpha}$ & 4.283 & & & $\mathrm{H}_{\beta 1}$ & 3.262 \\
\hline & & $\mathrm{H}_{\beta 2}$ & 3.135 & 8 & Val & $\mathrm{H}_{\mathrm{N}}$ & 8.245 \\
\hline & & $\mathrm{H}_{\beta 1}$ & 3.042 & & & $\mathrm{H}_{\alpha}$ & 4.25 \\
\hline \multirow[t]{6}{*}{4} & Leu & $\mathrm{H}_{\mathrm{N}}$ & 7.953 & & & $\mathrm{H}_{\beta}$ & 1.966 \\
\hline & & $\mathrm{H}_{\alpha}$ & 4.105 & & & $\mathrm{H}_{\mathrm{y} 2}$ & 0.827 \\
\hline & & $\mathrm{H}_{\beta 2}$ & 1.742 & & & $\mathrm{H}_{\mathrm{y} 1}$ & 0.778 \\
\hline & & $\mathrm{H}_{\beta 1}$ & 1.386 & 9 & Ile & $\mathrm{H}_{\mathrm{N}}$ & 7.072 \\
\hline & & $\mathrm{H}_{\mathrm{Y}}$ & 1.205 & & & $\mathrm{H}_{\alpha}$ & 4.258 \\
\hline & & $\mathrm{H}_{\delta}$ & 0.884 & & & $\mathrm{H}_{\beta}$ & 1.532 \\
\hline \multirow[t]{3}{*}{5} & Gly & $\mathrm{H}_{\mathrm{N}}$ & 7.47 & & & $\mathrm{H}_{\mathrm{y} 1}$ & 1.264 \\
\hline & & $\mathrm{H}_{\alpha 1}$ & 4.416 & & & $\mathrm{H}_{\mathrm{y} 2}$ & 1.097 \\
\hline & & $\mathrm{H}_{\alpha 1}$ & 4.327 & & & $\mathrm{H}_{\mathrm{\gamma} 3}$ & 0.715 \\
\hline $\mathrm{N} / \mathrm{A}$ & Pyr & $\begin{array}{l}\mathrm{H}_{4} \\
\mathrm{H}_{3}\end{array}$ & $\begin{array}{l}7.787 \\
7.847\end{array}$ & & & $\mathrm{H}_{\delta}$ & 0.672 \\
\hline
\end{tabular}

Continued on next page 
Pyritide A2 (2)

\begin{tabular}{|c|c|c|c|c|c|c|c|}
\hline $\begin{array}{l}\text { Residue } \\
\text { Number }\end{array}$ & $\begin{array}{c}\text { Residue } \\
\text { Name }\end{array}$ & Proton & $\begin{array}{c}\text { Chemical } \\
\text { Shift (ppm) }\end{array}$ & $\begin{array}{l}\text { Residue } \\
\text { Number }\end{array}$ & $\begin{array}{c}\text { Residue } \\
\text { Name }\end{array}$ & Proton & $\begin{array}{l}\text { Chemical } \\
\text { Shift (ppm) }\end{array}$ \\
\hline \multirow[t]{3}{*}{2} & Gly & $\mathrm{H}_{\mathrm{N}}$ & 8.078 & $\mathrm{~N} / \mathrm{A}$ & Pyr & $\mathrm{H}_{4}$ & 7.885 \\
\hline & & $\mathrm{H}_{a 1}$ & 3.61 & & & $\mathrm{H}_{3}$ & 7.924 \\
\hline & & $\mathrm{H}_{\mathrm{a} 2}$ & 3.504 & 8 & Trp & $\mathrm{H}_{\varepsilon 1}$ & 10.773 \\
\hline \multirow[t]{7}{*}{3} & Phe & $\mathrm{H}_{\mathrm{N}}$ & 8.036 & & & $\mathrm{HN}_{\mathrm{N}}$ & 8.813 \\
\hline & & $\mathrm{H}_{\varepsilon}$ & 7.306 & & & $\mathrm{H}_{\varepsilon 3}$ & 7.669 \\
\hline & & $\mathrm{H}_{\zeta}$ & 7.195 & & & $\mathrm{H}_{\zeta 2}$ & 7.284 \\
\hline & & $\mathrm{H}_{\delta}$ & 7.048 & & & $\mathrm{H}_{\delta 1}$ & 7.138 \\
\hline & & $\mathrm{H}_{\alpha}$ & 4.32 & & & $\mathrm{H}_{\eta 2}$ & 7.019 \\
\hline & & $\mathrm{H}_{\beta 1}$ & 3.129 & & & $\mathrm{H}_{\zeta 3}$ & 6.941 \\
\hline & & $\mathrm{H}_{\beta 2}$ & 3.035 & & & $\mathrm{H}_{\alpha}$ & 4.242 \\
\hline \multirow[t]{6}{*}{4} & Phe & $\mathrm{H}_{\mathrm{N}}$ & 9.174 & & & $\mathrm{H}_{\beta 1}$ & 2.863 \\
\hline & & $\mathrm{H}_{\varepsilon}$ & 7.304 & & & $\mathrm{H}_{\beta 2}$ & 2.773 \\
\hline & & $\mathrm{H}_{\zeta}$ & 7.224 & 9 & Leu & $\overline{\mathrm{H}_{\mathrm{N}}}$ & 7.331 \\
\hline & & $\mathrm{H}_{\delta}$ & 7.051 & & & $\mathrm{H}_{\alpha}$ & 3.873 \\
\hline & & $\mathrm{H}_{\alpha}$ & 4.26 & & & $\mathrm{H}_{\beta 1}$ & 1.721 \\
\hline & & $\mathrm{H}_{\beta}$ & 3.667 & & & $\mathrm{H}_{\beta 2}$ & 1.457 \\
\hline \multirow[t]{2}{*}{5} & Gly & $\mathrm{H}_{\mathrm{N}}$ & 8.581 & & & $\mathrm{H}_{\mathrm{Y}}$ & 1.115 \\
\hline & & $\mathrm{H}_{\alpha}$ & 4.926 & & & $\mathrm{H}_{\delta}$ & 0.798 \\
\hline \multirow[t]{8}{*}{6} & Arg & $\mathrm{H}_{\mathrm{N}}$ & 8.153 & 10 & Ile & $\mathrm{H}_{\mathrm{N}}$ & 8.519 \\
\hline & & $\mathrm{H}_{\alpha}$ & 5.117 & & & $\mathrm{H}_{\alpha}$ & 4.113 \\
\hline & & $\mathrm{H}_{\delta 1}$ & 3.1 & & & $\mathrm{H}_{\beta}$ & 1.596 \\
\hline & & $\mathrm{H}_{\delta 2}$ & 3.073 & & & $\mathrm{H}_{\mathrm{y} 1}$ & 1.555 \\
\hline & & $\mathrm{H}_{\beta 1}$ & 2.149 & & & $\mathrm{H}_{\mathrm{y} 2}$ & 0.876 \\
\hline & & $\mathrm{H}_{\beta 2}$ & 1.881 & & & $\mathrm{H}_{\delta}$ & 0.808 \\
\hline & & $\mathrm{H}_{\mathrm{Y} 1}$ & 1.578 & & & & \\
\hline & & $\mathrm{H}_{\mathrm{Y} 2}$ & 1.446 & & & & \\
\hline
\end{tabular}


Figure S13: HR-MS/MS of 2. (A) Structure of 2 with observed ions noted. (B) MS/MS spectrum of 2. A table comparing observed and theoretical $\mathrm{m} / \mathrm{z}$ values for fragments may be found in Table S3.

A

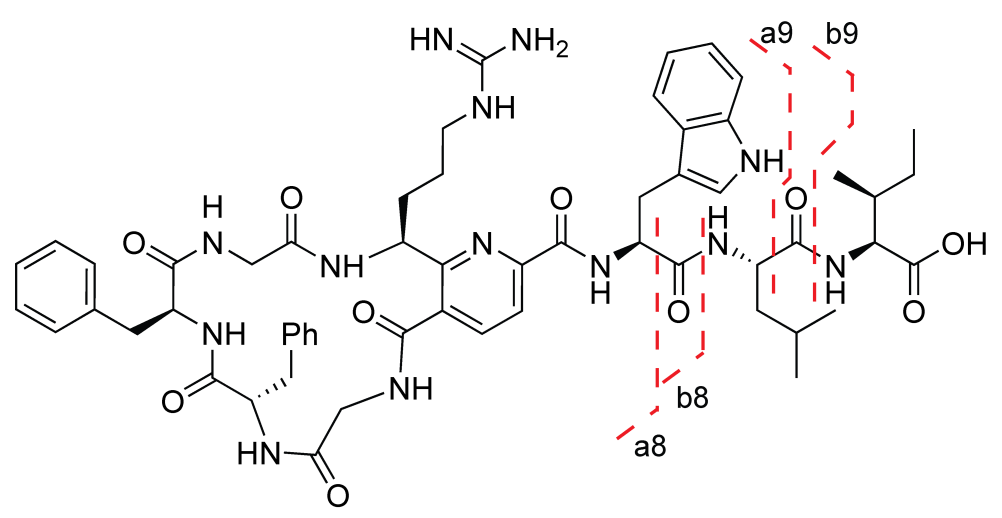

B

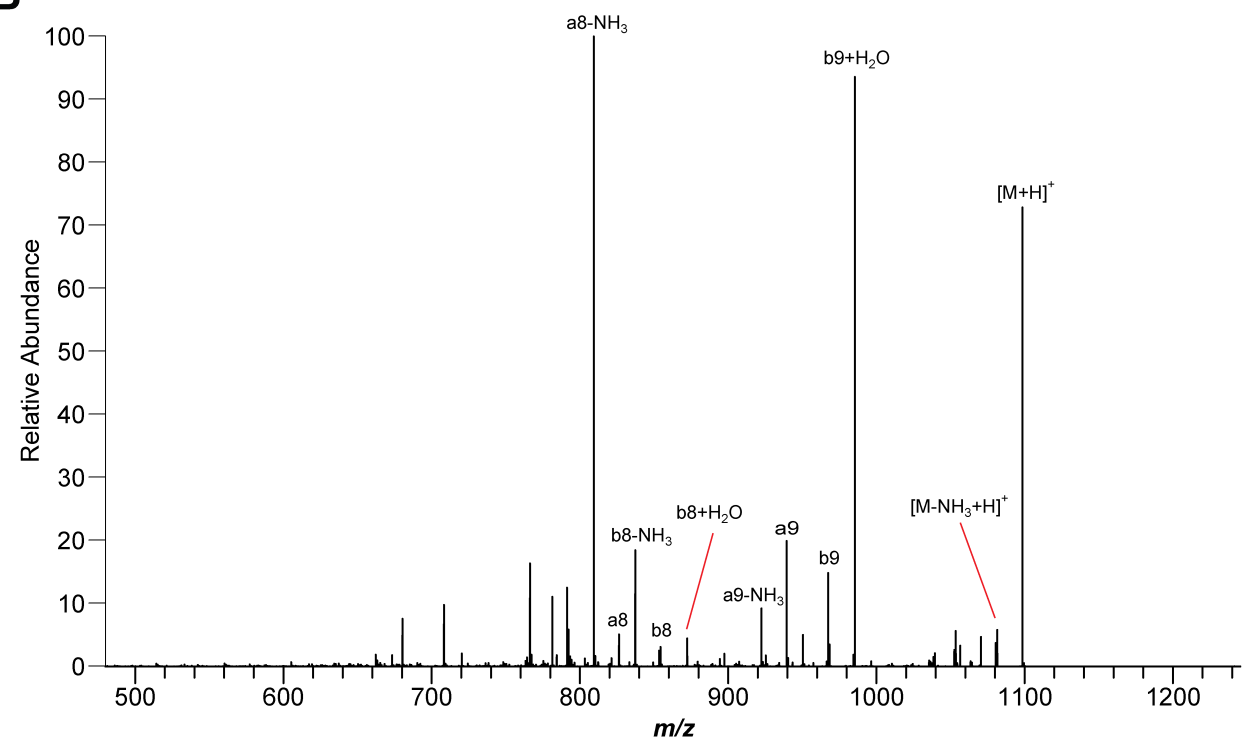


Figure S14: HR-MS/MS of MroA2 eliminated carboxamide leader peptide (6). (A) Primary sequence of the eliminated MroA2 leader peptide with a carboxamide C-terminus (red). (B) CID fragmentation of the carboxamide leader peptide, with an inset showing the exact mass of the parent ion and the predicted masses for both the carboxamide and carboxylic acid forms; the error on the latter is several orders of magnitude higher. A table comparing observed and theoretical $\mathrm{m} / \mathrm{z}$ values for fragments may be found in Table S3.

A

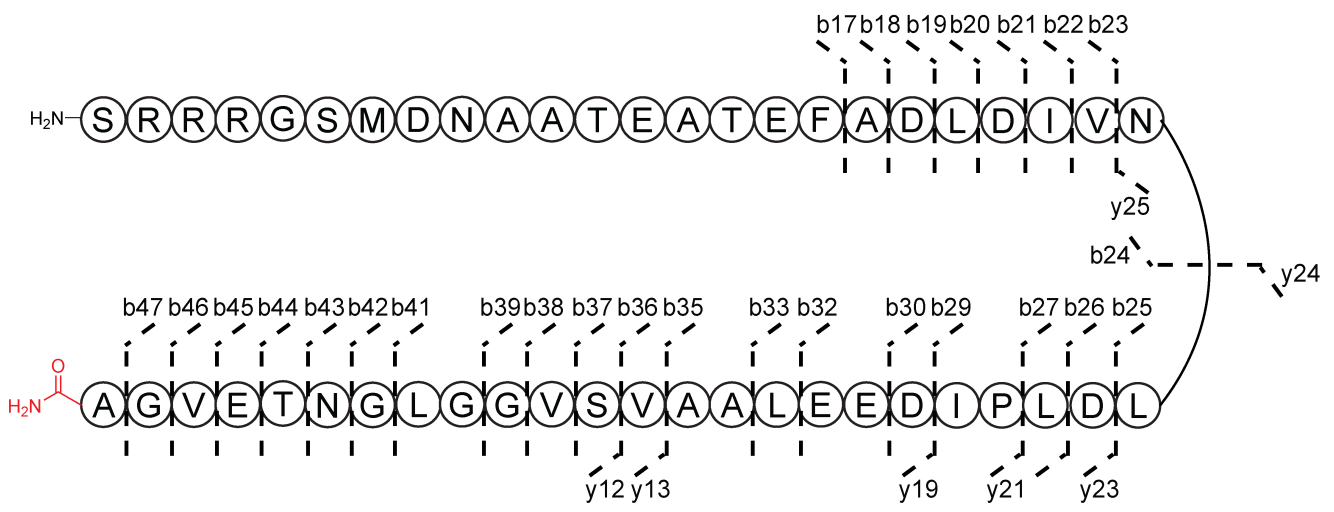

B

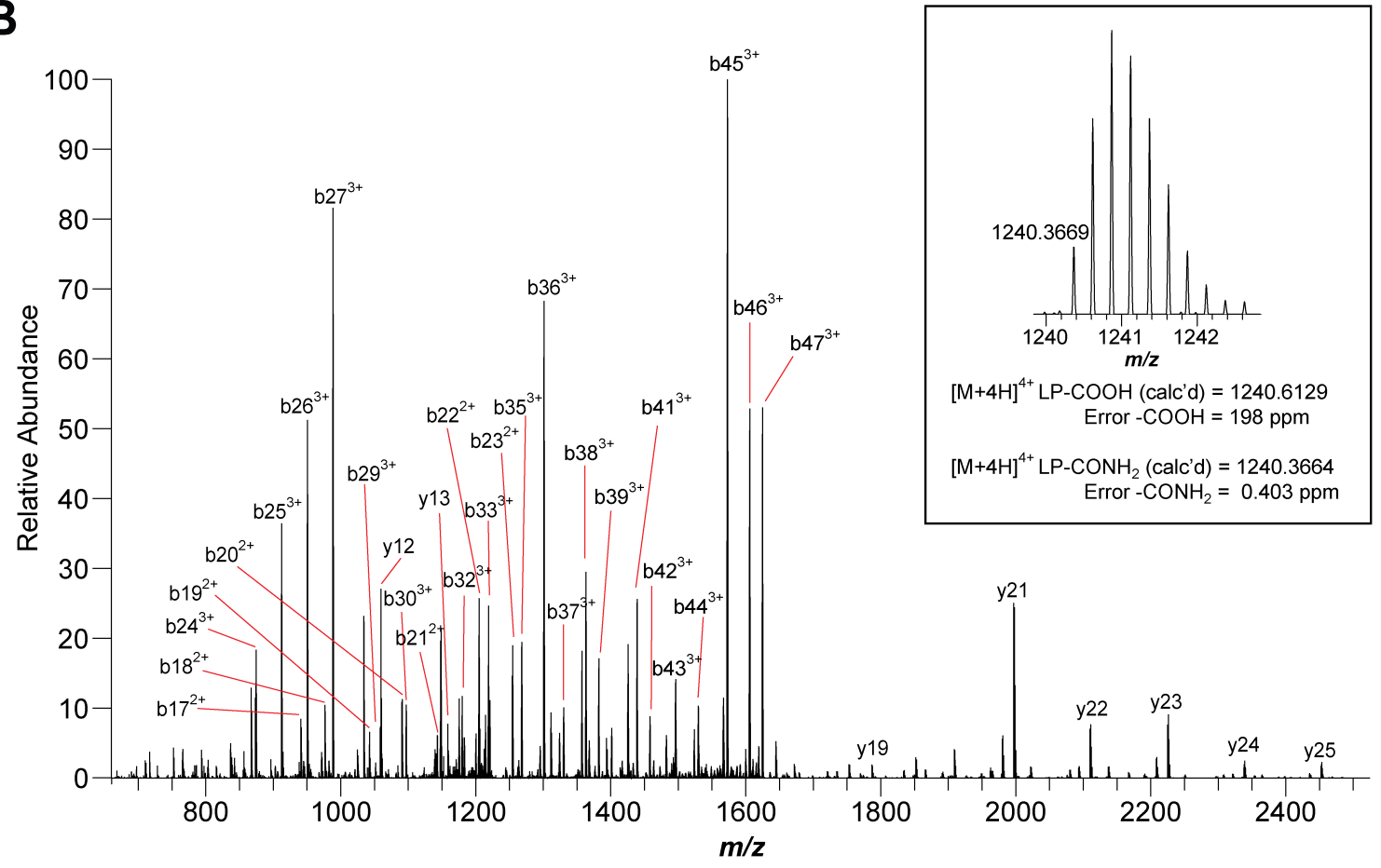


Table S3: MS fragment assignments. Mass values assigned to the fragmentation products with calculated and observed values and associated error. The figure associated with each table is given in parentheses.

Synthetic pyritide A1 (1, Figure S4 top)

\begin{tabular}{|l|c|c|c|}
\hline \multicolumn{1}{|c|}{ Species } & \multicolumn{1}{c|}{$\begin{array}{c}\text { Predicted } \\
\text { mass }\end{array}$} & $\begin{array}{c}\text { Observed } \\
\text { mass }\end{array}$ & $\begin{array}{c}\text { Error } \\
(\mathbf{p p m})\end{array}$ \\
\hline$[\mathrm{M}+\mathrm{Na}]^{+}$ & 955.4437 & 955.4429 & 0.8 \\
\hline$[\mathrm{b} 8+\mathrm{Na}]^{+}$ & 824.3491 & 824.3489 & 0.2 \\
\hline$\left[\mathrm{b} 8+\mathrm{H}_{2} \mathrm{O}+\mathrm{Na}\right]^{+}$ & 842.3596 & 842.3588 & 1.0 \\
\hline$[\mathrm{a} 8+\mathrm{Na}]^{+}$ & 796.3542 & 796.3543 & 0.1 \\
\hline$[\mathrm{b} 7+\mathrm{Na}]^{+}$ & 725.2807 & 725.2805 & 0.2 \\
\hline$\left[\mathrm{b} 7+\mathrm{H}_{2} \mathrm{O}+\mathrm{Na}\right]^{+}$ & 743.2912 & 743.2910 & 0.4 \\
\hline$[\mathrm{a} 7+\mathrm{Na}]^{+}$ & 697.2857 & 697.2856 & 0.1 \\
\hline$\left[\mathrm{b} 6+\mathrm{H}_{2} \mathrm{O}+\mathrm{Na}\right]^{+}$ & 557.2119 & 557.2117 & 0.4 \\
\hline
\end{tabular}

Chemoenzymatic pyritide A1 (1, Figure S4 bottom)

\begin{tabular}{|l|c|c|r|}
\hline \multicolumn{1}{|c|}{ Species } & $\begin{array}{c}\text { Predicted } \\
\text { mass }\end{array}$ & $\begin{array}{c}\text { Observed } \\
\text { mass }\end{array}$ & $\begin{array}{c}\text { Error } \\
\text { (ppm) }\end{array}$ \\
\hline$[\mathrm{M}+\mathrm{Na}]^{+}$ & 955.4437 & 955.4420 & 1.8 \\
\hline$[\mathrm{b} 8+\mathrm{Na}]^{+}$ & 824.3491 & 824.3479 & 1.4 \\
\hline$\left[\mathrm{b} 8+\mathrm{H}_{2} \mathrm{O}+\mathrm{Na}\right]^{+}$ & 842.3596 & 842.3578 & 2.2 \\
\hline$[\mathrm{a} 8+\mathrm{Na}]^{+}$ & 796.3542 & 796.3529 & 1.6 \\
\hline$[\mathrm{b} 7+\mathrm{Na}]^{+}$ & 725.2807 & 725.2794 & 1.7 \\
\hline$\left[\mathrm{b} 7+\mathrm{H}_{2} \mathrm{O}+\mathrm{Na}\right]^{+}$ & 743.2912 & 743.2901 & 1.5 \\
\hline$[\mathrm{a} 7+\mathrm{Na}]^{+}$ & 697.2857 & 697.2845 & 1.7 \\
\hline$\left[\mathrm{b} 6+\mathrm{H}_{2} \mathrm{O}+\mathrm{Na}\right]^{+}$ & 557.2119 & 557.2109 & 1.7 \\
\hline
\end{tabular}

Pyritide A2 (2, Figure S13)

\begin{tabular}{|l|c|c|c|}
\hline \multicolumn{1}{|c|}{ Species } & \multicolumn{1}{c|}{$\begin{array}{c}\text { Predicted } \\
\text { mass }\end{array}$} & $\begin{array}{c}\text { Observed } \\
\text { mass }\end{array}$ & $\begin{array}{c}\text { Error } \\
\text { (ppm) }\end{array}$ \\
\hline$[\mathrm{M}+\mathrm{H}]^{+}$ & 1098.5520 & 1098.5504 & 1.4 \\
\hline$\left[\mathrm{M}-\mathrm{NH}_{3}+\mathrm{H}\right]^{+}$ & 1081.5254 & 1081.5238 & 1.5 \\
\hline $\mathrm{b} 9^{+}$ & 967.4573 & 967.4560 & 1.4 \\
\hline$\left[\mathrm{b} 9+\mathrm{H}_{2} \mathrm{O}\right]^{+}$ & 985.4679 & 985.4663 & 1.6 \\
\hline $\mathrm{a} 9^{+}$ & 939.4624 & 939.4614 & 1.1 \\
\hline$\left[a 9-\mathrm{NH}_{3}\right]^{+}$ & 922.4359 & 922.4350 & 1.0 \\
\hline $\mathrm{b}^{+}$ & 854.3733 & 854.3721 & 1.4 \\
\hline$\left[\mathrm{b} 8+\mathrm{H}_{2} \mathrm{O}\right]^{+}$ & 872.3838 & 872.3827 & 1.3 \\
\hline $\mathrm{a} 8^{+}$ & 826.3784 & 826.3774 & 1.1 \\
\hline$\left[\mathrm{a} 8-\mathrm{NH}_{3}\right]^{+}$ & 809.3518 & 809.3508 & 1.2 \\
\hline
\end{tabular}

\section{Continued on next page}


MroA2 eliminated leader peptide, as a C-terminal carboxamide (Figure S14)

\begin{tabular}{|c|c|c|c|}
\hline Species & $\begin{array}{c}\text { Predicted } \\
\text { mass }\end{array}$ & $\begin{array}{c}\text { Observed } \\
\text { mass }\end{array}$ & $\begin{array}{l}\text { Error } \\
(\mathrm{ppm})\end{array}$ \\
\hline$[\mathrm{M}+4 \mathrm{H}]^{4+}$ & 1240.3664 & 1240.3669 & 0.4 \\
\hline b1 $7^{2+}$ & 940.9373 & 940.9352 & 2.3 \\
\hline $\mathrm{b} 18^{2+}$ & 976.4559 & 976.4539 & 2.0 \\
\hline b19 ${ }^{2+}$ & 1033.9693 & 1033.9674 & 1.9 \\
\hline b20 $2+$ & 1090.5114 & 1090.5091 & 2.1 \\
\hline $\mathrm{b} 21^{2+}$ & 1148.0248 & 1148.0228 & 1.8 \\
\hline $\mathrm{b} 22^{2+}$ & 1204.5669 & 1204.5649 & 1.7 \\
\hline$b 23^{2+}$ & 1254.1011 & 1254.0984 & 2.1 \\
\hline $\mathrm{b} 24^{3+}$ & 874.4176 & 874.4163 & 1.5 \\
\hline b2 $5^{3+}$ & 912.1123 & 912.1109 & 1.6 \\
\hline b26 $6^{3+}$ & 950.4546 & 950.4525 & 2.2 \\
\hline $\mathrm{b} 27^{3+}$ & 988.1493 & 988.1472 & 2.1 \\
\hline b29 $9^{3+}$ & 1058.1949 & 1058.1933 & 1.5 \\
\hline b30 $0^{3+}$ & 1096.5373 & 1096.5352 & 1.9 \\
\hline b32 $2^{3+}$ & 1182.5656 & 1182.5649 & 0.7 \\
\hline b33 $3^{3+}$ & 1220.2603 & 1220.2579 & 2.0 \\
\hline b35 $5^{3+}$ & 1267.6184 & 1267.6160 & 1.9 \\
\hline b36 $6^{3+}$ & 1300.6412 & 1300.6391 & 1.6 \\
\hline
\end{tabular}

\begin{tabular}{|c|c|c|c|}
\hline Species & $\begin{array}{c}\text { Predicted } \\
\text { mass }\end{array}$ & $\begin{array}{c}\text { Observed } \\
\text { mass }\end{array}$ & $\begin{array}{l}\text { Error } \\
(\mathrm{ppm})\end{array}$ \\
\hline b3 $37^{3+}$ & 1329.6519 & 1329.6498 & 1.5 \\
\hline b38 $8^{3+}$ & 1362.6747 & 1362.6726 & 1.5 \\
\hline b39 $9^{3+}$ & 1381.6819 & 1381.6797 & 1.6 \\
\hline b4 $41^{3+}$ & 1438.3837 & 1438.3802 & 2.4 \\
\hline b42 $2^{3+}$ & 1457.3908 & 1457.3873 & 2.4 \\
\hline$b 43^{3+}$ & 1495.4052 & 1495.4019 & 2.2 \\
\hline b44 $4^{3+}$ & 1529.0877 & 1529.0837 & 2.6 \\
\hline b45 $5^{3+}$ & 1572.1019 & 1572.0995 & 1.5 \\
\hline b4 $6^{3+}$ & 1605.1247 & 1605.1220 & 1.7 \\
\hline$b 47^{3+}$ & 1624.1319 & 1624.1293 & 1.6 \\
\hline $\mathrm{y} 12^{+}$ & 1059.5429 & 1059.5408 & 2.0 \\
\hline$y 13^{+}$ & 1158.6113 & 1158.6091 & 1.9 \\
\hline y19+ & 1786.8818 & 1786.8785 & 1.8 \\
\hline $\mathrm{y} 21^{+}$ & 1997.0186 & 1997.0121 & 3.2 \\
\hline $\mathrm{y}_{22^{+}}$ & 2110.1026 & 2110.0959 & 3.2 \\
\hline $\mathrm{y} 23^{+}$ & 2225.1296 & 2225.1238 & 2.6 \\
\hline y24+ & 2338.2137 & 2338.2054 & 3.5 \\
\hline y25 & 2452.2566 & 2452.2476 & 3.6 \\
\hline
\end{tabular}


Table S4: Minimum inhibitory concentrations (MICs) of 1, 2, and 1+2 against indicator strains.

\begin{tabular}{|l|c|c|c|}
\hline Organism & $\begin{array}{c}\text { MIC pyritide } \\
\mathbf{A 1}(\boldsymbol{\mu g} / \mathbf{m L})\end{array}$ & $\begin{array}{c}\text { MIC pyritide } \\
\mathbf{A 2}(\boldsymbol{\mu} \mathbf{g} / \mathbf{m L})\end{array}$ & $\begin{array}{c}\text { MIC pyritide A1 + A2 } \\
(\boldsymbol{\mu} \mathbf{g} / \mathbf{m L}, \mathbf{c o n c} \text { each })\end{array}$ \\
\hline Staphylococcus aureus USA300 & $>64$ & $>64$ & $>32$ \\
\hline Enterococcus faecium U503 & $>64$ & $>64$ & $>32$ \\
\hline Escherichia coli MC4100 & $>64$ & $>64$ & $>32$ \\
\hline Pseudomonas aeruginosa PAO1 & $>64$ & $>64$ & $>32$ \\
\hline Saccharomyces cerevisiae & $>64$ & $>64$ & $>32$ \\
\hline
\end{tabular}

No antimicrobial activity was observed under the assay conditions employed. 
Figure S15: NMR spectra of synthetic compounds used in this study (following pages).

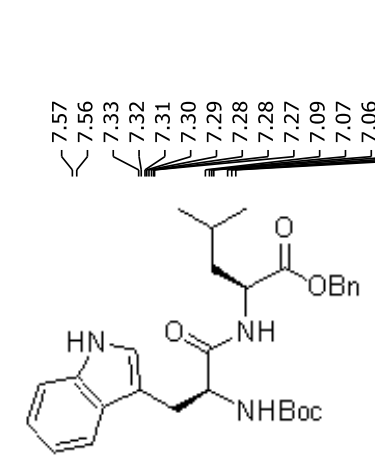

${ }^{1} \mathrm{H}, 500 \mathrm{MHz}, \mathrm{S} \mathrm{CD}_{3} \mathrm{OD}, 25^{\circ} \mathrm{C}$
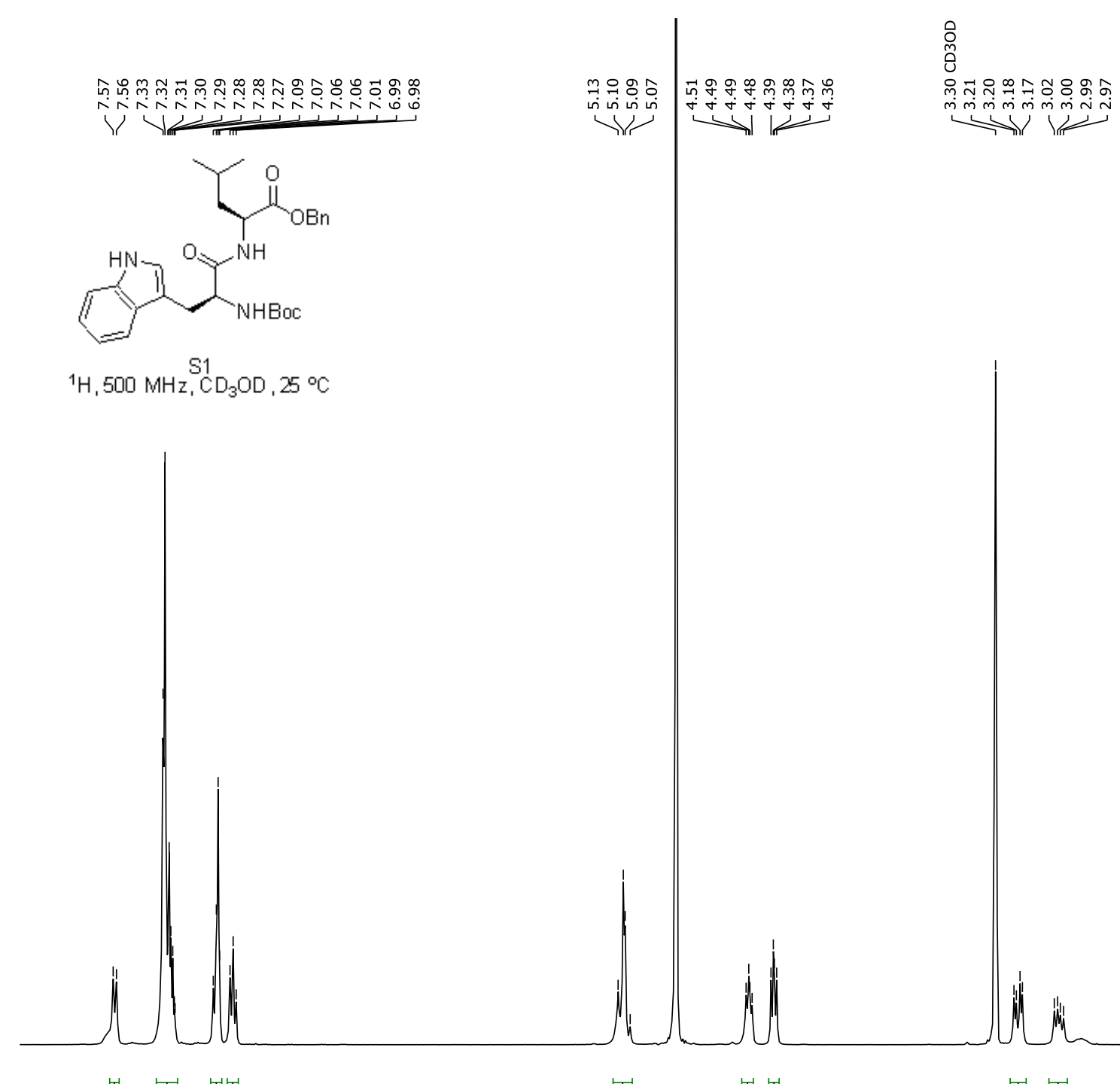

T. 'Tु

'T

T' T

Tं I

3.0

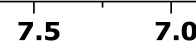

6.5

6.0

5.5

$\mathbf{5 . 0}$

4.5

4.0

f1 (ppm)

3.0

2.5

2.0

1.5

1.

0.0 


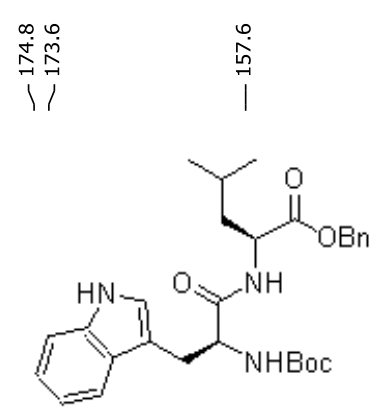

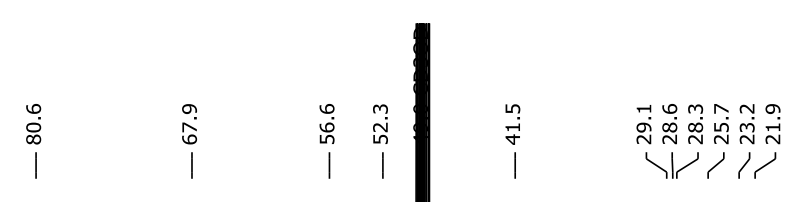

${ }^{13} \mathrm{C}, 126 \mathrm{MHz}_{1}, \mathrm{CD}_{3} \mathrm{OD}, 25^{\circ} \mathrm{C}$

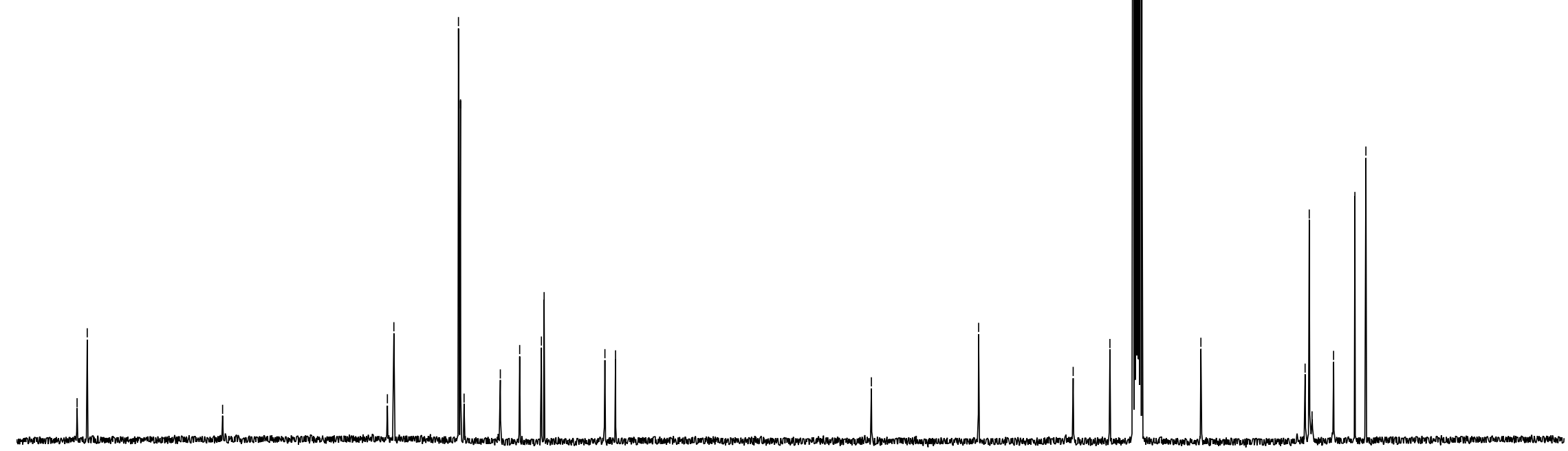

180

$170 \quad 160$

150

$140 \quad 130$

120

110

100

90

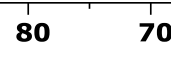

60

50

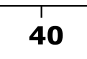

30

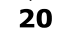
. 


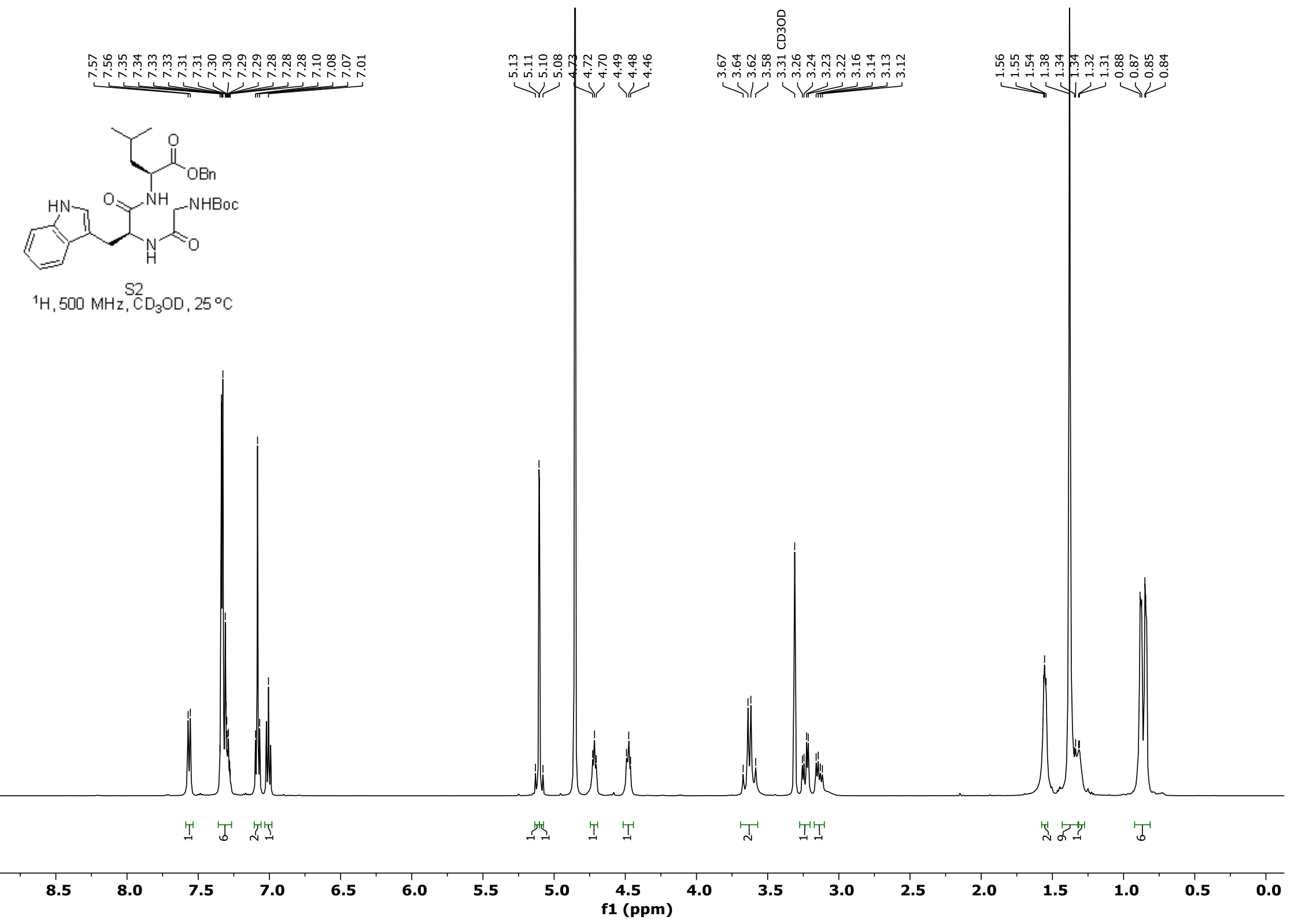




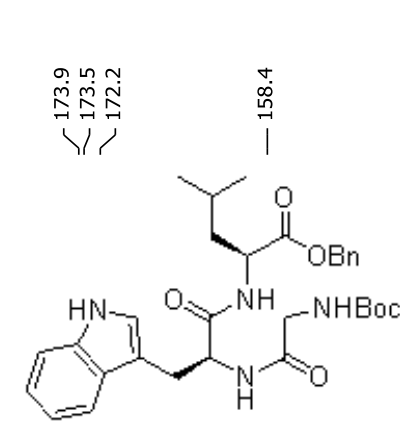

$\overbrace{}^{\infty}$

${ }^{13} \mathrm{C}, 126 \mathrm{MHZ}^{\mathrm{S}}, \mathrm{CD}_{3} \mathrm{OD}, 25^{\circ} \mathrm{C}$

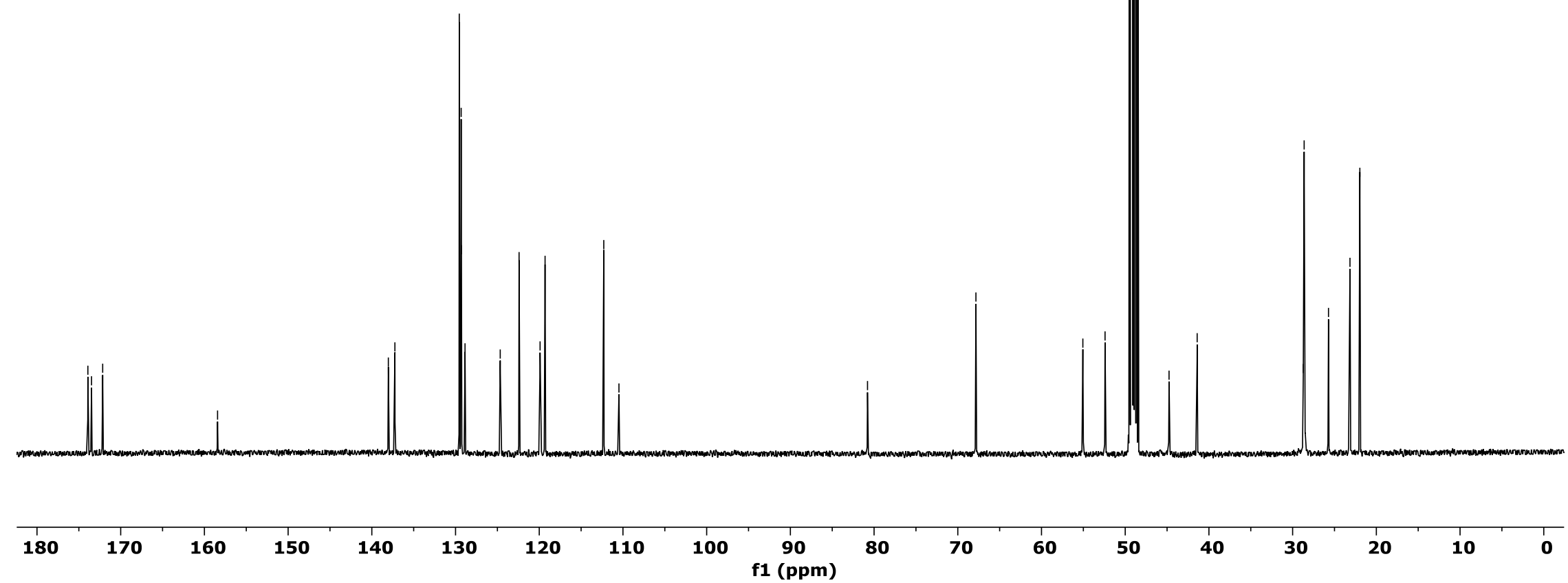




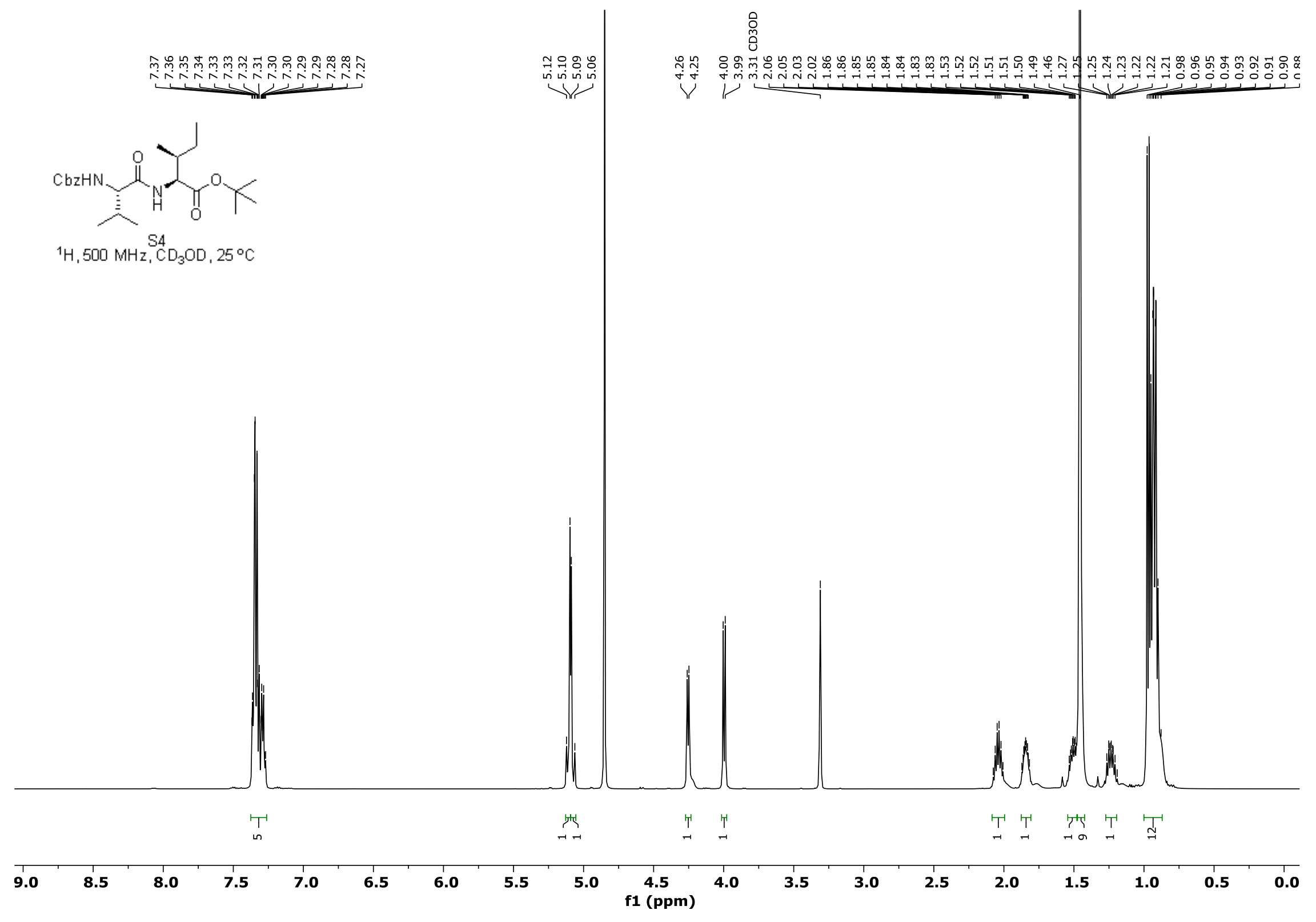



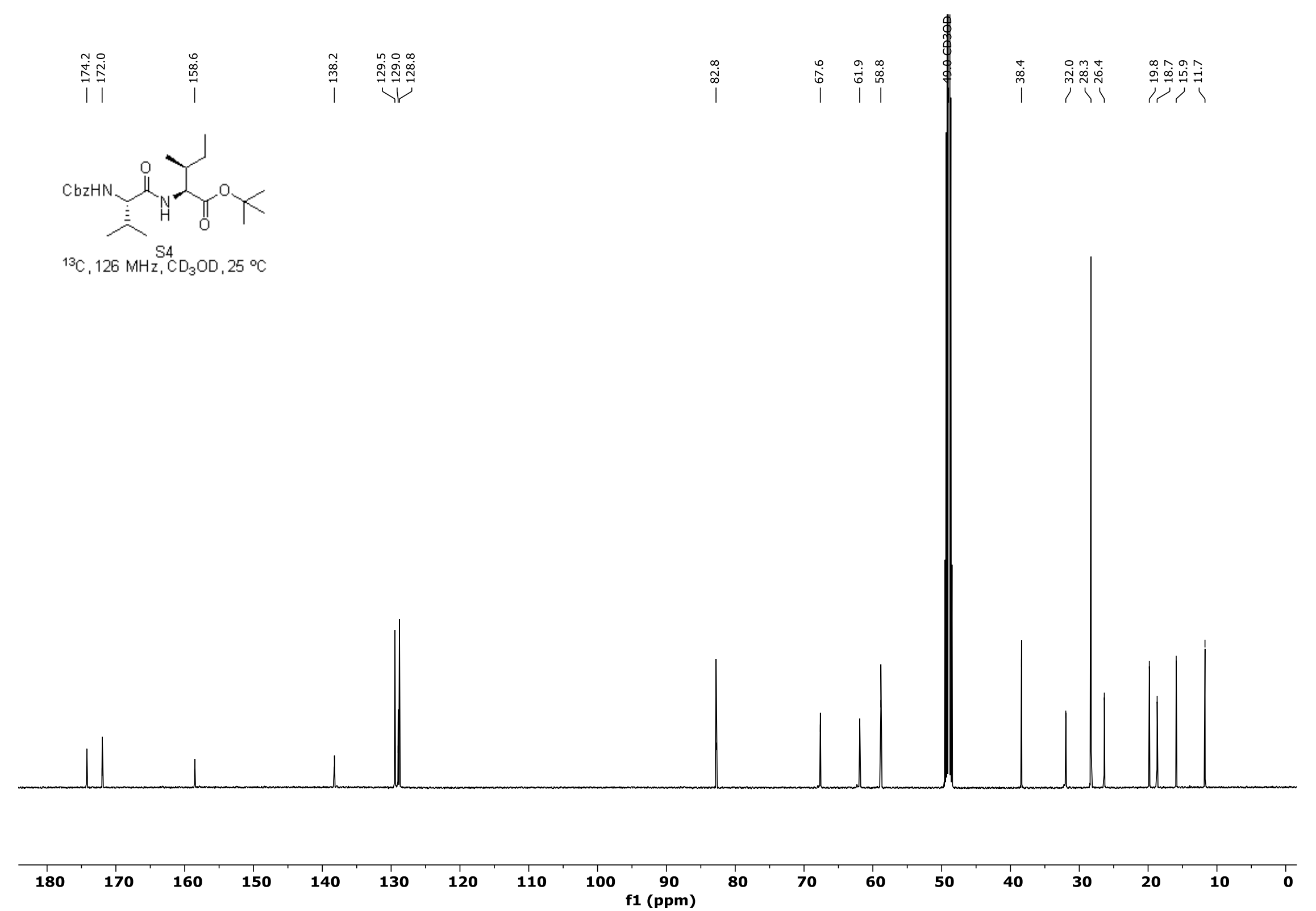


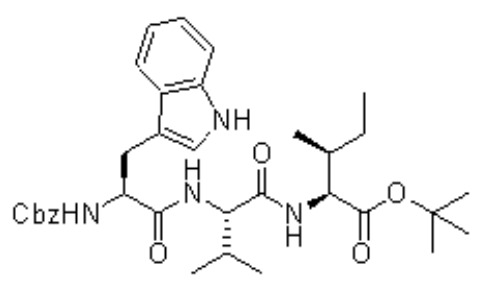

${ }^{1} \mathrm{H}, 500 \mathrm{MHz}, \mathrm{CD} \mathrm{CD}_{3} \mathrm{OD}, 25^{\circ} \mathrm{C}$

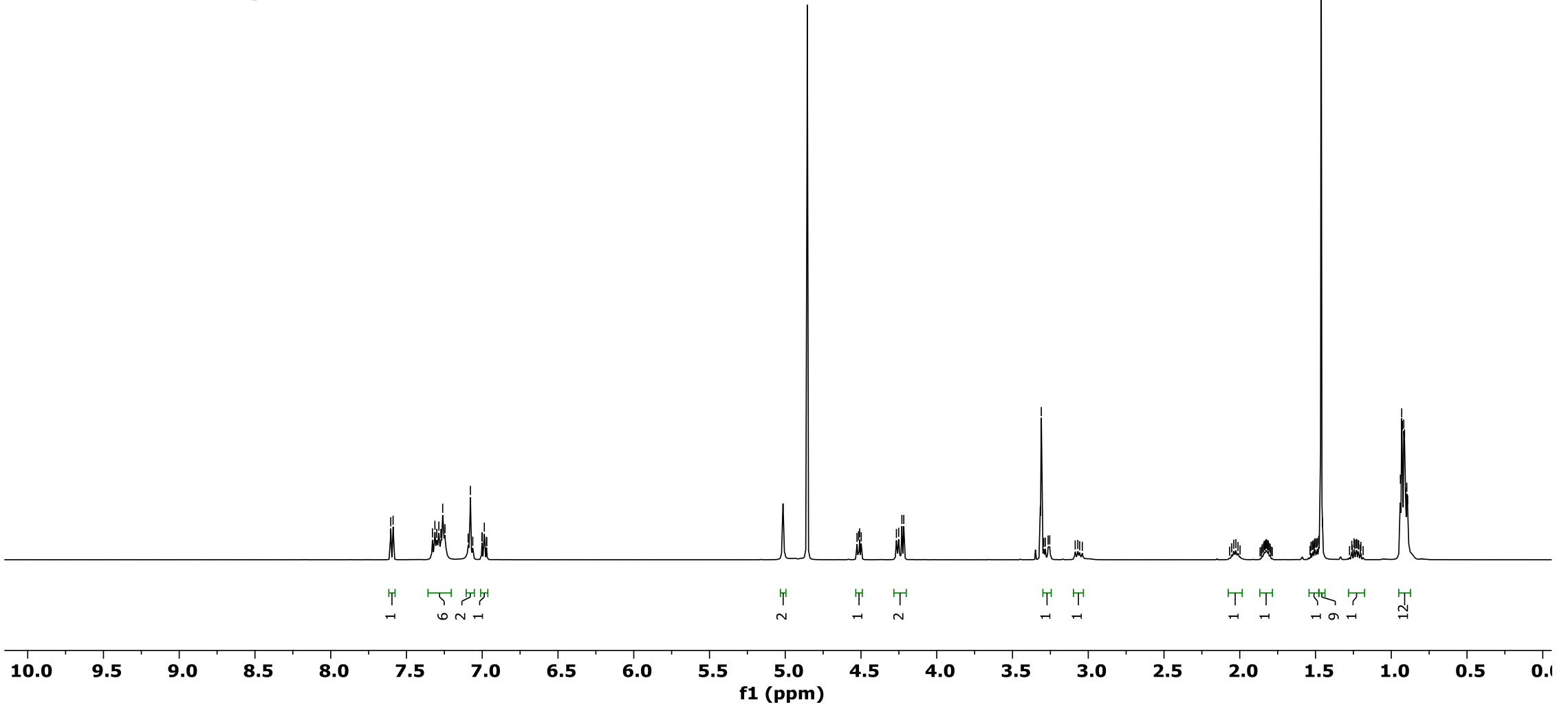



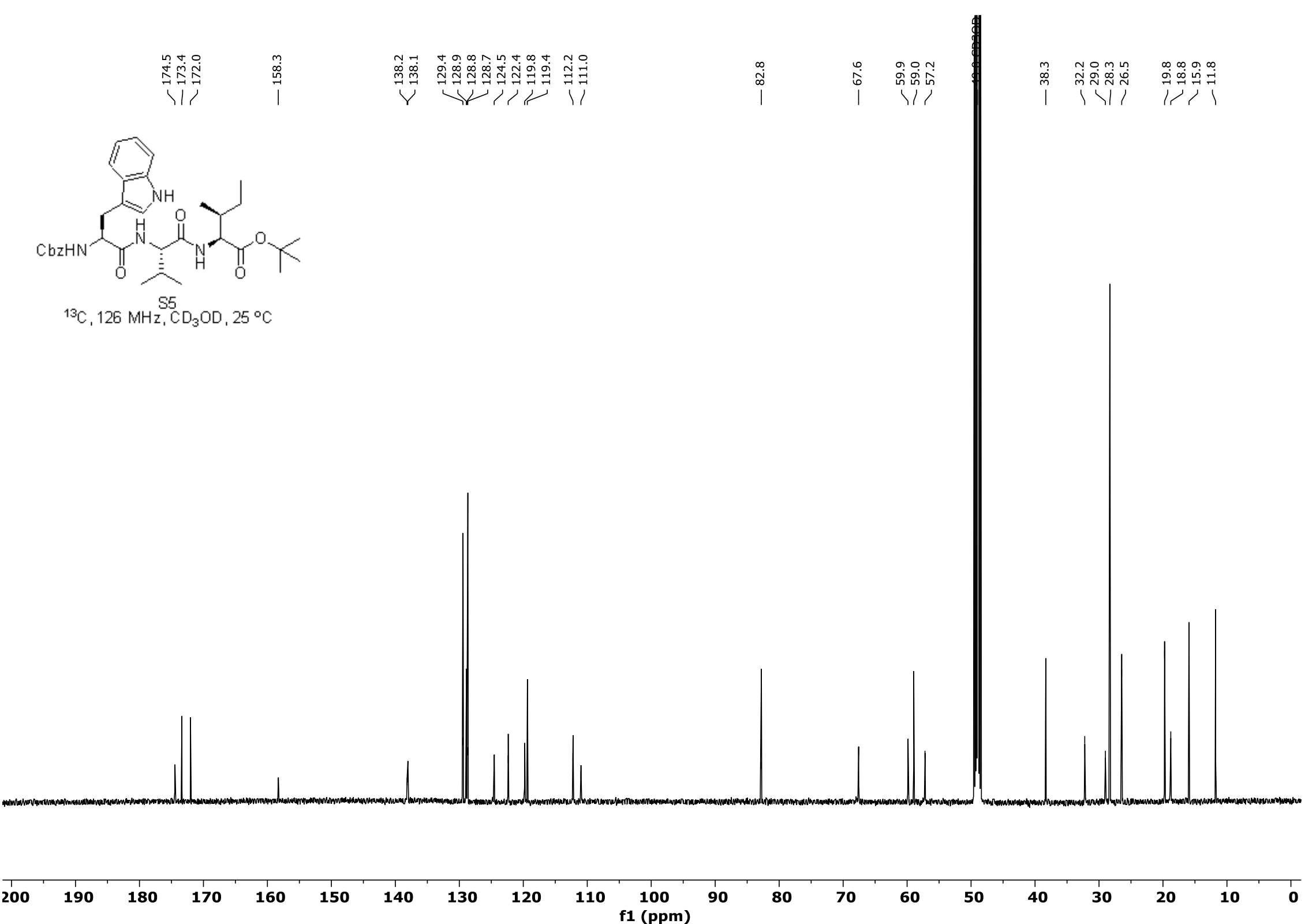


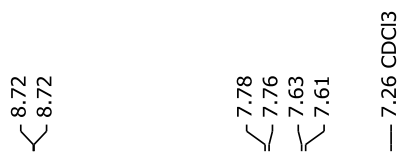

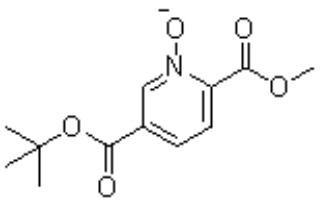

${ }^{1} \mathrm{H}, 500 \mathrm{MHz}, \mathrm{CDCl}_{3}, 25^{\circ} \mathrm{C}$

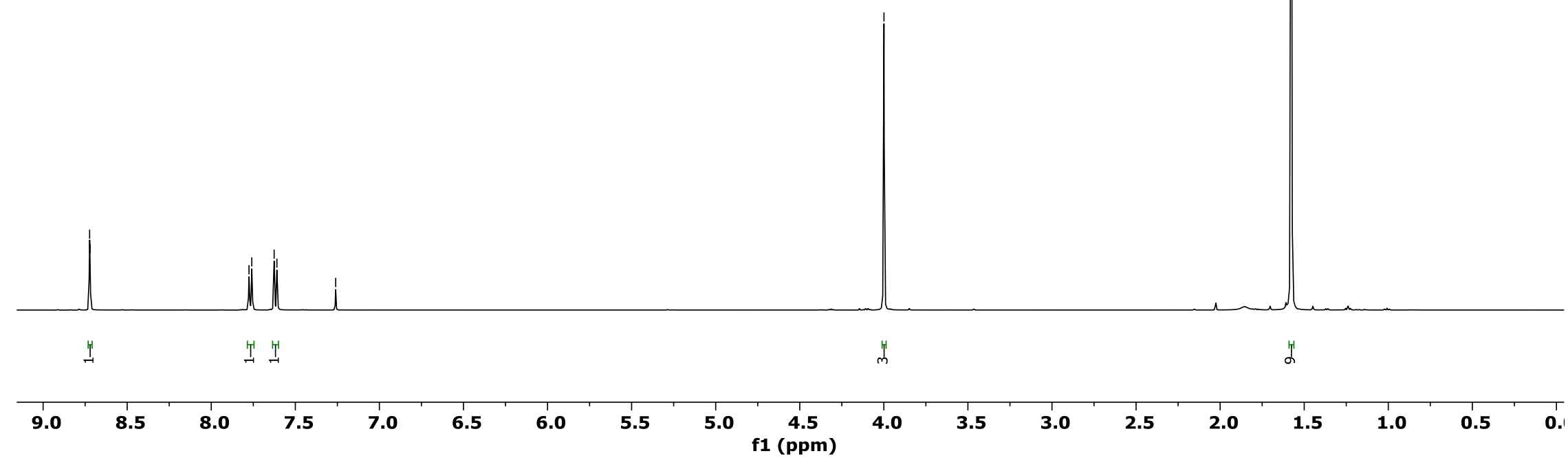



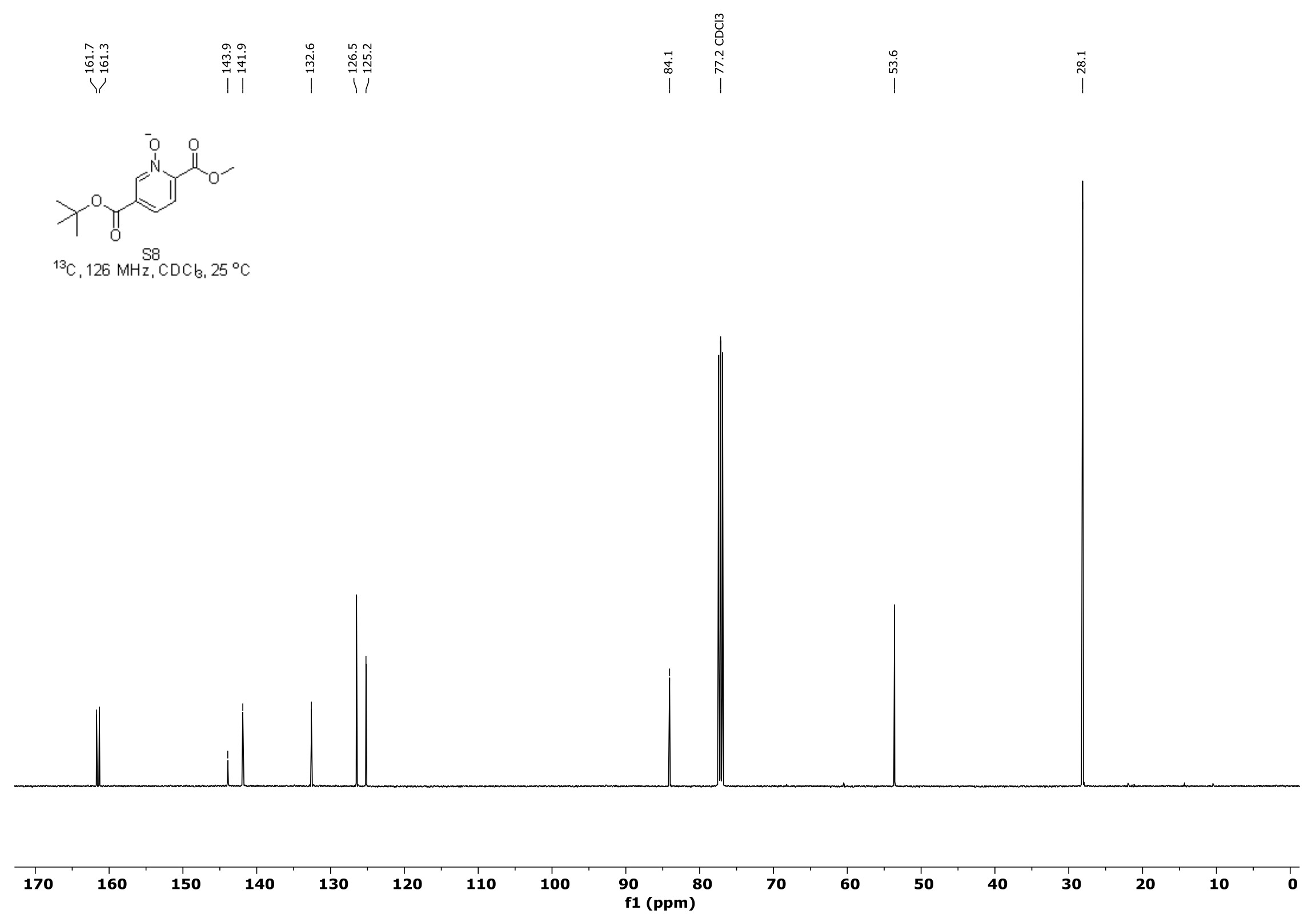


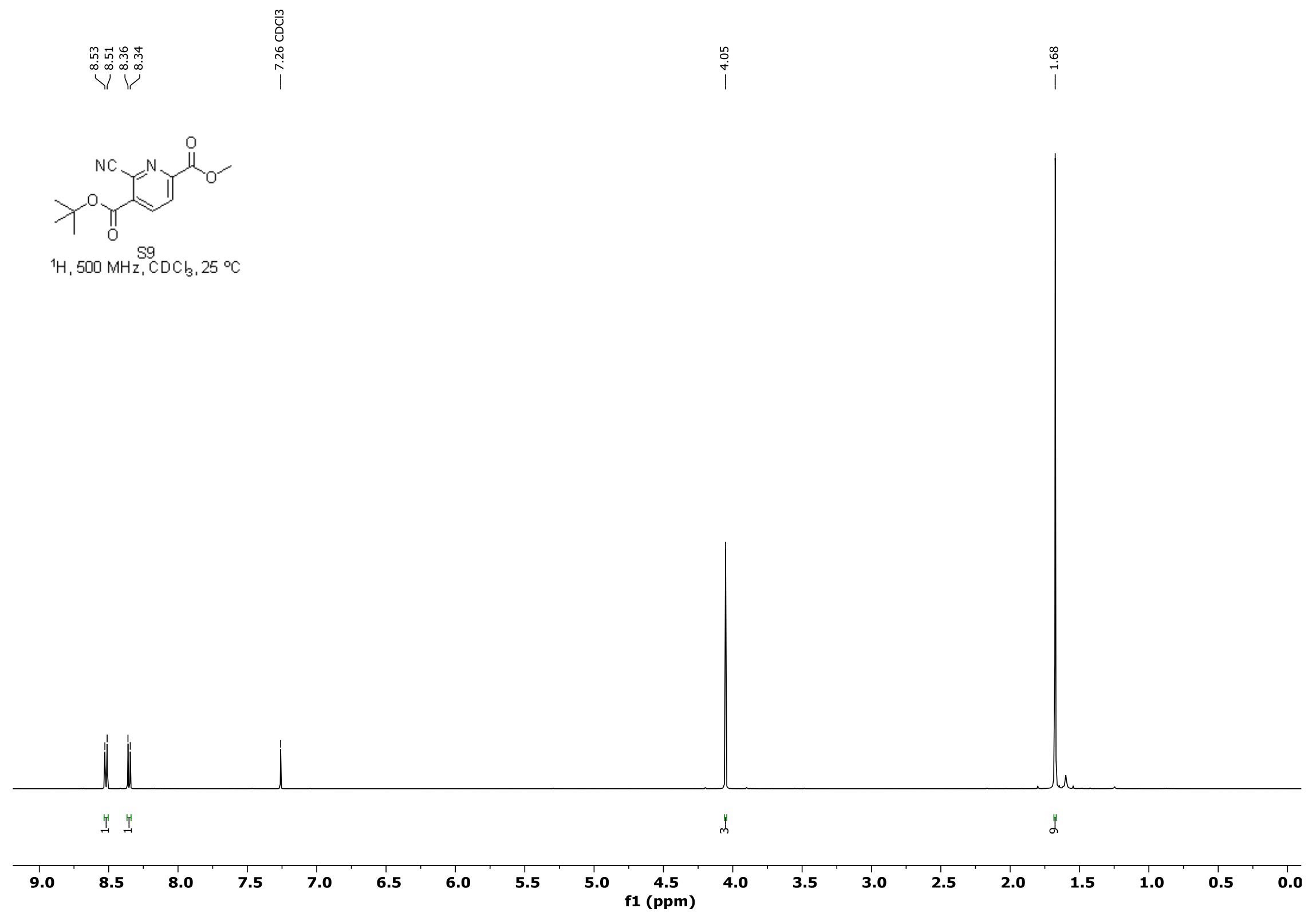



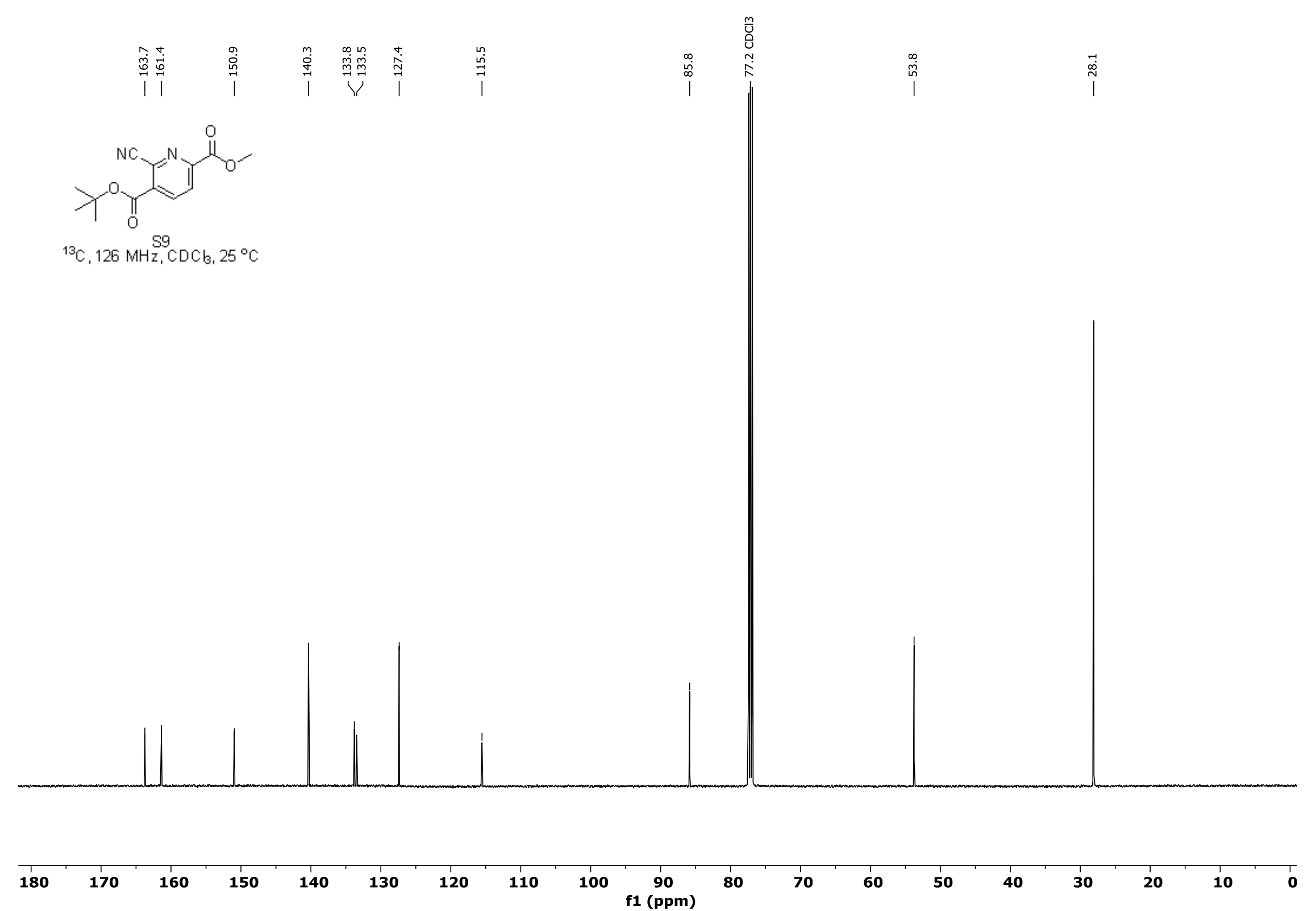
ભm

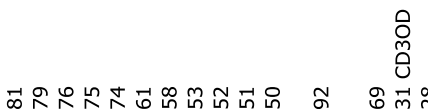

各

$\underbrace{-1}$

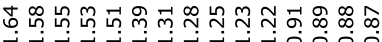

位

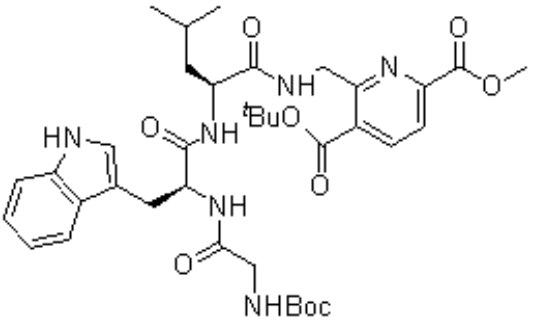

${ }^{1} \mathrm{H}, 500 \mathrm{MHz}, \mathrm{CD}_{3} \mathrm{OD}, 25^{\circ} \mathrm{C}$

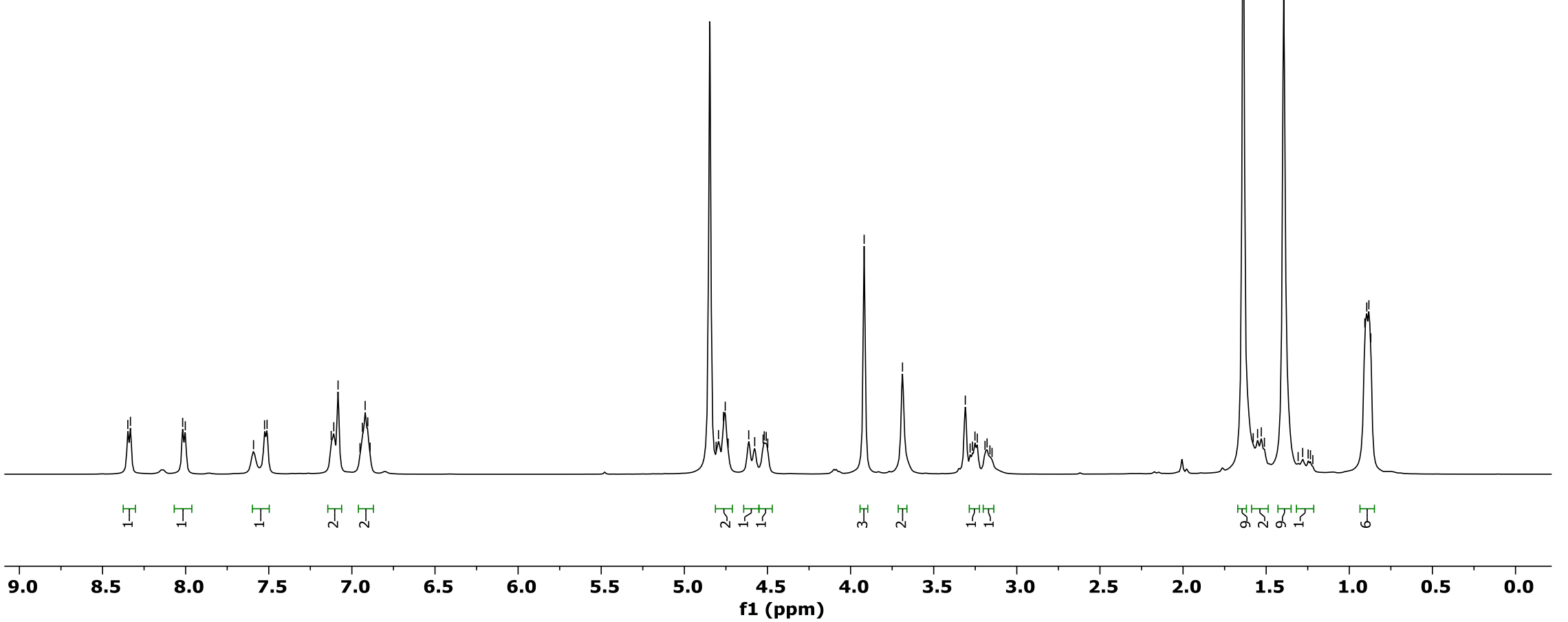




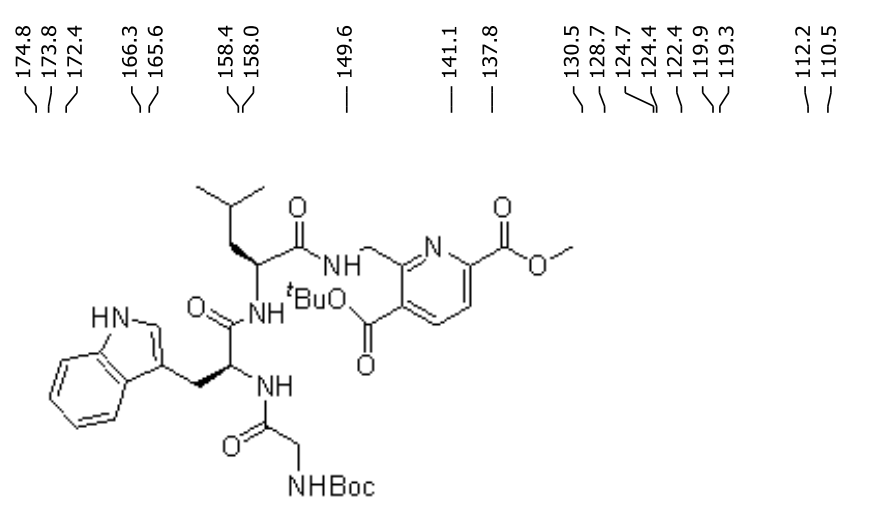

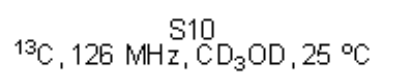

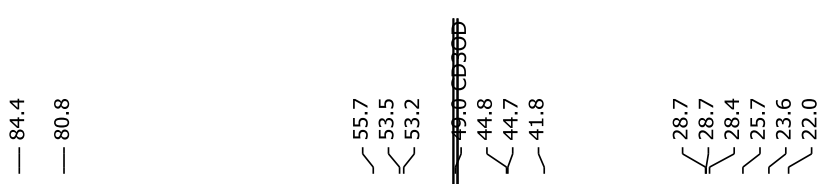
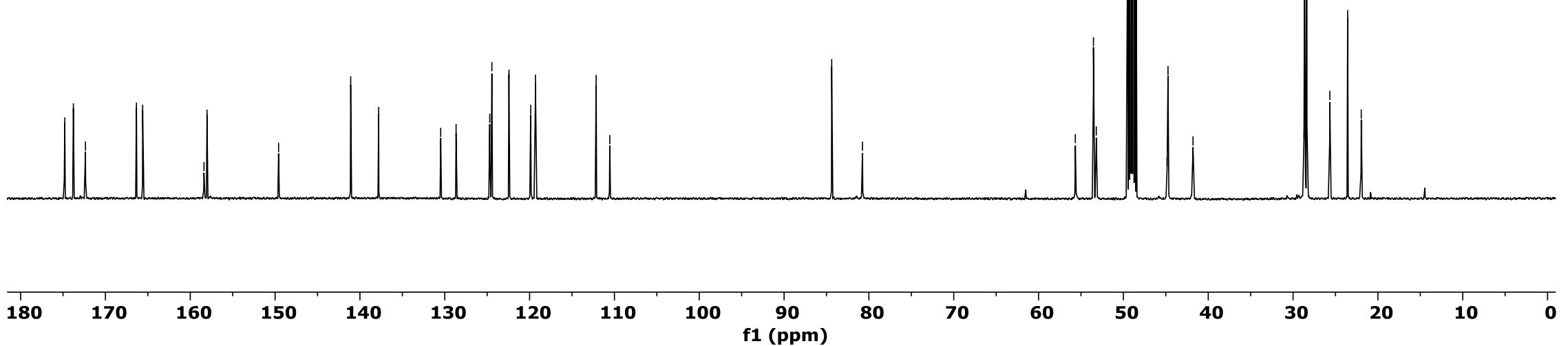


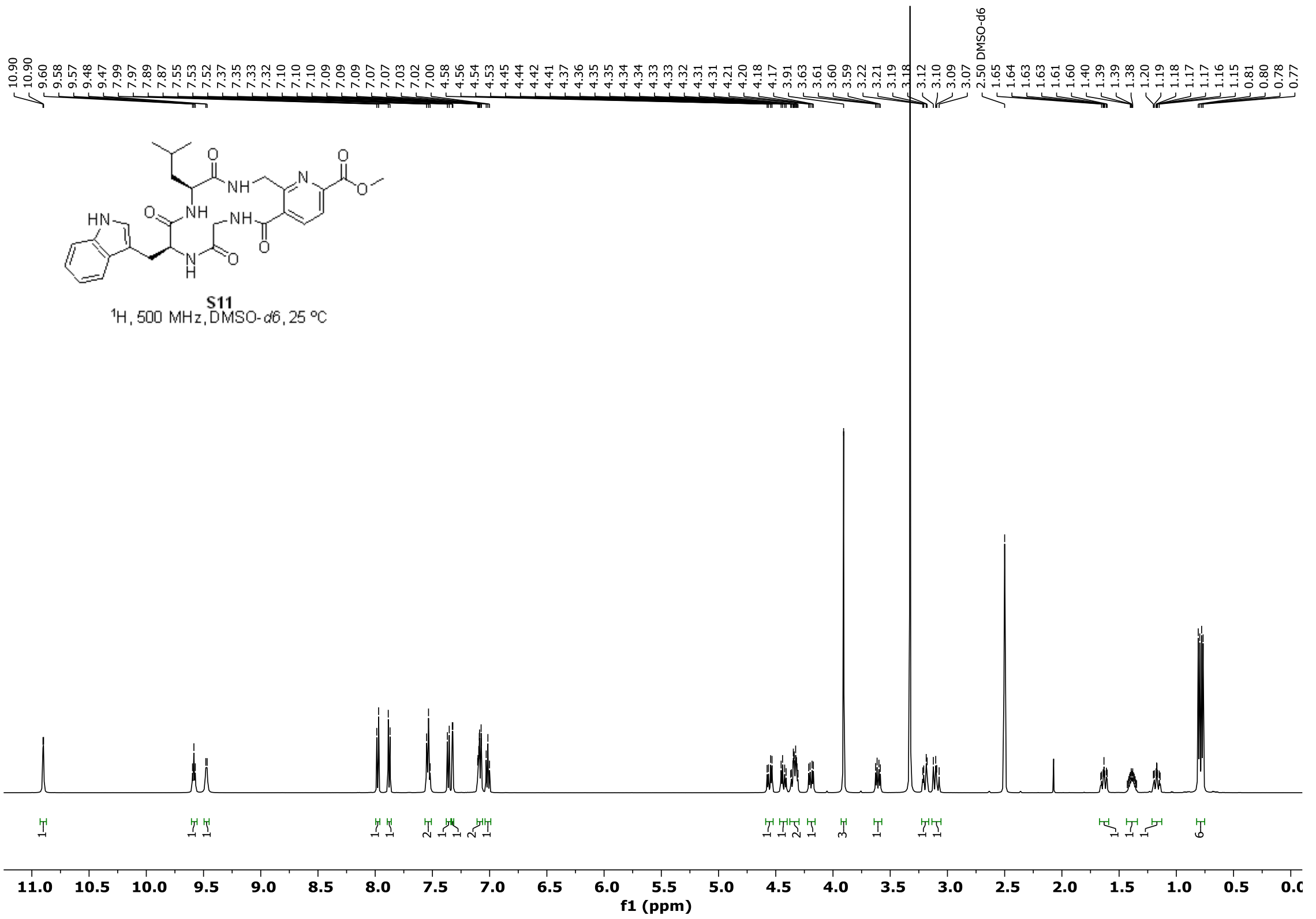




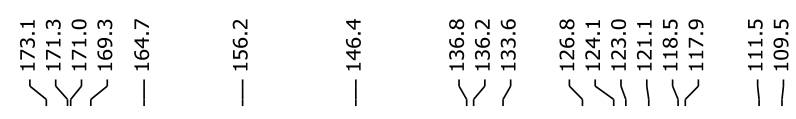

1.

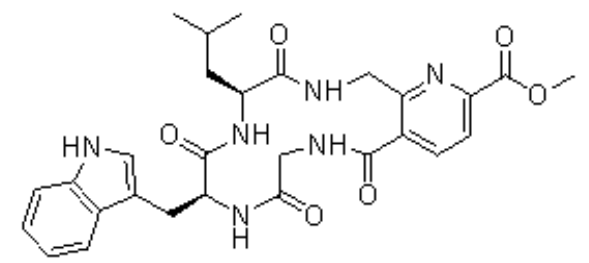

${ }^{13} \mathrm{C}, 126 \mathrm{MHz}, \mathrm{DMSO}-d 6,25^{\circ} \mathrm{C}$
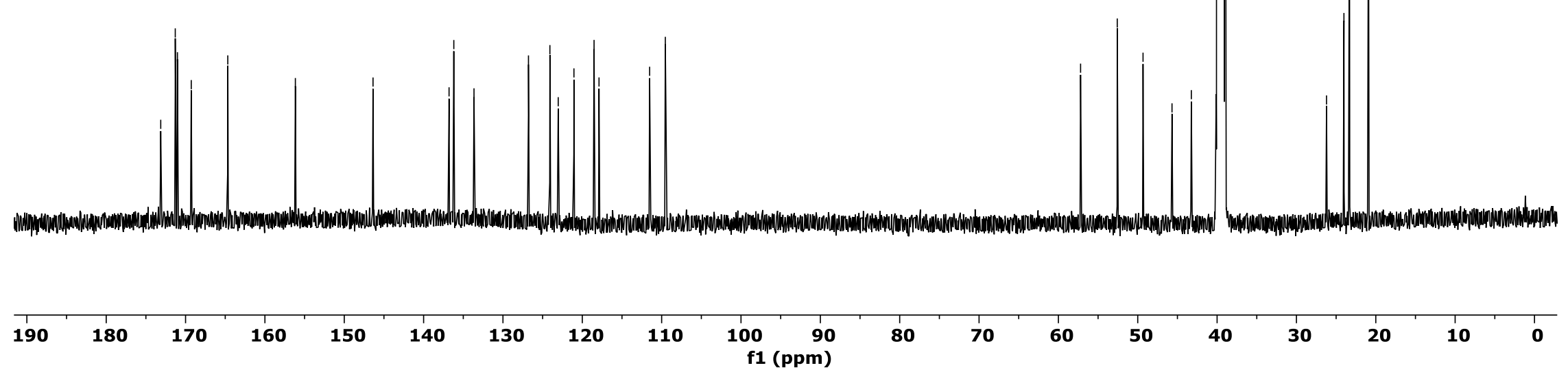


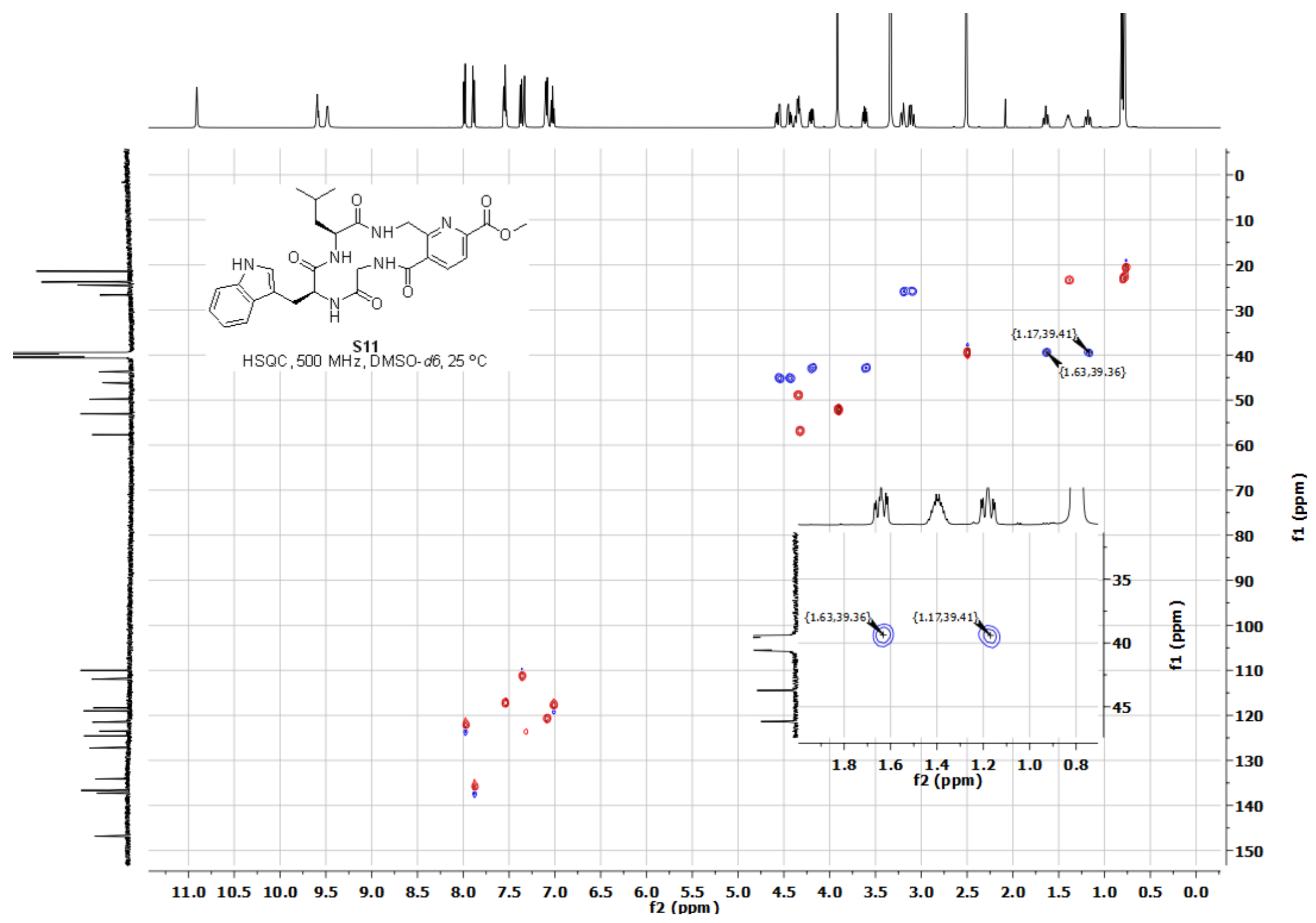



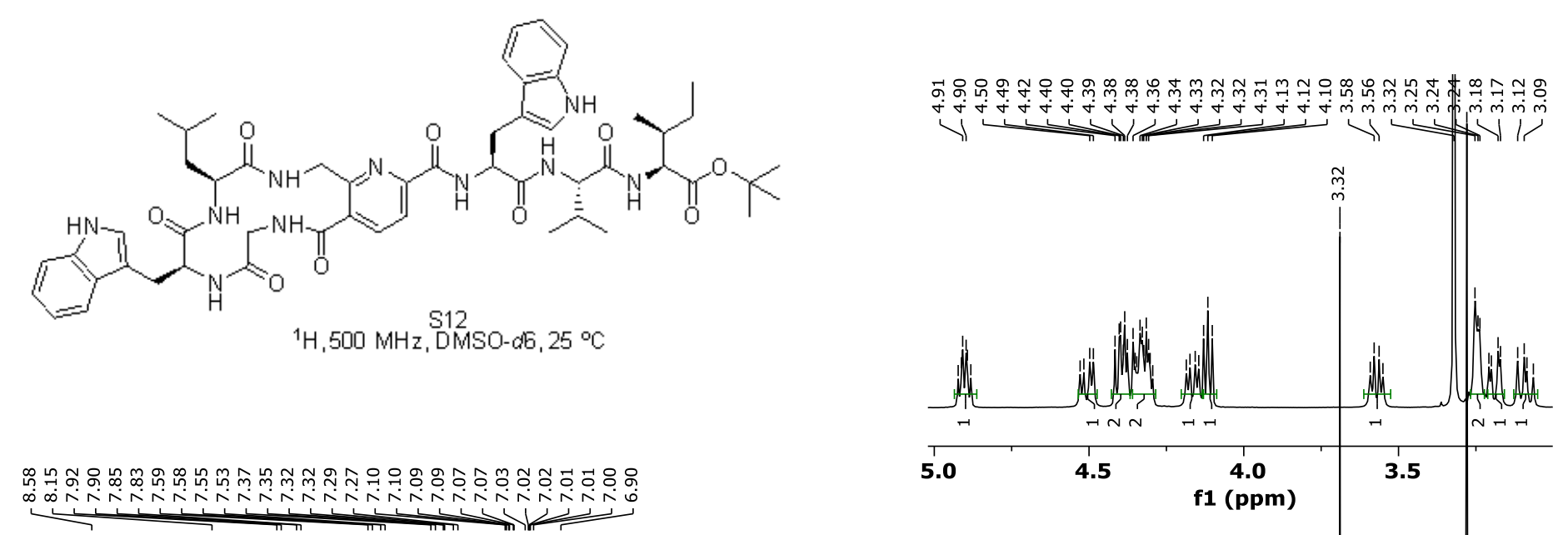

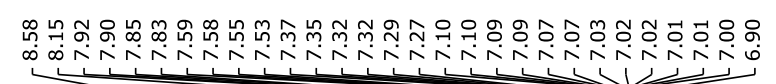
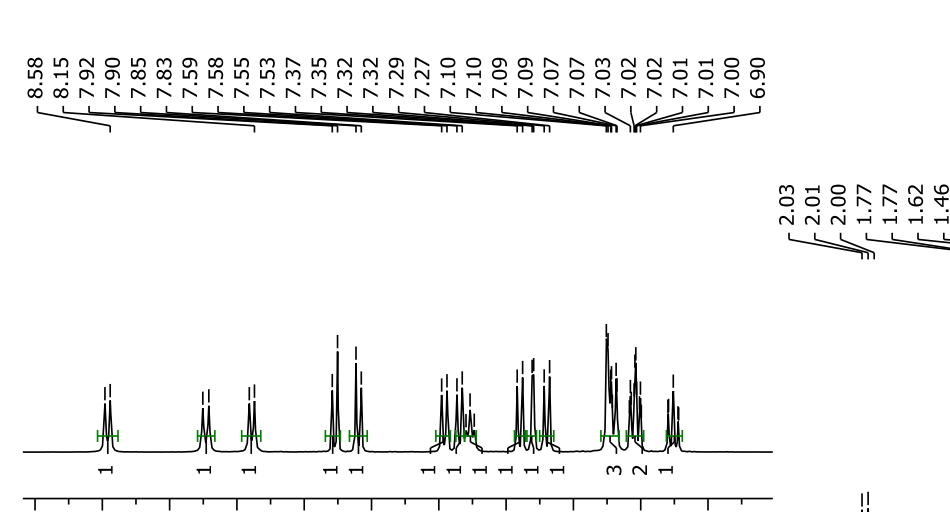

$\begin{array}{lllllllllllllll}8.8 & 8.6 & 8.4 & 8.2 & 8.0 & 7.8 & 7.6 & 7.4 & 7.2 & 7.0 & 6.8\end{array}$

f1 (ppm)
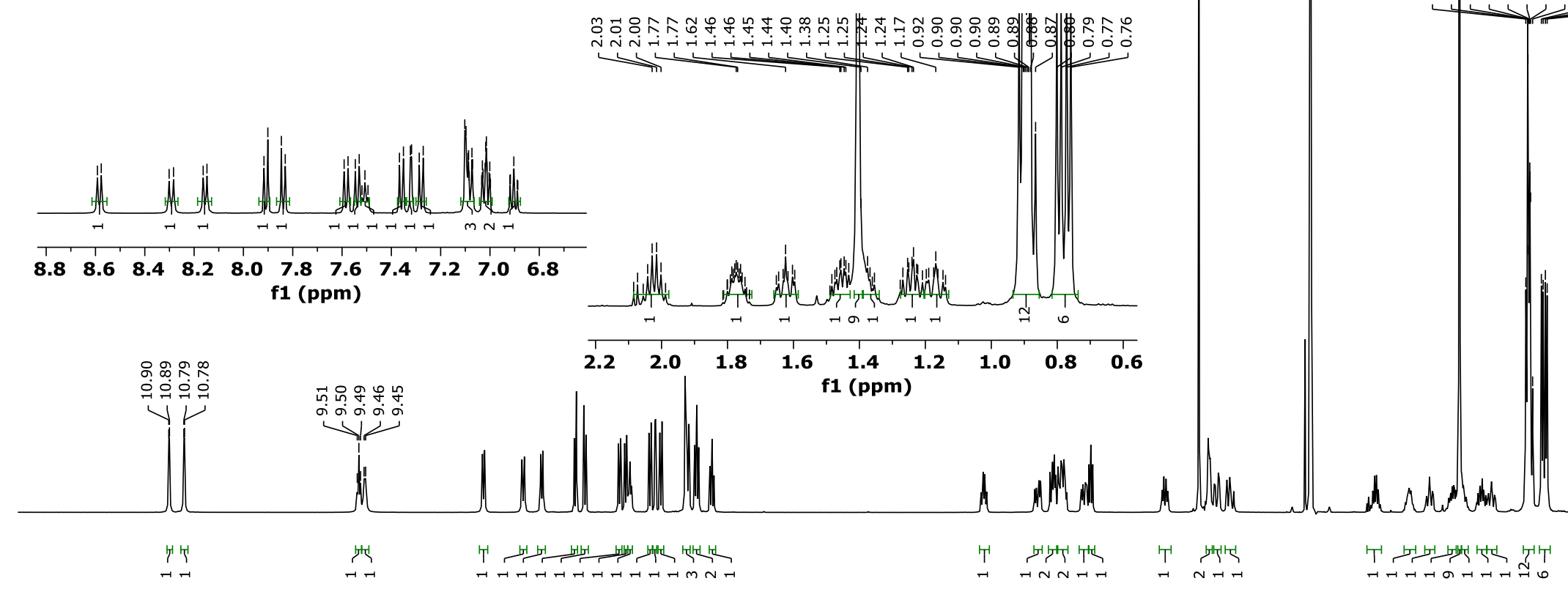

\begin{tabular}{lllllllllllllllllllllllllllllllll}
\hline 2.0 & 11.5 & 11.0 & 10.5 & 10.0 & 9.5 & 9.0 & 8.5 & 8.0 & 7.5 & 7.0 & 6.5 & 6.0 & 5.5 & 5.0 & 4.5 & 4.0 & 3.5 & 3.0 & 2.5 & 2.0 & 1.5 & 1.0 & 0.5 & 0.0
\end{tabular} 


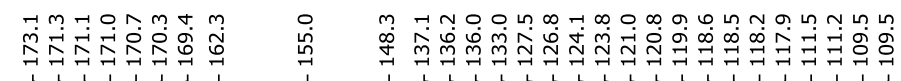

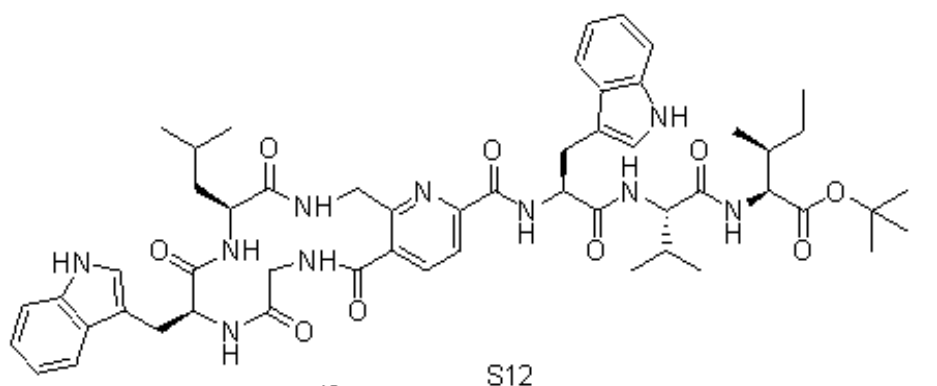

${ }^{13} \mathrm{C}, 126 \mathrm{MHz}, \mathrm{SMMO}-26,25^{\circ} \mathrm{C}$

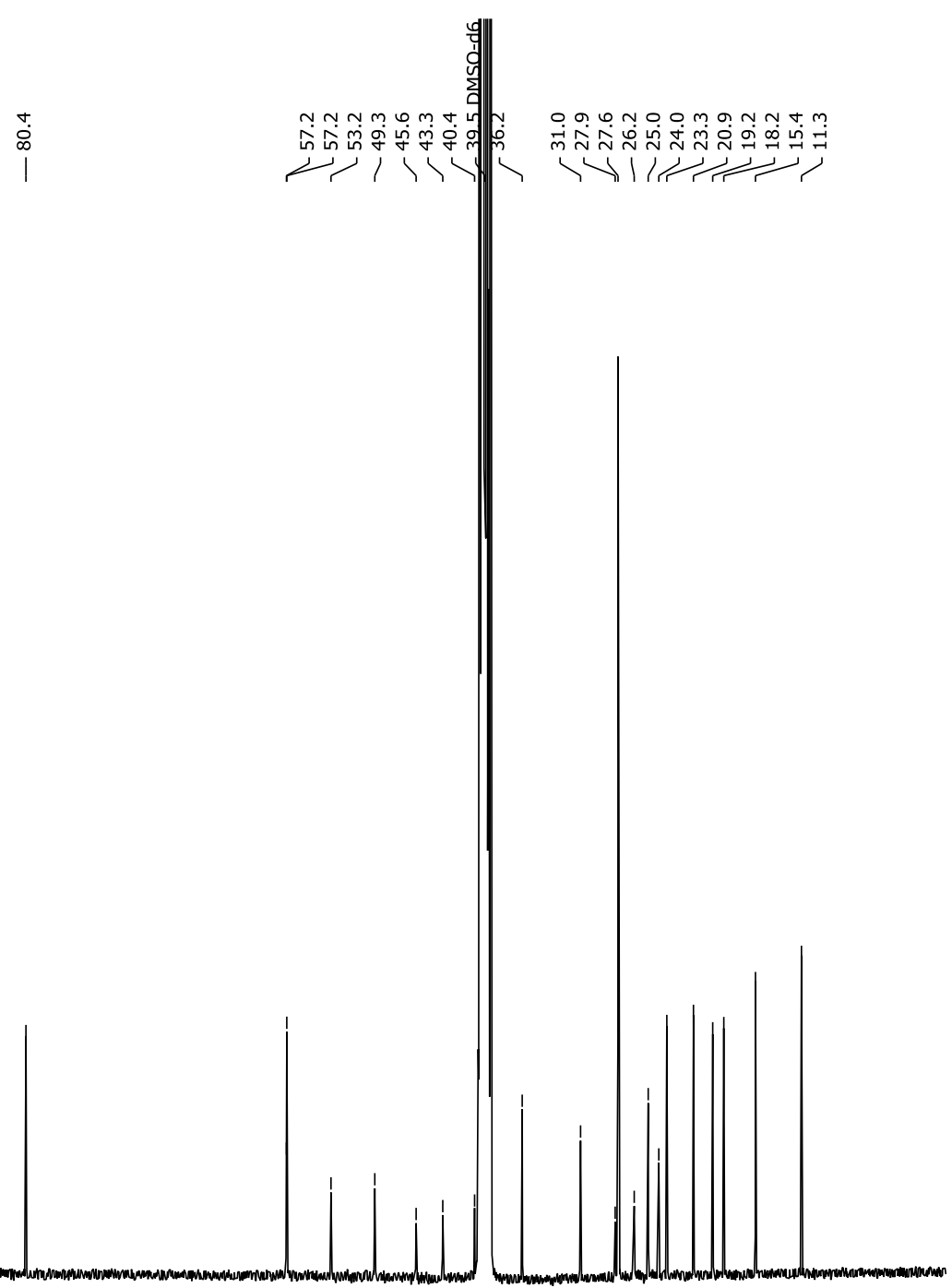

180

170

160

150

140

130

120

110

100

f1 (ppm)

80

$70 \quad 60 \quad 50$

40

30

20

10

0 


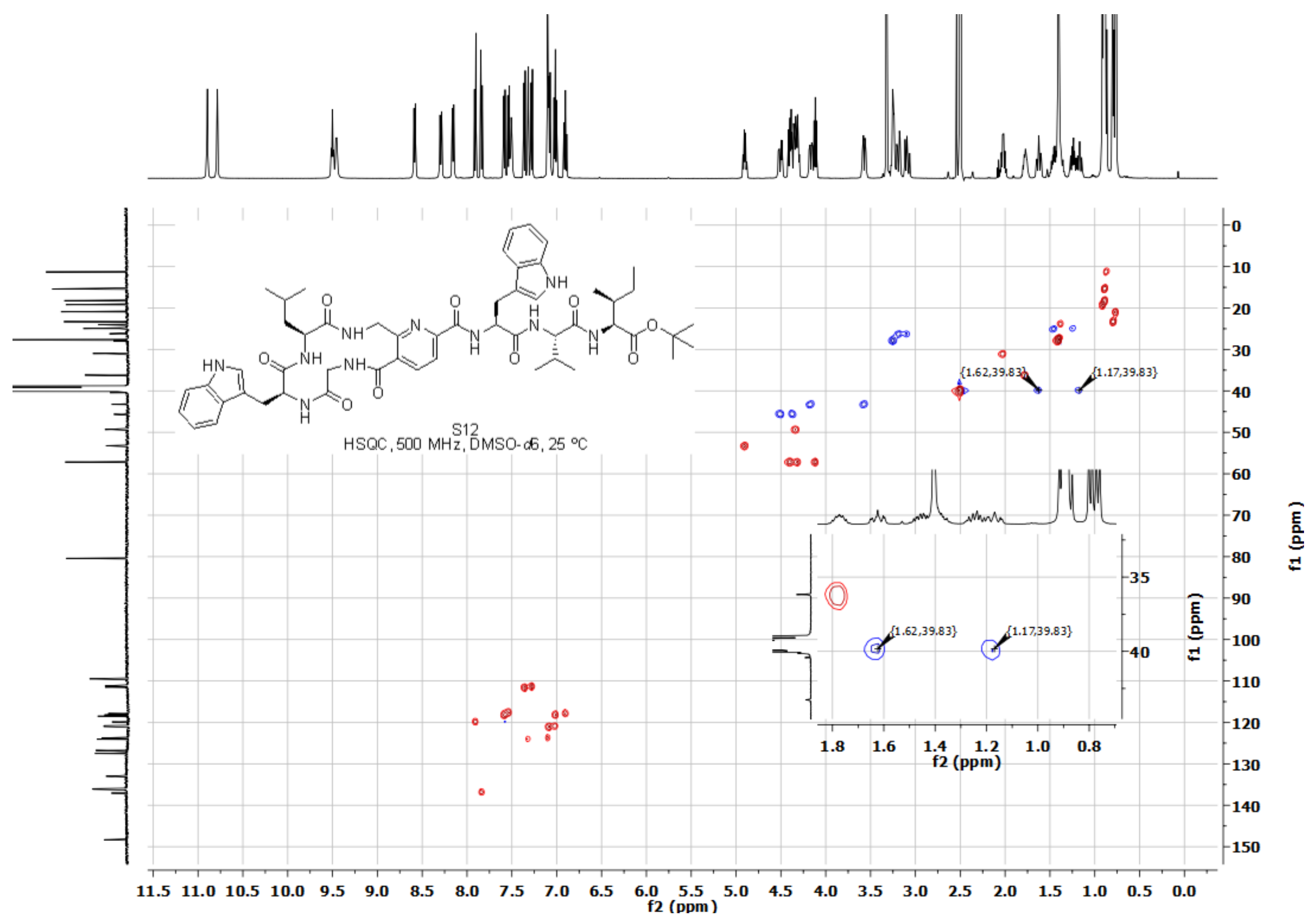




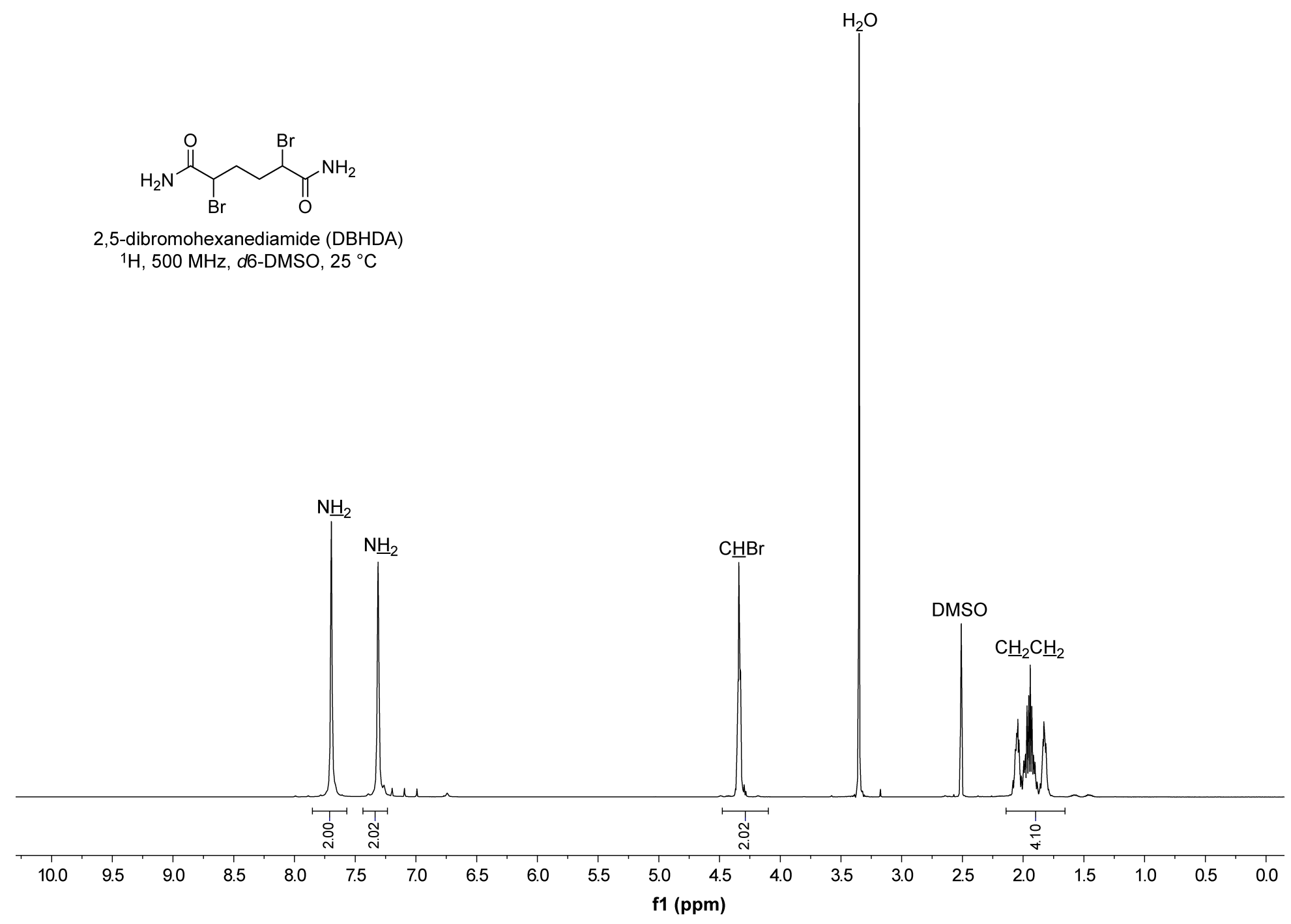




\section{Supporting References}

(1) Tietz, J. I.; Schwalen, C. J.; Patel, P. S.; Maxson, T.; Blair, P. M.; Tai, H.-C.; Zakai, U. I.; Mitchell, D. A. A New Genome-Mining Tool Redefines the Lasso Peptide Biosynthetic Landscape. Nat Chem Biol 2017, 13, 470-478.

(2) Schwalen, C. J.; Hudson, G. A.; Kille, B.; Mitchell, D. A. Bioinformatic Expansion and Discovery of Thiopeptide Antibiotics. J. Am. Chem. Soc. 2018, 140 (30), 9494-9501.

(3) Sato, K.; Itoh, Y.; Aida, T. Columnarly Assembled Liquid-Crystalline Peptidic Macrocycles Unidirectionally Orientable over a Large Area by an Electric Field. J. Am. Chem. Soc. 2011, 133 (35), 13767-13769.

(4) Steib, P.; Breit, B. Enantioselective Rhodium-Catalyzed Dimerization of $\omega$-Allenyl Carboxylic Acids: Straightforward Synthesis of C2-Symmetric Macrodiolides. Angew. Chem. Int. Ed. 2018, 57 (22), 6572-6576.

(5) Wever, W. J.; Bogart, J. W.; Baccile, J. A.; Chan, A. N.; Schroeder, F. C.; Bowers, A. A. Chemoenzymatic Synthesis of Thiazolyl Peptide Natural Products Featuring an Enzyme-Catalyzed Formal $[4+2]$ Cycloaddition. J. Am. Chem. Soc. 2015, 137 (10), 3494-3497.

(6) Chalker, J. M.; Gunnoo, S. B.; Boutureira, O.; Gerstberger, S. C.; Fernández-González, M.; Bernardes, G. J. L.; Griffin, L.; Hailu, H.; Schofield, C. J.; Davis, B. G. Methods for Converting Cysteine to Dehydroalanine on Peptides and Proteins. Chem. Sci. 2011, 2 (9), 1666-1676.

(7) Delaglio, F.; Grzesiek, S.; Vuister, G. W.; Zhu, G.; Pfeifer, J.; Bax, A. NMRPipe: A Multidimensional Spectral Processing System Based on UNIX Pipes. J. Biomol. NMR 1995, 6 (3), 277-293.

(8) Lee, W.; Tonelli, M.; Markley, J. L. NMRFAM-SPARKY: Enhanced Software for Biomolecular NMR Spectroscopy. Bioinformatics 2014, 31 (8), 1325-1327.

(9) Katoh, K.; Standley, D. M. MAFFT Multiple Sequence Alignment Software Version 7: Improvements in Performance and Usability. Mol. Biol. Evol. 2013, 30 (4), 772-780. 